WORKING PAPERS IN

\section{Early Childhood Development}

Delivering quality

early learning in low-resource settings

Progress and challenges in Ethiopia

Kate Orkin, Workneh Abebe Yadete and Martin Woodhead
STUDIES IN

Early Childhood Transitions

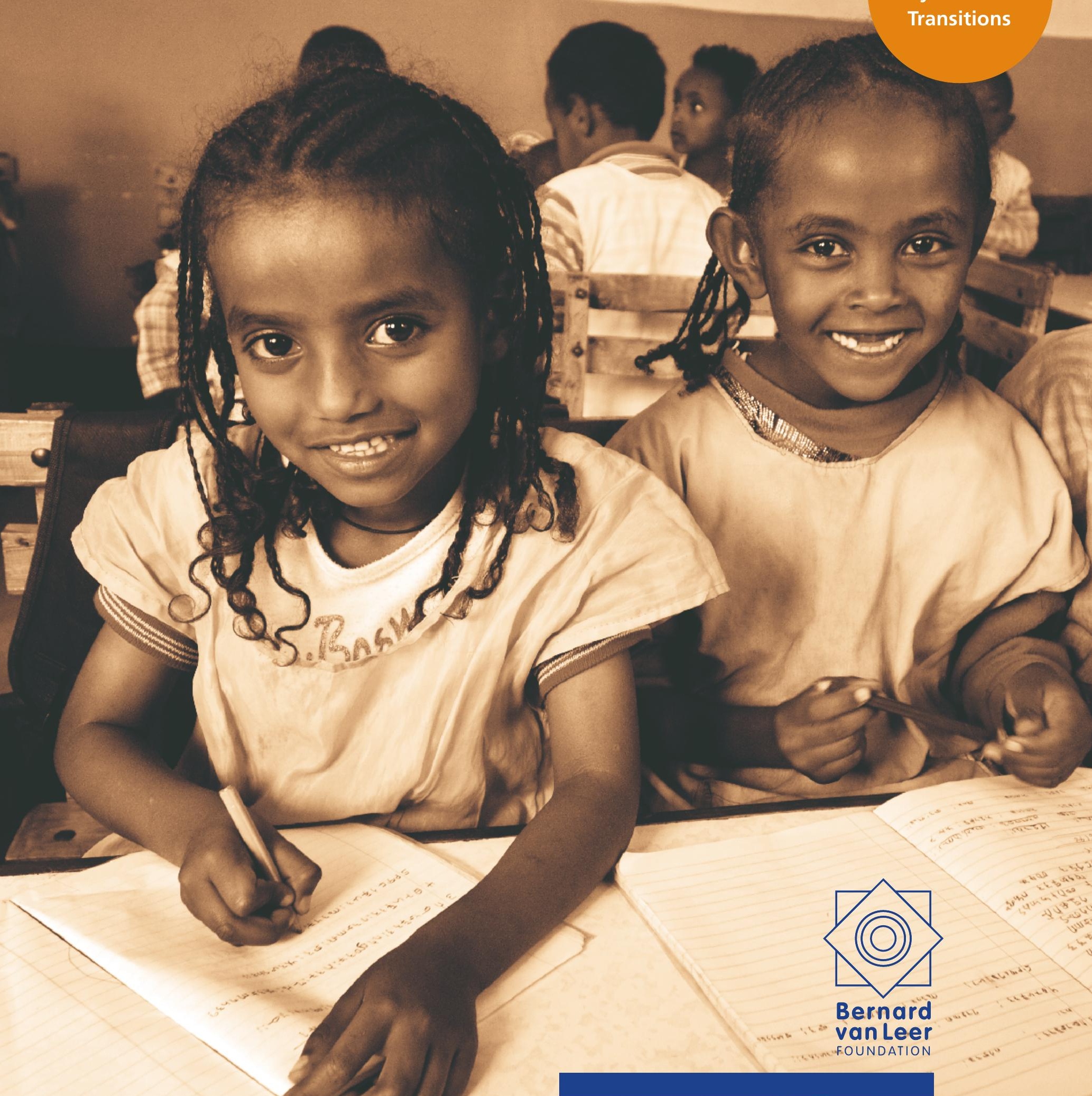




\section{Studies in Early Childhood Transitions}

This working paper is part of a series on early transitions from Young Lives, a 15 year longitudinal study of childhood poverty in Ethiopia, India, Peru, and Vietnam. Further information about Young Lives research is available on the website: www.younglives.org.uk

\section{Also in the Series}

Vogler, P., Crivello, G., and Woodhead, M. (2008). 'Early childhood transitions research: A review of concepts, theory, and practice.' Working Paper 48: Studies in Early Childhood Transitions. The Hague: Bernard van Leer Foundation.

Woodhead, M., Ames, P., Vennam, U., Abebe, W., and Streuli, N. (2009). 'Equity and quality? Challenges for early childhood and primary education in Ethiopia, India, and Peru.' Working Paper 55: Studies in Early Childhood Transitions. The Hague: Bernard van Leer Foundation.

Ames, P., Rojas, V., and Portugal, T. 'Continuity and respect for diversity: Strengthening early transitions in Peru.' (2010). Working Paper 56: Studies in Early Childhood Transitions. The Hague: Bernard van Leer Foundation.

Streuli, N., Vennam, V., and Woodhead, M. (2011). 'Increasing choice or inequality? Pathways through early education in Andhra Pradesh, India.' Working Paper 58: Studies in Early Childhood Transitions. The Hague: Bernard van Leer Foundation.

Cover photo: A church run pre-school in Ethiopia @ Jorgen Schytte/Specialist Stock.

Design: Valetti, vormgeving en communicatie, The Hague, The Netherlands (www.valetti.nl)

Editing and proofreading: Green Ink (www.greenink.co.uk) 


\section{9}

WORKING PAPERS IN

Early Childhood Development

\section{Delivering quality early learning in low-resource settings}

Progress and challenges in Ethiopia

By Kate Orkin, Workneh Abebe Yadete and Martin Woodhead

STUDIES IN

Early Childhood

Transitions

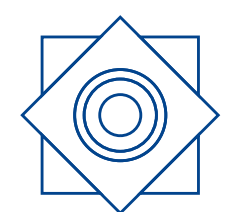

Bernard

van Leer

FOUNDATION 
Copyright ( 2012 by the Bernard van Leer Foundation, The Netherlands. The Bernard van Leer Foundation encourages fair use - except modifications - of this material. Proper citation is requested. This publication may not be resold for profit.

The views expressed in this publication are those of the author and are not necessarily those of the Bernard van Leer Foundation.

\section{About the authors}

Kate Orkin is a Research Associate at Young Lives in Oxford. She is a DPhil candidate in Development Studies at the University of Oxford. Her research in rural Ethiopia uses qualitative and econometric methods to analyse how factors, such as the length of the school day, language of instruction and teacher quality affect children's participation and achievement at school. Orkin has consulted for the World Bank and has designed and supported the management of surveys in Ethiopia for the International Food Policy Research Institute and for Young Lives.

Workneh Abebe Yadete is an Education Researcher at Young Lives in Ethiopia. He led data collection for the first school survey run by Young Lives in 2010. His research has focused on the educational experiences of pre-primary and primary school-aged children. Prior to his work on the Young Lives school survey, Yadete worked as a researcher with Young Lives on two rounds of qualitative research in 2007 and 2008 and for the Wellbeing in Developing Countries (WeD) Poverty, Inequality, and Quality of Life research project. He worked for five years as a practitioner in child protection and currently heads operations at SOS Enfants Ethiopie in Addis Ababa. Yadete holds a MA in History from Addis Ababa University.

Martin Woodhead is Professor of Childhood Studies at the Open University and Associate Research Director of Young Lives at the University of Oxford. He led the Young Lives/Bernard van Leer Foundation sub-study on early childhood transitions. His thirty year research career has included a focus on early childhood development, education, and care and has involved policy studies, extensive international work and numerous publications.

\section{Citation}

Orkin, K., Abebe, W., Yadete and Woodhead, M. (2012). Delivering quality early learning in low-resource settings: Progress and challenges in Ethiopia. Working Paper No. 59, Studies in Early Childhood Transitions. The Hague, The Netherlands: Bernard van Leer Foundation

ISSN 1383-7907

ISBN 978-90-6195-126-1 


\section{Contents}

Acronyms $\quad \mathrm{v}$

Acknowledgements $\quad$ vii

Executive summary $\quad$ ix

Introduction 1

Chapter 1: Early childhood in sub-Saharan Africa: Opportunities and challenges $\quad 5$

Chapter 2: Early childhood and primary education in Ethiopia $\quad 15$

Chapter 3: Studying early childhood transitions in Ethiopia 33

Chapter 4: Unequal pathways into education: Case studies from an urban community 47

Chapter 5: Accessing 'Education for All': Multiple challenges in a rural community 61

Chapter 6: Discussion and conclusions $\quad 75$

Appendix: The Young Lives communities 83

References $\quad 85$ 


\section{Acronyms}

\begin{tabular}{|c|c|}
\hline c-IMCI & Community-based Integrated Management of Childhood Illness \\
\hline CREATE & Consortium for Research on Educational Access \\
\hline CSA & Central Statistics Agency \\
\hline DfID & United Kingdom Department for International Development \\
\hline DHS & Demographic and Health Survey \\
\hline $\mathrm{DRC}$ & Democratic Republic of Congo \\
\hline ECCE & Early Childhood Care and Education \\
\hline ECD & Early Childhood Development \\
\hline EFA & Education For All \\
\hline EPRDF & Ethiopian People's Revolutionary Democratic Front \\
\hline ESDP & Education Sector Development Plan \\
\hline ETP & Education Training Policy \\
\hline FBO & Faith-Based Organisation \\
\hline FTI & Fast-Track Initiative \\
\hline GEQIP & General Education Quality Improvement Programme \\
\hline GER & Gross Enrolment Rate \\
\hline HDI & Human Development Index \\
\hline KG & Kindergarten Group \\
\hline LDC & Least-Developed Country \\
\hline LKG & Lower Kindergarten \\
\hline MDG & Millennium Development Goals \\
\hline NER & Net Enrolment Rate \\
\hline NGO & Non-Governmental Organisation \\
\hline NLA & National Learning Assessment \\
\hline PRSP & Poverty Reduction Strategy Paper \\
\hline PSNP & Productive Safety Net Programme \\
\hline SNNPR & Southern Nations, Nationalities and People's Region \\
\hline UKG & Upper Kindergarten \\
\hline UNDP & United Nations Development Programme \\
\hline UNESCO & United Nations Educational, Scientific and Cultural Organization \\
\hline UNICEF & United Nations Children's Fund \\
\hline USAID & United States Agency for International Development \\
\hline TTI & Teacher Training Institute \\
\hline YL & Young Lives \\
\hline
\end{tabular}




\section{Acknowledgements}

Young Lives is an innovative, longitudinal study investigating the changing nature of childhood poverty. Young Lives is tracking 12,000 children in Ethiopia, India (Andhra Pradesh), Peru and Vietnam over 15 years through a quantitative survey and participatory qualitative research, linked to policy analysis. Young Lives seeks to:

- improve understanding of the causes and consequences of childhood poverty and to examine how policies affect children's well-being;

- inform the development and implementation of future policies and practices that will reduce childhood poverty.

Young Lives is receiving core funding from 2001 to 2017 from the UK Department for International Development (DfID) for the benefit of developing countries and is co-funded by the Netherlands Ministry of Foreign Affairs from 2010 to 2014. Sub-studies are funded by the Inter-American Development Bank (in Peru), the International Development Research Centre (in Ethiopia), and the Oak Foundation. Support for focused research on early transitions was provided by the Bernard van Leer Foundation to the Open University as a Young Lives partner.

We thank Paul Dornan, Suadik Hassen, Lynette Okengo and Alula Pankhurst for their comments and suggestions. We acknowledge Natalia Streuli's contributions to the development of this paper, until her untimely death in February 2012. We thank Gina Crivello and Laura Camfield for their role in coordinating Young Lives early transitions qualitative research and the Ethiopian team members Yisak Tafere and Asham Assezinew for their support in data collection. We thank the children and families who participate in Young Lives research, as well as the teachers and head teachers who open their schools and classrooms to us. Further information about Young Lives is available at: www.younglives.org.uk.

The views expressed here are those of the authors. They are not necessarily those of, or endorsed by Young Lives, the University of Oxford, DfID or other funders. 


\section{Executive summary}

Ethiopia offers a case study of the opportunities and challenges in developing early childhood care and education (ECCE) in low-resource settings. These challenges need to be understood in the context of recent government priorities to universalise primary education. In many respects, Ethiopia is a success story of Education For All (EFA), a global movement to provide high quality, basic education for all children, youths and adults. In 1992, after the end of the civil war, nearly four in five children were out of school. By 2009, the number of children who were out of school had been reduced to one in five, as a result of the abolition of fees, a 140 percent increase in the number of primary schools, training of teachers, local government campaigns to get children enrolled and large donor contributions (Engel 2010:3).

As in many other African countries, numerous ongoing access and quality challenges affect primary education, which in turn impacts ECCE. Large numbers of children enrol in school late, many are overage for their grade and dropout rates are high. Poverty, demands that children work on family farms or in the home, family illnesses, distance to schools, and concerns about the variable quality and hidden costs of school all contribute. Data from Young Lives research in Ethiopia show that 15 percent of a sample of 2000 children who enrolled in the first four grades of primary school in 2007/8 had dropped out before completing the school year. Because of the generally low quality of teaching and learning, children have tended to progress slowly through grades. Among an older sample of Young Lives children, who were enrolled by the age of 8 in 2002, only 22 percent remained enrolled and passed four grades during the years between 2002 and 2006. And even if children did attend school, their progress in learning has often been very slow. In 2006, only 29 percent of 12-year-old Young Lives children were able to read a simple sentence in their mother tongue. Since 2009, these challenges are being addressed through the General Education Quality Improvement Programme (GEQIP), which is led by the government of Ethiopia and supported by a number of donors.

Given the major reforms taking place to achieve EFA and the Millennium Development Goals (MDGs) for universal primary education, the Ethiopian government has, until recently, paid much less attention to ECCE. The ECCE services have been offered almost entirely by private, non-governmental and faith-based providers. As a result, very few children have been able to access them. The national Gross Enrolment Rate $(\mathrm{GER})^{1}$ for pre-school, which covers children from the ages of four to six, was only 4.2 percent in 2008/9 (Ministry of Education 2010a: 21). This is much lower than the sub-Saharan African rate, which rose from 12 percent in 2000 to 17 percent

\footnotetext{
1 The GER is the total enrolment at a specific level of education, regardless of age (UNESCO 2009).
} 
in 2008 (UNESCO 2010a). The pre-school GER has not improved much since 2008: in 2010/11 it was 5.2 percent (Ministry of Education 2012).

In 2010, in collaboration with United Nations Children's Fund (UNICEF) and other non-governmental organisations (NGOs), the Ethiopian government designed a national framework for ECCE that includes ideas from many innovative low-cost programmes in the rest of Africa. The development of the ECCE Framework is a welcome policy advance. The goal is for the government to continue to regulate private sector and NGO providers, but also to begin to offer low-cost alternative ECCE programmes using two approaches. Government primary schools are being asked to provide a reception year and teachers will be asked to train Grade 5 and 6 children to lead Child-to-Child programmes, focusing on pre-school age children in their communities.

This paper builds on the messages of earlier working papers in the series, especially regarding the challenges of delivering the potential benefits of ECCE in contexts where resources are scarce, where government engagement is limited and where there is heavy reliance on the private sector (Woodhead et al. 2009). Progressing towards greater equity in access to and quality of ECCE is a major challenge. As a rule, children from poorer households and rural children are least likely to gain access to ECCE services, with the consequence that inequalities linked to their home circumstances are amplified by inequitable educational opportunities. While small numbers of NGO and donor-supported programmes target specific disadvantaged groups, these programmes reach a relatively small proportion of children that might benefit from ECCE.

We highlight the different challenges in rural and urban areas. Overall, ECCE has been increasing dramatically in urban areas of Ethiopia and the government is likely to continue to rely on the non-governmental and private sectors to provide services. In this situation, increasing access as well as improving registration and regulation of urban pre-schools becomes a priority, across all providers. There is also a need for curricula and quality assurance mechanisms. Private pre-schools tend to be replicas of primary schools, with few concessions made to the stage of development of younger students. The organisation of these private pre-schools reflects the perception of quality held by relatively wealthy and aspiring parents and includes uniforms, lesson-based academic instruction and, in some cases, instruction in English. It may be difficult for the government to persuade teachers (and parents) to adopt child-centred and play-based curriculum and to teach in the children's mother tongue.

Many poorer parents in urban areas use faithbased facilities, which aim to teach children basic literacy so they can read the Koran or Bible and to instruct them in aspects of religious faith. Relying on these facilities to provide ECCE will require the availability of basic short courses for the people running them and the provision of a curriculum and materials. This assumes, of course, that churches and mosques 
are prepared to be part of the government's national plan for providing ECCE, which is by no means certain, as little consultation on the plan had taken place at the time of writing in early 2012. Finally, NGO and faith-based facilities may not be available in smaller urban centres, so the government may need to adapt public ECCE services that have been largely designed for rural areas for use by the poorest children in urban areas. The biggest risk of relying on private for profit and low fee faith-based pre-schools is that it puts the most disadvantaged families at risk of being excluded from any form of ECCE unless targeted, governmentsubsidised strategies are introduced.

Our research in rural areas offers a very different picture. There, ECCE is minimal and basic primary school systems are still being consolidated. As noted earlier, children often enrol late and tend to have difficult trajectories through school, with irregular attendance and many dropping out or progressing slowly. In part, this may be due to the low quality of schools and the long journeys involved to reach them, as well as the competing demands on children to continue to take on responsibilities in the household or in farming. Additionally, in the absence of universal birth records, primary school teachers have difficulty in assessing the ages of children and their readiness for school and they may be challenged by parents who are eager to gain admission for a child who appears 'too young.' Our research highlights the need to strengthen quality ECCE throughout rural Ethiopia in order to smooth the transition of children to and through primary school. Yet it is in rural areas that the government faces the greatest challenges in implementing ECCE.

The 2010 Framework for ECCE in Ethiopia proposes that schools become involved in constructing ECCE facilities attached to primary schools and that Grade 1 and 6 teachers train Child-to-Child facilitators drawn from children in Grades 5 and 6. Yet our rural case study shows that school directors, class teachers and children themselves are struggling to carry out the roles and responsibilities that have come with the rapid expansion of the primary education system. Schools are short of resources and must deal with large increases in enrolment. Teachers are putting a huge effort into getting primary school children enrolled at the correct age, following up when they drop out and managing large classes. Many children in Grade 5 and 6 are already battling to stay in school and to balance competing pressures. Many of them work for pay in order to buy their school materials and must deal with very difficult circumstances at home. Although they would learn a lot from the experience, spending time as Child-to-Child facilitators might have severe impacts on their own achievements.

In the long term, the new ECCE Framework offers a real opportunity to provide universal, low-cost and quality ECCE in Ethiopia, as long as it is carefully phased in and enough resources are provided. However, if the Framework is implemented without sufficient extra resources, it is likely to place a significant additional burden on an already overstretched primary education system. While capacity-building, 
professional training, parent education, quality assurance and adequate regulation are all pre-requisites for implementing scaled-up and sustainable ECCE in low-resource settings, inadequate finance is likely to be the core obstacle. Faced with this challenge, governments and international donors are increasingly exploring alternative financing models.

We offer the following conclusions:

- The Ethiopian government's 2010 ECCE Framework is an important advance in policy development for the youngest children. To make progress in its implementation, donors and the government will need to source the additional resources for ECCE urgently. Communities could still contribute resources, as they currently do to primary schools, but are unlikely to be able to absorb the entire cost burden.

- The government can retrain existing teachers to provide ECCE, but this is unlikely to provide enough teachers without creating a shortage in the primary school sector. The government will therefore need to consider recruiting ECCE staff from outside the existing pool of teachers. Short courses can be developed to cater to a variety of personnel types and efforts can be made to train ECCE specialists who are likely to agree to work in rural communities. Adequate budget is required for salaries, otherwise teachers and other personnel will be poorly motivated, turnover will be high, and children's learning will suffer.

- The idea of recruiting older children as Child-to-Child facilitators is based on a well-proven model but it needs to recognise that older children face many constraints on their time and often struggle to make their own way through school. They may require a small stipend to help reduce the burden of paid or unpaid work they would otherwise be expected to do.

- The 2010 ECCE Framework anticipates preschool classes in primary schools. This will minimise the infrastructure costs of providing formal pre-schools. However, there is a risk that ECCE will become overly formalised if pre-school classes are attached to primary schools. The national ECCE curriculum envisions play-based, mother tongue ECCE instruction. In contrast, the National Grade 1 curriculum currently anticipates that children will learn basic numeracy and literacy in pre-school. The National Grade 1 curriculum and ECCE curriculum need to be better aligned. Otherwise, it is likely that ECCE facilities based in primary schools will largely use formal teaching methods, already commonly observed in early primary grades, and will emphasise basic literacy and numeracy, rather than adhering to the ECCE curriculum. In rural areas, it would be useful to explore other low-cost methods of ECCE that place less of a burden on primary schools, such as Rapid School Readiness Programmes or community-based centres.

- In urban areas, if the government continues to rely largely on non-governmental providers, there will be a need for stronger governance, regulation and quality assurance of these providers as well as some form of subsidy arrangements or vouchers to ensure that the poorest children can access ECCE. 


\section{Introduction}

This Working Paper is part of the Transitions in Early Childhood series, published by the Bernard van Leer Foundation and based on data from Young Lives, a 15 year longitudinal study of children growing up in poverty in Ethiopia, India, Peru and Vietnam. In each country, the study tracks approximately 2000 children from infancy to their late teenage years, as well as a comparison cohort of 1000 children, who were first surveyed when they were eight.

Early childhood transitions offer the chance to examine factors that shape the use of basic education services by children and to analyse why some children have more opportunities for development than others, as explained in the first paper in the series (Vogler et al. 2008). Issues of equity in access and quality were explored in the second paper in the series, which compares Ethiopia, India, and Peru (Woodhead et al. 2009). The third paper in the series (Ames et al. 2010) looked at these issues in detail for Peru, with particular emphasis on continuity and respect for diversity. The fourth paper focused on Andhra Pradesh, India, specifically regarding how different social, cultural, and economic factors shape children's diverse and unequal pathways through early education and into primary school at a time when a relatively unregulated private sector is becoming a major provider of ECCE and primary education (Streuli et al. 2011).
This final paper in the series focuses on Ethiopia, the poorest country in the Young Lives study. It reports on the experiences of children and their families during early childhood and the initial grades of primary school. Only 36 percent of the country's population aged 15 and above is literate (UNESCO 2010b). The priority for the government of Ethiopia has been to expand primary education very rapidly, partly in order to achieve EFA/MDG targets. The government had considerable success in raising the net enrolment rate in primary education from 33 percent to 85 percent between 1999 and 2010/11 (Ministry of Education 2012). A recent UNESCO Global Monitoring Report highlighted and applauded improvements in gender equity: a growth from 38 percent of boys versus 28 percent of girls enrolled in 1999 to 71 percent of boys versus 66 percent of girls in 2005 (UNESCO 2008: 291). Despite such rapid progress in enrolment statistics, the quality challenges remain enormous.

In this context, the potential of early childhood programmes has received little attention in Ethiopia. However, in 2010 the government introduced a new Early Childhood Care and Education (ECCE) ${ }^{2}$ Policy Framework built around four pillars. The first two pillars - parental education and a comprehensive programme of early child health and stimulation - focus on children from the prenatal

\footnotetext{
2 Early childhood is defined as the period below eight years of age. ECCE is the acronym commonly used by UNESCO and is used here for consistency with the rest of the monographs in the series and because it is the term used in Ethiopia. Early childhood development $(E C D)$ is another widely used concept, which is more comprehensive and focused on children rather than on a particular care or education model (UNESCO 2010b).
} 
period to age three and fall under the Health Ministry. The third and fourth pillars are more targeted at children aged four to six. The third pillar - non-formal school readiness - consists primarily of the initiation of Child-to-Child initiatives, through which Grade 6 children act as facilitators in a programme of play designed to improve school readiness. The fourth pillar is the establishment of pre-schools of various kinds, including community-based pre-schools, private pre-schools and pre-schools attached to primary schools.

Ethiopia offers a strong case study of the opportunities and challenges of delivering high quality early learning in low-resource contexts. This paper has been written at a time when the case for introducing quality ECCE is more widely accepted than ever before, both in global research and in international policy development. For example, in 2011, a Global Child Development Group of interdisciplinary researchers published a follow up to their highly influential, 2007 Lancet report. They offered further evidence on the risks to children's development and learning from poverty and other largely preventable risks, as well as the potential for transforming children's lives through high quality, targeted early childhood interventions (Engle et al. 2011; Walker et al. 2011).

The research evidence is now complemented by global agreement that the development of policies for early childhood should be a top priority. The first goal of the Dakar Framework for Action on Education for All called for the expansion and improvement of "comprehensive early childhood care and education, especially for the most vulnerable and disadvantaged children" (UNESCO 2000: 8). Goal 2 of the Millennium Development Goals (MDGs) set out to achieve universal primary education by the year 2015 as a means to achieve poverty reduction. Similarly, the 2010 EFA Global Monitoring Report states that ECCE is "the bedrock of Education for All," helping children prepare for later schooling and observes that children from the poorest households have the most to gain from good ECCE because these programmes "can play an important role in offsetting social, economic and language-based disadvantages" (UNESCO 2010b: 49). Inability to access pre-school education has been identified as the first "Zone of Exclusion" from the goal of EFA (Lewin 2007). The World Bank has recently reframed their strategy as promoting "Learning for All," with ECCE identified as the bottom line:

"Invest early. Invest smartly. Invest for all. First, foundational skills acquired early in childhood make possible a lifetime of learning; hence the traditional view of education as starting in primary school takes up the challenge too late..." (World Bank 2011: 4).

Delivering on the promise of ECCE is one of the greatest challenges we face, especially in the world's poorest countries, and among the poorest and most disadvantaged communities within those countries. UNESCO's Global Monitoring Report made the point most strongly:

“...early childhood services of good quality remain inaccessible to the majority of the world's children. This is especially true for children in the poorest countries - and for 
the most disadvantaged among them. The upshot is a perverse outcome for equity: those with the most to gain from ECCE are least likely to participate"(UNESCO 2009: 42).

The huge gulf between the elaboration of young child rights and their implementation in practice has also been signalled in the UN Secretary General's 2010 report to UN General Assembly 65:

“...Many young children start life with a double burden: (a) their mothers are among the least educated and have the fewest resources to support them; and (b) they are the least likely to have access to quality health care, proper nutrition, education, and protection. All too often these disadvantages are amplified by marginalization and in some cases discrimination, throughout early childhood, particularly affecting children with disabilities, indigenous children, minority children and other marginalised communities..." (United Nations, General Assembly 2010, New York A/65/206 2010).

The gulf between aspiration and reality is the starting point for this working paper. On the one hand, a well-articulated human rights agenda and well-developed policy frameworks are now available, along with multiple ECCE models of proven effectiveness, underpinned by an abundance of human development research evidence. On the other hand, poverty and inequalities are endemic. The lives of the poorest and most marginalised people do not automatically improve at times of economic growth (Boyden and Dercon 2012), as revealed by basic poverty, health, and education indicators. Even when economies grow, infrastructures often remain weak and the poorest people have limited access to services to support their human development.

Chapter 1 of this paper describes recent developments in ECCE in the rest of sub-Saharan Africa, and identifies some shared challenges, which provide a context for what follows. Chapter 2 describes Ethiopia's basic education system in detail and outlines the government's approach to delivering on the goal of EFA, with a focus on the 2010 ECCE Framework. Chapter 3 summarises evidence from Young Lives quantitative data about the pre-school opportunities available to the younger and older cohorts in Ethiopia. The contrasting opportunities for urban and rural children in Young Lives countries have been highlighted in previous working papers in this series (Ames et al. 2010; Streuli et al. 2011; Woodhead et al. 2009). In Ethiopia, these urban-rural contrasts are even more striking, and they are explored in Chapters 4 and 5. These chapters provide an analysis of the different trajectories of urban and rural children through ECCE and the early years of primary school, based on qualitative data from two rounds of fieldwork in 2007 and 2008. We examine the transitions that children make from home or pre-school to primary school and how these differ between rural and urban areas, by children's socio-economic status, and by gender. Chapter 6 discusses implications for the implementation of the 2010 ECCE Framework in Ethiopia and reflects more generally on the continuing challenges for ECCE in lowresource contexts. 


\section{Chapter 1: Early childhood in sub-Saharan Africa: Opportunities and challenges}

As a result of increased international attention to ECCE, progress has been made in enhancing access to early childhood care and education worldwide. UNESCO (2007) has estimated a 300 percent increase in enrolment in pre-primary education globally since 1970 . By 2005, the World Bank had financed loans to 52 developing countries for child development programmes, for a total of US\$1680 million (Engle et al. 2007). By 2007, over 30 governments had national policies for ECCE and dozens more were being developed.

Sub-Saharan Africa lags behind much of the rest of the developing world in terms of access to ECCE. In 2007, less than 12 percent of African children aged four to six were enrolled in any form of early childhood programme, a much lower proportion than in East Asia (40 percent) or North America and Europe (77 percent). The gross pre-school enrolment rate in sub-Saharan Africa has been increasing, from 12 percent in 2000 to 17 percent in 2008. Even so, only two out of five children live in areas with access to ECCE programmes (UNESCO 2010a: 10-11).

As Figure 1 makes clear, sub-Saharan Africa (like other world regions) also faces a major challenge: ensuring that ECCE services target the most disadvantaged children and do not

Figure 1: Poverty and pre-school attendance for three-and four-year-olds

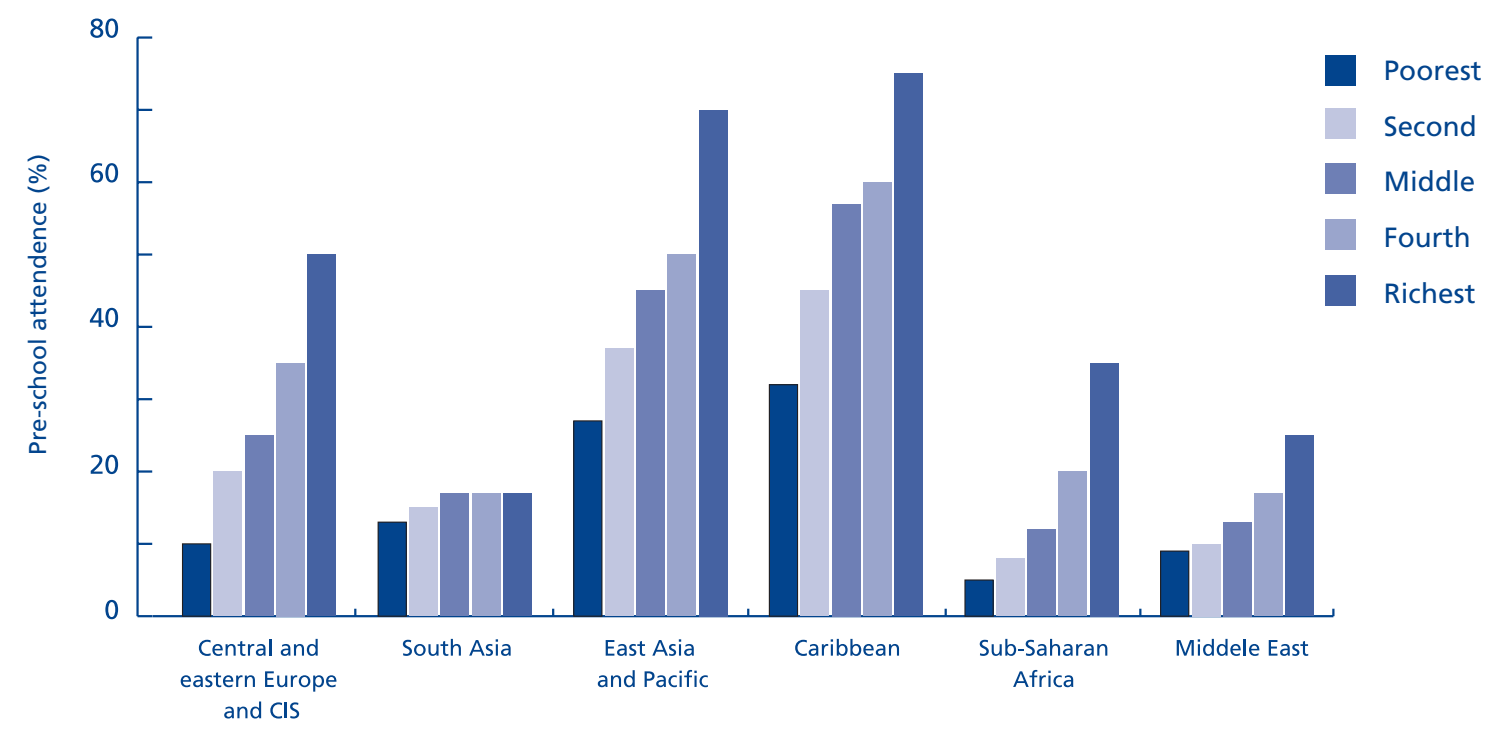

Source: Engle et al. (2011). 
merely reinforce existing inequalities of opportunity and outcome. Currently, children from better-off families are much more likely to access ECCE than are children from the poorest families.

This chapter examines efforts to provide greater access to ECCE in the African context. Overall, significant progress has been made in the last two decades. Governments largely accept that accessible and high quality ECCE is a core element of any EFA strategy and have developed policy frameworks and plans to ensure it. A few countries, such as Kenya and Ghana, have made substantial progress in the development of ECCE services. The region has also become a major focus for international donors that are concerned about enhancing child development outcomes, (e.g. the World Bank's Africa Early Childhood Development (ECD) Initiative, which started in 2008, as well as initiatives by
UNICEF, Save the Children, the Open Society Foundation and many others). Some innovative, low-cost approaches are being used to deliver ECCE through community-based initiatives but systematic evaluations of programme effectiveness are relatively rare. One notable exception is the randomised impact evaluation of a Save the Children community-based programme in rural Mozambique, which demonstrated cognitive, fine motor and socio-emotional benefits, as well as higher levels of school readiness and significantly increased primary school enrolment (Martinez et al. 2012).

Acknowledging the increasing number of diverse and innovative initiatives in the region, it is nonetheless possible to identify five general and widespread characteristics of ECCE (summarised in Box 1.1). The rest of the chapter expands on these characteristics.

\section{Box. 1.1: Characteristics of ECCE programming in sub-Saharan Africa}

- With a few exceptions, governments have only recently begun to prioritise ECCE, largely relying on private providers and NGOs, including community and faith-based initiatives.

- ECCE has been included in many multi-sectoral and sectoral policies and strategic plans, but implementation of these policies and plans is hampered by a severe shortage of government funding, although much support comes from donors.

- Many governments have yet to establish effective governance of ECCE, including regulation and quality monitoring in private, faith-based and community facilities.

- There are significant shortages of skilled early years teachers and other ECCE personnel, including managers and community workers.

- Much ECCE is still based on a model of formal pre-schools in urban areas. Some African countries have introduced innovative, low-cost, community-based programmes. 


\section{ECCE providers are largely non- governmental}

Private institutions account for about two thirds of pre-school enrolment in the majority of sub-Saharan African countries, as shown in Figure 2 (UNESCO 2010a: 36). Many private early learning centres are located in urban areas and require the payment of fees, so access is limited to more advantaged groups. Children from poor households and those living in rural areas have limited access to ECCE services.

UNESCO (2010a: 39) presents one possible reason that private and community providers have not delivered widespread access to ECCE in sub-Saharan Africa. Private programmes will only be provided where there is a market and community programmes will only be provided where communities want them to be established. UNESCO notes that "the people most in need [of ECCE] are those that are the least informed and therefore not likely to make any requests" (UNESCO 2010a: 39). The UN agency contends that it is vital for countries to formulate policies that do not result in ECCE services being provided only where there is demand for them, as is currently the case.

Community and faith-based programmes are playing an increasingly important role, although very little data is available. Such programmes are particularly strong in Zimbabwe, Swaziland, Kenya and Malawi (Okengo 2010: 17). Community programmes have grown mainly in countries where service delivery is decentralised to communities, such as the DRC, Malawi, Mozambique, Swaziland, Zambia, and Zimbabwe. Care is often provided by volunteer or very low-paid caregivers.

Figure 2: Gross pre-school enrolment rate and the percentage of children enrolled in private schools in sub-Saharan Africa

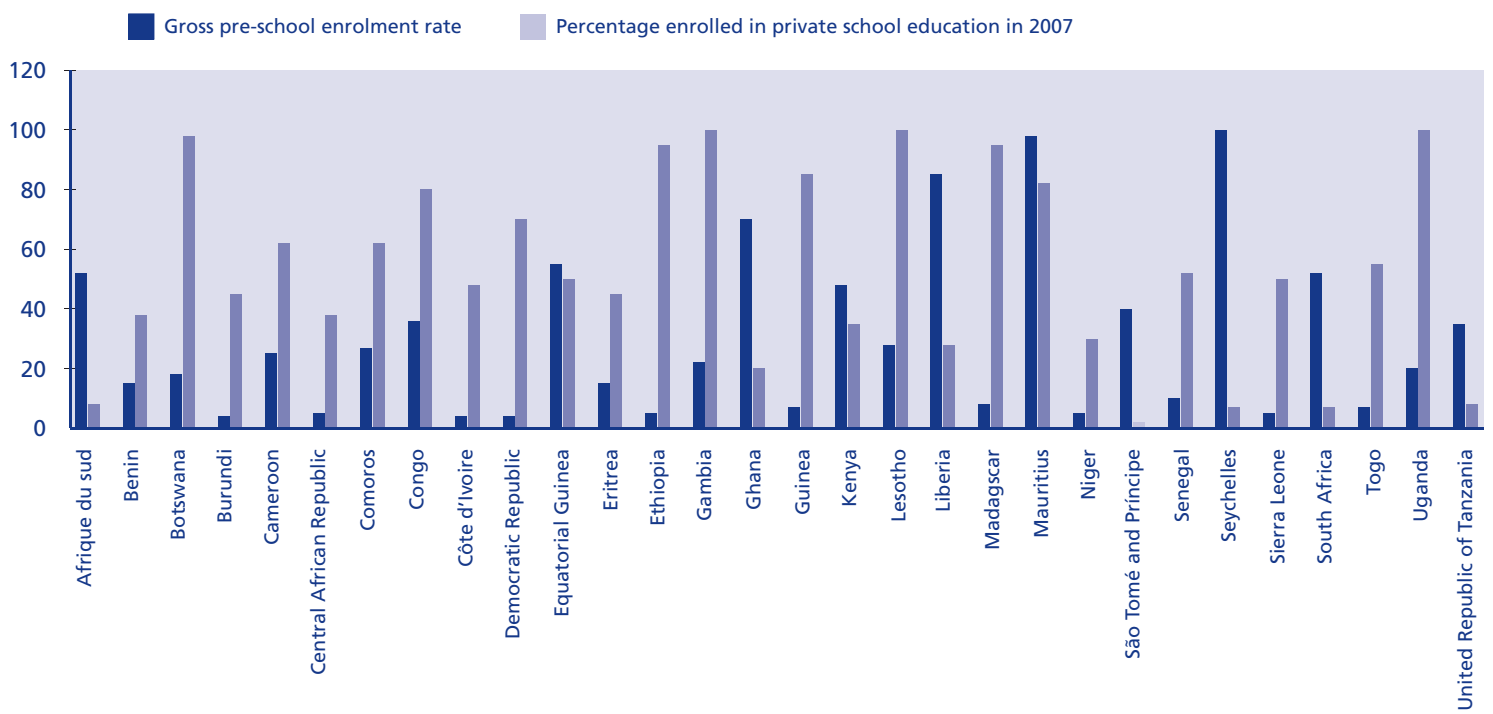

Source: UNESCO (2010a: 39), drawn from the Global Monitoring Report (2007) updated by UNESCO Institute for Statistics Dakar 


\section{Many frameworks, but few operational plans and limited budgets}

Sub-Saharan African countries have picked up on the increased emphasis on the importance of ECCE in research and policy. By December 2008, 19 sub-Saharan African countries had adopted ECCE policies, 20 were currently preparing them and 12 had not yet begun. Twenty six countries had included ECCE in multi-sectoral and sectoral policies and strategic plans, such as Poverty Reduction Strategy Papers (PRSPs), EFA goals, targets for education, and health sector-wide programmes or national plans for education, health, nutrition, and protection. Eleven countries have included ECCE in their Fast Track Initiative (FTI) Action Plans (UNESCO 2010a: 13).

Nevertheless, budgets for ECCE are seriously lacking. Governments "still provide only limited funds for programme implementation and the vast majority of programmes remain heavily dependent on external funds" (Okengo 2010: 7). In sub-Saharan Africa, the median share of public spending on pre-primary programmes was 0.3 percent (UNESCO 2010a: 72). ECCE must compete with other aspects of education, health and social assistance for limited government budgets.

Although most financing for ECCE comes from donors, donor funding for ECCE is relatively limited when compared to spending in other areas. Only about two percent of donor aid for basic education in sub-Saharan Africa is allocated to pre-primary education (UNESCO 2010a: 11). Aid for basic education dropped from US $\$ 1.72$ billion in 2007 to US $\$ 1.65$ billion in 2008, which means that spending per pupil has dropped by seven percent if increases in enrolment are taken into account (UNESCO 2010a: 225); thus ECCE is competing for its share of a diminishing total pool of funding.

Donor funding is limited partly because many countries have not yet developed credible operational plans. Many national strategies are "too generic, voluntary and qualitative, but hardly operational" (UNESCO 2010a: 52). It is difficult to use these national strategies as the basis for operational plans or medium term budgets, which are needed to attract major donor funding. ECCE also depends on several ministries and requires co-ordination between them to develop operational plans. This makes it very difficult for government departments to elaborate very specific national strategies and for donors to support them. Box 1.2 offers a commentary on the difficulties involved in developing practical and implementable ECCE strategies in contexts where there has been very little public or private provision of ECCE.

Donors have recently attempted to increase funding for ECCE. In May 2010, the multi-donor Fast Track Initiative (FTI) Catalytic Fund, managed by the World Bank, agreed to extend funding for all six EFA goals, including ECCE (UNESCO 2010a: 74). The World Bank's African ECD initiative, launched in 2008, has provided funding and technical support to ten countries selected by competition, because they exhibited a national interest and potential for moving ahead with a major ECCE policy. Ethiopia was not one of these countries. 


\section{Box. 1.2: Working on the impossible: Early childhood policies in Namibia}

Helen Penn (2008) offers an account of the challenges of implementing early childhood policies in Namibia. The government, encouraged by the World Bank, drew up an ambitious policy document as part of a World Bank-funded education sector-wide improvement plan. This aimed to provide some child development support to all young children in Namibia. However, in the Namibian context, "the reality is that there is little provision of any kind; nor is there infrastructure to support the development of provision" (Penn 2008: 380).

The proposal was to implement a pre-school year for children aged five to six, beginning with the poorest groups. Various interventions (tax breaks, easy access to land and credit and easier registration) were also proposed to encourage private sector providers to set up centres catering to younger children, particularly in poorer areas. But there was no extra money for ECCE, apart from that provided by donors, so the policy document envisioned that facilities would have to generate income by charging fees to parents. It suggested that the government should provide scholarships for children in need.

\section{Penn highlights three major issues:}

(i) Private centres were financially unsustainable. Parents in most of the 20 areas that she visited would not be able to pay fees sufficient to cover the costs of constructing basic centres and paying caregivers, even without purchasing equipment, providing transport or feeding the children. Many centres set up by NGOs or donors had battled to continue operations after funders pulled out because poor parents could not afford to pay fees.

(ii) With regard to the school-based pre-school year, schools were already very full; many were considering implementing shift systems just to keep up with demand and there were chronic shortages of early years teachers.

(iii) The ministry responsible had almost no capacity to consult stakeholders on the development of an ECCE programme, let alone to provide for the registration of facilities or ongoing technical support.

Penn argues that donor preconceptions about what interventions are necessary for development are powerful and senior officials in the local administration will adopt them even if they are inoperable. This leads to national policy frameworks that are impractical to implement.

\section{Difficulties in regulation and quality assurance}

Many governments have battled to regulate and assure quality in private, faith-based and community facilities. As a rule, in sub-Saharan Africa many private early learning centres follow highly formal models of education, focusing on the "acquisition of the 3R's (read- 
ing, writing and arithmetic) and relying on teacher-centred methods for development of knowledge and skills" (Okengo 2010: 7). This may be partly because parents see this as the most appropriate approach to preparing children for later schooling (Biersteker et al. 2008: 228).

Private centres tend to have better facilities than faith-based or community facilities, which are often not tailored to children's needs. Classrooms are overcrowded (community schools in the countries in sub-Saharan Africa that collect the relevant data have, on average, nine children per square metre). Play materials are often fragile and unsuitable for the children's age group. Many countries have not yet developed ECCE curricula. Where countries do have curricula, as in South Africa, Kenya and Ghana, the amount of time that children spend in ECCE facilities is highly variable. Many facilities use a language of instruction that is not the mother tongue of the students. ECCE can be effective in assisting children to develop language skills, but this is much more difficult unless at least some instruction is in their mother tongue (UNESCO 2010a: 11).

\section{Shortages of skilled personnel}

Progress in the development of teacher training courses that focus on ECCE has been slow. Only a quarter of teachers or caregivers in Africa have at least one year of skills training, although this varies across countries. Senegal and Benin have nearly 100 percent trained staff, while other countries have less than 20 percent trained staff. As a result, pupil-teacher ratios are higher than in any other region in pre-primary education. In 2004, pupil-teacher ratios were above 25:1 in more than half of all sub-Saharan African countries. Research indicates that a pupil-teacher ratio closer to $14: 1$ is more appropriate for child-centred teaching with young children (UNESCO 2010a: 36).

Even when there is political will for major ECCE expansion, shortages of skilled personnel can be a major barrier. In Nigeria, for example, the federal government directed states to establish at least one ECCE class at every public school. However, there was a major gap in the availability of teachers, which prevented the directive being implemented initially. ECCE studies are now being mainstreamed into the curriculum at 18 pre-service teacher training colleges to address the shortage of teachers (UNESCO 2010a: 48).

In 2010, most of the countries in Southern Africa had no systematic national training available for ECCE (Okengo 2010: 15). Few governments actually provide funds for teacher training. Only Lesotho, Zimbabwe, and Botswana have one or two year teacher training programmes. Most countries rely on one to two week workshop-type training activities conducted by partners. Although these are useful capacity-building avenues, they are mostly uncoordinated and are not systematically aimed at promoting an agreed national curriculum. They depend upon the availability of funds and are implemented by a variety of organisations. As a result, most community care providers are untrained or inadequately trained. There is a serious need for governments to either 
establish specific and appropriate ECCE training programmes or to regulate, supervise, and accredit training programmes offered by others (Okengo 2010: 19).

In Lesotho, Kenya, South Africa, and Zimbabwe, where there are large numbers of community-based facilities, early education teachers are often poorly paid (Biersteker et al. 2008: 244). Teacher motivation is thus often a problem, leading many teachers to leave community-based schools for the private sector.

Some countries have introduced a year of preschool in primary schools (usually called the 'reception year'). In South Africa, Zimbabwe, and Kenya this has created pressures to formalise training for reception year teachers because they are less qualified than primary school staff (Biersteker et al. 2008: 244). South Africa and Zimbabwe have integrated reception year training into the training programme for teachers up to the third grade and have put opportunities into place for upgrading qualifications through in-service training. This raises the status of reception year teachers, but it also means that there is more focus on teaching skills for the early grades of primary school, which tends to result in a more formal approach.

\section{Difficulties in designing scalable low- cost programmes, but some innovative policies}

Much of ECCE programme design is still based on the idea of pre-schools designed for urban areas. Okengo (2010) notes that parent/caregiver and parent/child interaction programmes have largely been absent from government strategies. Governments tend to focus on setting up new ECCE centres, although currently such centres cater for only about 20 percent of children. It is known that formal pre-school education is not a good model for extending the system of preschool: it is costly, there are not enough trained personnel, and it is often not suited to rural areas, where many of the most underprivileged children who should be targets of the programme are found (UNESCO 2010a: 52).

Okengo (2010) argues that existing community entry points, such as non school-based, preschool education and health centres, may be useful and cost-effective for providing ECCE. (See also Okengo 2011, specifically on Kenya's success in scaling up ECCE). Some African countries have introduced innovative low-cost programmes based in communities or homes (see Box 1.3). There have been many difficulties in taking these to scale as national programmes. However, where the programmes are successful, it is possible to improve enrolment rates relatively quickly. Using a combination of low-cost initiatives, Lesotho, Kenya, Namibia, Cameroon, Equatorial Guinea, South Africa, and São Tomé and Principe managed to increase pre-primary gross enrolment rates by more than seven percentage points over two years (UNESCO 2010a: 36).

When faced with limited ECCE provision by the non-state sector, some countries have decided to begin providing pre-school education through the government's basic education system, as detailed in Box 1.4. There are considerable advantages to hosting one year 


\section{Box. 1.3: Low-cost government ECCE programmes in sub-Saharan Africa}

- Namibia has launched a 10 week Rapid School Readiness Programme, which has been incorporated into the Grade 1 school curriculum to enhance the school readiness of children with no ECCE experience (Okengo 2010).

- Kenya launched a similar two month programme targeted at children from poor households in arid and semi-arid lands districts. The programme focused on children between five and eight who had not enrolled in ECCE or free primary education (UNESCO 2010a: 41). Eighty percent of the 5000 children involved in the programme have transitioned to primary school, where they did better than children who go to primary directly, but less well than those who attend regular ECCE.

- The DRC, Malawi, Mozambique, Swaziland, Zambia, and Zimbabwe have established communitybased ECCE programmes targeted at young disadvantaged children (Okengo 2010).

- Tanzania has established home-based ECCE services linked to the community-based Integrated Management of Childhood IIIness (C-IMCI) health programmes that already reach communities. Early stimulation is incorporated into the home-visiting programme to enhance parental knowledge and skills to support school readiness among children with no access to ECCE services (Okengo 2010).

of pre-school in primary schools instead of setting up independent facilities specifically for ECCE. There is usually some fixed infrastructure and management system available and co-location can ease children's transition into formal school. However, there is also the risk of 'schoolifying' early childhood, i.e. offering “... a crash course for children who are about to enter formal schooling, rather than a gradual process of building a foundation for lifelong learning, focusing on children's holistic development" (UNESCO 2004: 2).

This risk may occur because school-based services tend to fall under education ministries, which focus on academic skills. In Kenya and South Africa, "despite a curriculum that is intended to be based on active learning experiences, there is pressure in many primary schools for a more formal approach and a focus on academic skills rather than on holistic child development" (Biersteker et al. 2008: 243). Yet if the pre-school year is run by ministries other than the Education Ministry, there may be integration concerns.

\section{Summary}

- Until recently, the priority for governments across sub-Saharan Africa has been to achieve EFA goals for primary education. In many cases, ECCE was neglected and the overall balance of access is inequitable, favouring more advantaged urban children. In many countries, private providers and NGOs, including faith and communitybased initiatives, play a major role in ECCE services.

- $\quad$ Private providers are unlikely to supply 


\section{Box. 1.4: Countries that have attached pre-school classes to primary schools}

- South Africa has phased in a reception year. Grade R is provided by public schools, community-based centres, and private schools. In 2004, about 40 percent of five-year-olds were enrolled in Grade $R$ and 42 percent of Grade R programmes were community-based. The programme is funded by government grants to community-based centres and schools that employ Grade R teachers. Subsidies are targeted at the poorest schools. Funding per child is still roughly seven times lower than for a Grade 1 child, teachers are poorly paid, teacher-student ratios are high, and teachers have tended to employ more formal teaching methods. But school-based Grade R classes have improved educational access dramatically. They do not charge fees and, in the poorest schools, they provide meals. However, they have attracted parents away from community-based programmes, which have lost fee income as a result (Biersteker et al. 2008: 230-32).

- Liberia has attached pre-schools to all primary schools. There is currently a 145 percent GER in preprimary schools, partly because even older children who enrolled late because of the civil war are beginning school with pre-school (UNESCO 2010a: 20).

- Since the 1980s, Kenya has worked to improve access to ECCE. Seventy percent of primary schools in the country now have a pre-primary class and the GER of four to five year olds is 35 percent. Fortysix percent of teachers are professionally trained. However, access in urban slums and arid areas is much more limited. The government funds curriculum development and teacher training, but not salaries or per child costs such as food and materials. The need to pay fees has resulted in lower uptake and teachers often move to the private sector because of poor salaries. There is lack of connection between the ECCE and the primary school curriculum. Children are allocated to primary schools based on tests of achievement, which increases the pressure for an academic orientation at pre-school (Biersteker et al. 2008: 230-32).

- Zimbabwe replaced a widespread system of community-based centres with a pre-school year attached to primary schools. The government provides salaries for in-service trainers and curriculum development but not for teacher's salaries or running costs (Biersteker et al. 2008: 230-32).

- In Lesotho, the National Council of Women organised some early childhood education in the 1970s, which was later funded by the Bernard van Leer Foundation and UNICEF. The association of preschools advocated for the government to absorb and take over ECCE, which it began to do in 1995. Enrolment stood at 33 percent in 2005. In 2008, pre-primary education was not free and was still largely community-based. The government was piloting a programme, funded by the World Bank and UNICEF, to implement a reception year in ten schools. The programme would also fund two years of teacher training, feeding programmes, school fees for orphans, building maintenance, and education materials (Biersteker et al. 2008: 239-40).

- Gambia has piloted a child-friendly school initiative and a school readiness programme. The aim is to annex ECCE centres to all primary schools in deprived rural areas (UNESCO 2010a: 42). 
services in very poor or rural areas as they are unlikely to be profitable. Faith-based and community programmes can provide access to ECCE, particularly in rural areas, although such services may be of highly variable quality. Donor funding is limited, although it has recently increased. Donors usually require relatively well-developed operational plans that fit into wider agendas.

- Strategic and operational plans for ECCE must be realistic in terms of how rapidly they seek to expand access to ECCE. Governments may have limited capacities to implement ECCE, not only financially but also in terms of infrastructure and management.

- Many private and government ECCE facilities have emphasised formal learning as a preparation for the first few grades of primary school. School-based reception years tend to follow formal curricula, particularly if training for ECCE is integrated into training for Grade 1 to 4 teachers. There is an urgent need to introduce more developmentally appropriate child-centred curricula, supported by adequate training and supervision.

- Even when there is the political will for major ECCE expansions, shortages of skilled ECCE professionals can be a major barrier, especially where training courses are insufficient to meet demand.

- If teachers are volunteers or are poorly paid, there will tend to be high turnover, leading to the loss of investment in training.

- There are considerable advantages to locating a year of pre-school in primary schools, where there is usually some fixed infrastructure and management system available. However, any such plans should take account of available management capacities and the number of available teachers and should ensure that adding new pressures on primary schools will not undermine their existing activities.

- Some African countries have introduced innovative low-cost programmes based in communities or homes. Taking these to scale as national programmes faces many difficulties. However, it is possible to improve enrolment rates relatively quickly and at lower cost through these programmes than through formal schoolbased programmes. Greater attention should be devoted to developing and scaling up low-cost but high quality alternatives to formal pre-schools. 


\section{Chapter 2: Early childhood and primary education in Ethiopia}

Ethiopia is currently the second most populous country in Africa. According to the 2007 census, the population was estimated at 78 million in 2009 and has grown rapidly, at an average annual rate of 2.6 percent between 1994 and 2007. It is a least-developed country (LDC), ranking 171st out of 181 countries on the UN Development Programme (UNDP) Human Development Index (HDI) (UNDP 2010). Roughly 84 percent of the population lives in rural areas, where most people's livelihoods are based on subsistence agriculture. Sixty five million people live in the highland, temperate part of the country, where most are sedentary farmers, while approximately 12 million inhabit the lowlands, which cover 60 percent of the country's landmass, and are mostly pastoralist (Ministry of Education 2010b: 6).

Efforts to provide educational access to all Ethiopian citizens have faced many challenges: the country's vast territory, diversity within the population (which includes 80 different ethnic groups), frequent economic shocks and natural disasters, and persistent political turmoil (Yamada 2007). Nonetheless, in recent years rapid progress has been made, especially in primary education where the Net Enrolment Rate (NER) ${ }^{3}$ increased from 22.5 percent in 1992 to 85.3 percent in 2010/11 (Ministry of Education 2012). Less attention has been given to early childhood education until recently, when the government announced a National Policy Framework for Early Childhood Care and Education (Ministry of Education 2010b).

In this chapter, we briefly trace the history of early childhood and primary education in Ethiopia. The first section gives a brief history of ECCE and primary education in Ethiopia. The second section outlines Ethiopia's achievements since 1991 in rapidly improving enrolment in basic education and highlights the challenges facing the sector: high dropout and low throughput, declining achievement scores, and a shortage of resources. The third section describes the slow progress in the development of the ECCE sector. The final section describes the government's 2010 ECCE Strategy. We note that the government hopes that ECCE will address some of the challenges faced in primary education by increasing the number of children enrolling on time and by improving outcomes in primary school.

\footnotetext{
3 The NER is the "enrolment of the official age group for a given level of education expressed as a percentage of the corresponding population, with a high NER denoting a high degree of coverage for the official school age population. It excludes overage students to more accurately capture the system's coverage and internal efficiency." The GER is the total enrolment in a specific level of education, regardless of age (UNESCO 2009).
} 


\section{Brief history of early childhood and primary education in Ethiopia}

Secular primary education in Ethiopia began at the start of the twentieth century. The first government primary school was opened in 1908 in Addis Ababa. Haile Selassie’s imperial regime (1930-1974) largely limited educational access to students from an elite background in urban areas; the system was criticised for being bureaucratic, wasteful, overly academic and irrelevant to the lives of most Ethiopians (Teshome 2008). During the imperial regime, the Ethiopian Orthodox Church opposed the establishment of a modern public educational system and provided its own elementary and intermediate religious schools. Male children began the first stage of religious school (known colloquially as 'priest school') at the age of four, when they attended services and participated in drilled practices of the alphabet and numbers. Although priest schools were not directly linked to religious services, the children who did well went on to become deacons. Similarly, mosques gave education in the Koran for boys, although girls were able to attend if they wished (Poluha 2004).

The first secular pre-schools opened during the first decades of the twentieth century and were attached to private schools in Addis Ababa, such as the English School, the German School and the Lycee Gebre Mariam. It was only in 1962 that the Ministry of National Community Development and Social Affairs set up a few pilot pre-schools in urban areas; these were initially staffed by Swedish and American volunteers and later taken over by female community workers. The first six month training programme for pre-school workers was established in 1971. By 1972, there were 37 privately owned pre-schools and 30 community pre-schools in urban centres (Tefera et al. 2009).

In 1974, a revolution, led by Mengistu Haile Mariam, deposed the Emperor and set up a Marxist regime run by a revolutionary committee, the Derg. The regime made major efforts to expand access to primary education. As a result, the number of primary schools increased from 3196 in 1974/75 to 7900 in 1985/86 and the number of children attending increased from fewer than 1 million to 2.4 million in this period (Teshome 2008). The rapid pace of expansion resulted in low-quality buildings and teachers with only very basic or no training. Instruction was in English and Amharic, rather than in the children's mother tongue, and the curriculum was deeply politicised (Engel 2010: 5).

The Derg also prioritised state childcare, linked to the policy of encouraging women to participate in public life. Accordingly, the government encouraged communities to establish preschools, leading to the first secular pre-schools in rural areas. Enrolment at the national level increased from 7573 children in 1975 to 102,000 children in 1990 (Tefera et al. 2009). A preschool curriculum was developed, along with a training centre for early education teachers in Addis Ababa (with the assistance of UNICEF). Nevertheless, many rural childcare facilities were very basic and were run by untrained village workers. 
From the late 1970s to 1991, Ethiopia was embroiled in civil war, starting in the north and later spreading to the southeast. There were also severe droughts and a famine, which lasted from 1984 to 1986. These developments reversed much of the improved access to primary education that had been achieved. In 1991, the Ethiopian People's Revolutionary Democratic Front (EPRDF) and its allies overthrew the Derg. At this point, the country's infrastructure was devastated, access to education was low, and extreme poverty was widespread.

When EPRDF took power in 1991, the leadership identified education and health as two priority social sectors. The government's objectives regarding education have been strongly linked to attaining the MDGs, but EFA goals have not been given equal priority, with universal primary enrolment and gender equity generally seen as primary goals (Shibeshi and Arsano 2007).

\section{Rapid increases in primary enrolment}

The 1994 Education and Training Plan (ETP)

laid out the framework for the post-Derg education system, which included reorganising the school system (Ministry of Education 1994). Pre-school education was defined as catering for children aged 4 to 6 years but was not made compulsory. Primary education was divided into a first (Grades 1 to 4 ) and a second (Grades 5 to 8 ) cycle, both of which are compulsory. The main goal of the first cycle is functional literacy, while the second cycle prepares students for two years of general secondary education (Grades 9 to 10) and two years of upper secondary education (Grades 11 to 12). In 1994,
Ethiopia adopted automatic grade promotion policies for Grades 1 to 4 . Students are assessed continuously, rather than through examinations, and teachers are expected to assist struggling children so that all students are able to pass. However, in many schools this has been understood to mean that students in Grades 1 to 4 should be promoted if they have attended regularly, which has led to rapid increases in net enrolment rates (UNESCO 2007).

Since 1997, the federal government has produced an Education Sector Development Programme (ESDP) every four years as part of its broader PRSP. These lay out strategic priorities for the sector and financial requirements for implementation. Successive ESDPs and PRSPs have prioritised education as a means of ensuring equality, pro-poor growth, and rural transformation. The first three ESDPs strongly emphasised ensuring educational access.

In 2008, Ethiopia was identified in an EFA Global Monitoring Report as one of the countries making most rapid progress towards achieving the Dakar goals of universal enrolment and gender parity at the primary level (UNESCO 2007). The primary school NER has more than doubled since 1999 and is fast approaching the GER, which indicates that the primary school structure is close to a condition where children are enrolled at the appropriate age. The NER was 22.5 percent in 1992 , 75 percent in 2007/8 and 83 percent in 2008/9 (Ministry of Education 2010a). This has been a remarkable achievement that can be attributed to three major factors: the abolition of school 
fees, locally led drives to improve enrolment and extremely rapid increases in the number of schools and teachers.

\section{The abolition of fees}

School fees were abolished for primary and lower secondary schools starting in 1995/6, leading to a 23 percent increase in total enrolment and a 29 percent growth in Grade 1 intakes from 1994/95 to 1995/96, along with a further 13 percent increase in the following year (Engel 2010: 16). Communities are still encouraged to make substantial financial contributions to schools, but the removal of fees is believed to have played a significant role in achieving dramatic improvements in enrolment (Dom 2010).

\section{Community enrolment drives}

In the run-up to the 2005 elections, the EPRDF launched a massive enrolment drive. Local structures undertook advocacy efforts to encourage parents to send their children (particularly girls) to schools. Enrolment is normally the responsibility of district education offices, but parent-teacher associations and kebele administrations (elected village authorities, who are also responsible for other areas of local government) also became heavily involved. In the 2004/05 school year, Grade 1 intake increased by 38 percent compared with the previous year, partly because of the concerted efforts of local structures (UNICEF/ World Bank 2009).

The involvement of local governments has often been highly constructive: qualitative research has found that, in some areas, vil- lage authorities call community meetings to address low school attendance and will follow up with students who have not enrolled or are repeatedly absent (Anis 2007). But Engel (2010: 7) notes that some local officials have been perceived to be somewhat heavy-handed, and that "there have been efforts to return to more open community consultations on the quality of service delivery and a less coercive approach to fostering participation.”

\section{Rapid increase in inputs into education}

Finally, the Education Ministry and regional bureaus delivered dramatic increases in the number of teachers and schools. Shortages remain, but the scale of increases achieved over a short period of time is impressive compared to other countries in the region.

Between 1996/7 and 2008/9, the number of primary schools in operation increased by over 140 percent. Of the almost 15,000 new primary schools, 80 percent were built in rural areas (Ministry of Education 2010e). The government has focused on providing a first cycle (Grade 1 to 4) primary school within ten kilometres of every family and, in the regions covered by the Young Lives study (which excludes pastoralist areas and less-populated emerging regions), this goal has largely been achieved. The government has focused on building schools near marginalised communities in areas where there are large out-of-school populations because distance to school is considered a key barrier to access, particularly for girls (UNESCO 2009). However, because of resource shortages, school buildings are frequently of poor quality, 
particularly those constructed by communities from local materials.

Compared to other countries, which have seen large increases in enrolment as a result of fee-free access to primary schools, the Ethiopian government has managed to train a significant number of new teachers. The Teacher Development Programme included increases in the number of teacher training college places and summer programmes, where in-service teachers upgraded their qualifications from certificates to diplomas or degrees through short courses (Ministry of Education 2006). Between 2004/5 and 2008/9, the number of primary school teachers increased at a rate of 11.9 percent, and, impressively, the proportion of qualified primary school teachers was over 85 percent in 2007/8. This means that over 130,000 teachers were trained and deployed or upgraded their qualifications in the course of seven years (Engel 2010: 18).

In the face of resource shortages, communities have made substantial contributions to schools. Community contributions in cash and in kind to building and maintaining school facilities, hiring extra teachers or other staff, and school running costs make up a remarkable proportion - between 10 and 20 percent - of the average district budget (Garcia and Rajkumar 2008). Contributions tend to be made by all commu- nity members, not only those whose children are enrolled in school.

\section{Challenges in delivering quality basic education}

Although there have been significant recent successes in improving access to basic education, there remain significant challenges in ensuring that education is of adequate quality. The Ethiopian government is now focused on improving the quality of education while continuing to endeavour to reach populations with low rates of enrolment.

\section{Low throughput}

Not all children who have been able to enrol have managed to complete primary education and the education system is functioning less efficiently than would be ideal. Dropout rates are a major cause for concern: in 2008/9, 19.1 percent of boys and 17.6 percent of girls who were enrolled in Grade 1 dropped out (Ministry of Education 2010e: 82). The gross intake in the last grade of primary school ${ }^{4}$ - a proxy for primary completion - has grown in recent years, from 21 percent in 1999 to 52 percent in 2008, as shown in Figure 3 (Engel 2010: 9).

However, 2007/8 indicators showed a decline in survival rates. ${ }^{5}$ The Education Statistics Annual Abstract (Ministry of Education 2010a) observed

\footnotetext{
4 The gross intake is a proxy measure of primary school completion and is calculated by taking the total number of new entrants in the last grade of primary education, regardless of age, expressed as a percentage of the population at the theoretical entrance age to the last grade of primary school. It is indicative of the capacity of the education system to provide completion for the theoretical entrance age population to the last grade of primary school.

5 The survival rate measures the retention capacity and internal efficiency of an education system and is defined as the percentage of a cohort of students in the first grade of a given level or cycle of education in a given school year that are expected to reach successive grades.
} 
Figure 3: Progression and completion indicators in Ethiopia, $1999^{6}$

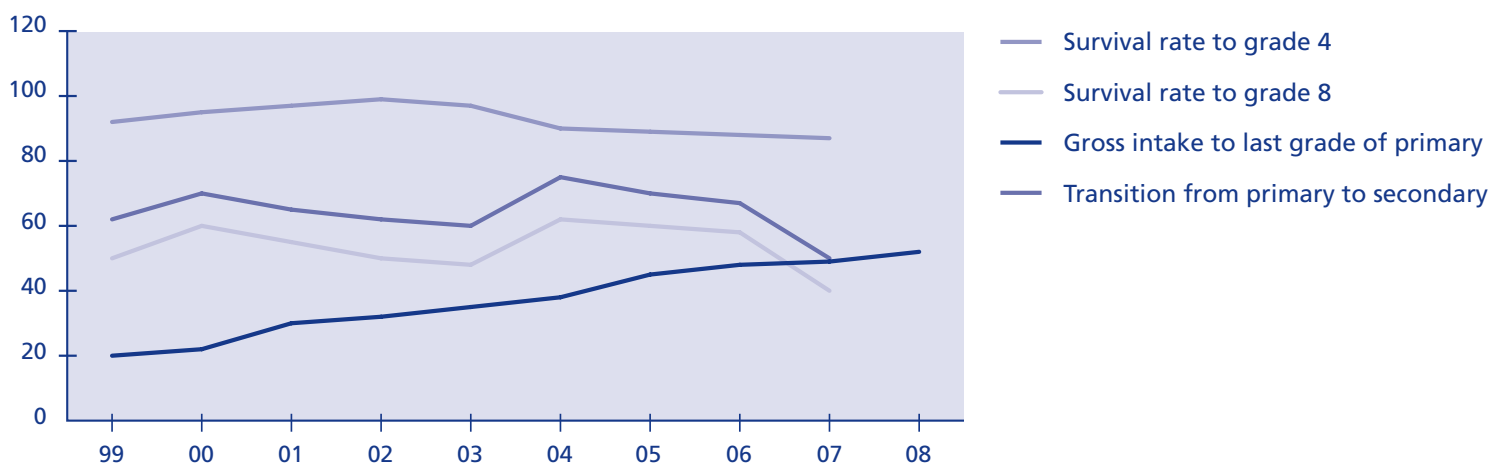

Source: UNESCO Institute for Statistics (www.uis.unesco.org/) in Engel (2010: 9).

that this decline may be linked to problems with population estimates, but also noted:

“The fact that there seems to be a 'pause' in the increase in survival rates suggests that some of the earlier, comparatively easy wins in enrolling and retaining students in primary grades may have peaked, and that additional, very focused work is necessary, particularly in rural areas ..."

Students who drop out of primary school represent a significant loss of resources to the education system (World Bank 2005a: 16). Dropout in the early grades of primary school is particularly troubling because children are unlikely to be functionally literate.

\section{Declining achievement}

Overall achievement levels in basic education have declined during the same period that educational access has increased. The National Learning Assessment (NLA), funded and supported by USAID, tested students in Grades 4 and 7 in 2000, 2004 and 2007. The 2007 NLA showed a substantial decline in student scores: the mean composite scores of students from Grades 4 and 8 (40.9 and 35.6, respectively) were lower than they had been in 2004 (48.5 and 39.7) and 2000 (48.1 and 41.1) (Ministry of Education/USAID 2008). The NLA also conducted focus groups with parents, teachers and students, who were critical of the quality of education and said that students did not acquire the knowledge and skills they expected.

\footnotetext{
6 The transition rate is the number of students admitted to the first grade of secondary education (Grade 9) in a given year, expressed as a percentage of the number of students enrolled in the final grade of the lower level of education (Grade 8) in the previous year. It conveys information on the degree of access or transition from one cycle or level of education to a higher one.
} 
Dom (2010) argues that declines in achievement are also likely to be "a predictable consequence of the shift to a more universal system, in which students facing more difficult living conditions are now involved." The NLA's own research finds that, in addition to the level of teacher training and supervision and the ability of schools to provide adequate study materials and to generate internal income, the capacity of parents to buy clothes, study supplies and meals is strongly associated with achievement scores (Ministry of Education/USAID 2008). Poorer children, who are apt to enrol in the system in greater numbers, are less likely to do well.

\section{Continued resource shortages}

Decline in achievement may be partly a result of decreases in overall school quality as a result of rapid expansion. As described above, the government has trained substantial numbers of new teachers. Nevertheless, a large proportion of teachers still do not have adequate qualifications. In 2008/9, 89.4 percent of teachers in Grades 1 to 4 had the required minimum qualification: a one year Teacher Training Institution (TTI) certificate. The minimum requirement has since increased to a two year diploma, leaving many teachers without the necessary qualification. And only 71.6 percent of teachers in the second cycle (Grades 5 to 8 ) had the required two year Teachers Training College diploma (Ministry of Education 2010a: 30). Engel (2010: 10) writes:

"Given the number of students entering the system, the decline in quality could have been significantly worse without the gov- ernment's supply-side efforts to...provide sufficient and timely resources to hire, train and deploy teachers. Therefore, education quality in Ethiopia most likely has not suffered as much as in other countries that have recently experienced enrolment surges following abolition of fees."

Nevertheless, there is no doubt that there remains a shortage of trained teachers and that this has a negative impact on the quality of instruction. Skilled teachers are particularly necessary to compensate for the low level of resources available in the system. Much of the budget goes to teacher salaries and many schools have little or no money for school administration, building, and the improvement of facilities and teaching resources (World Bank 2005a: 172). Classes are often very large. The national target for pupil-teacher ratio in primary school is 1:50. Although the national average for primary school decreased from 1:66 in $2004 / 5$ to $1: 54$ in $2008 / 9$, the ratio in the first four grades is still an average of 1:62 nationally (the ratio in Grades 5 to 8 is 1:52) (Ministry of Education 2010a: 28). There is also substantial regional variation, as shown in Figure 4.

\section{An increased focus on quality improvement}

The 2005 elections were a turning point in the development of primary education. Opposition parties made the low quality of primary education a major issue, building on frustration at pressures placed on families by the EPRDF to enrol their children and on more general concerns about growing pupil-teacher ratios and lack of classrooms. 
Figure 4: Pupil-teacher ratios by region

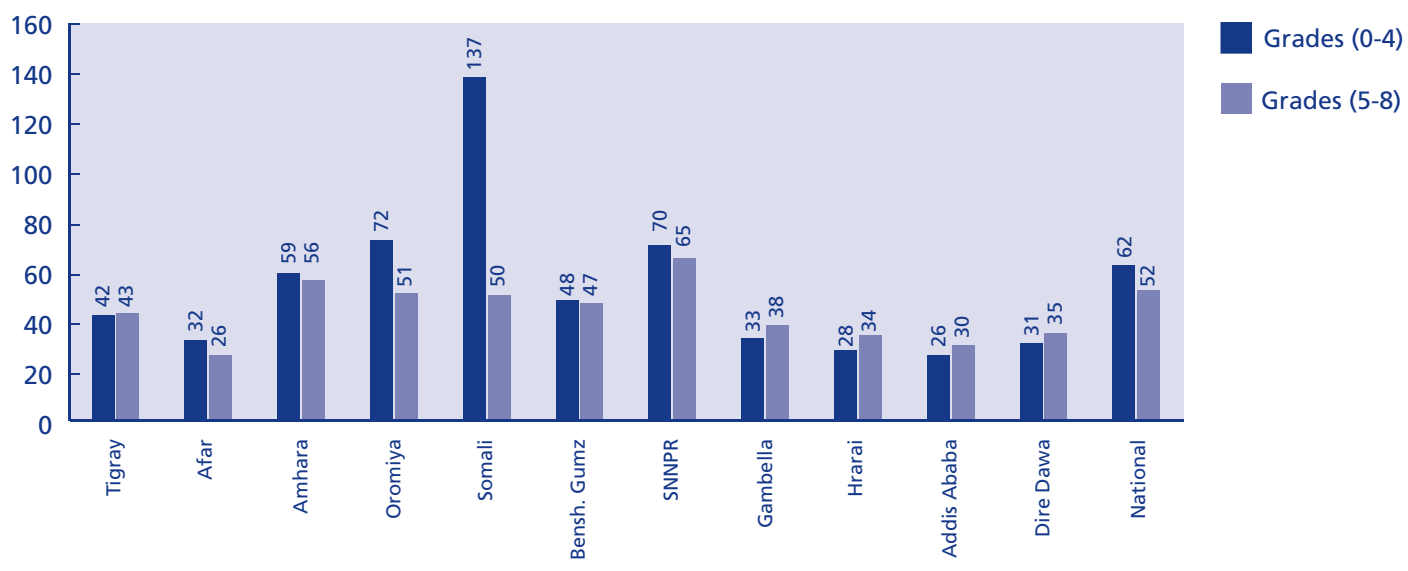

Source: Ministry of Education (2010a: 30).

The quality of education has become a key focus of subsequent education policies. The fourth ESDP was published in 2010. The sections on basic education concentrate on improving access and developing programmes "which help attract the unreached and the disadvantaged into school and ensure that they complete basic education" (Ministry of Education 2010e: 3). However, the document also argues for an emphasis on improving rates of throughput and primary school completion, arguing that "without a significant decrease in the dropout rates in the early grades (which also demands the promotion of Early Childhood Education), universal primary enrolment will never be achieved.” The 2010 ESDP also aims for:

“...a strong improvement in student achievement through a consistent focus on the enhancement of the teaching/learning process and the transformation of the school into a motivational and child-friendly learning environment" (Ministry of Education 2010e: 3).
To address the decline in education quality and the continued shortages of resources, the government launched the General Education Quality Improvement Programme (GEQIP) in 2009 (World Bank 2008). GEQIP has four pillars: the implementation of a new curriculum; the provision of textbooks and teacher guides in local languages, written centrally with donor technical support; the improvement of teacher training; the building of administrative capacity at district and school levels; and a programme of school improvement planning and school grants.

GEQIP is a multi-donor project and a number of key donors in the education sector have coordinated their assistance. The first four years of the programme cost $\$ 400$ million, of which the Ethiopian government will contribute $\$ 85$ million, the World Bank \$50 million, the FTI \$168 million, DfID \$31 million, the Netherlands \$26 million, and Italy, Sweden, and Finland a total of $\$ 41$ million (Ministry of Education 2007). 
Little information is currently available on the implementation of GEQIP. A recent social assessment by DfID found that there have been some difficulties in getting grants to schools in remote areas (Jennings et al. 2011: 50). In the first year of implementation in 2009/10, the school grants came late in the year. But the grants have been highly useful in some areas. In Somali, school grants financed maintenance, the purchase of equipment and stationary, connections to water supplies, the fencing of school compounds, and the construction of additional classrooms.

\section{Slow progress in establishing ECCE}

The focus of Ethiopia's education policy to date has been on improving primary schools in terms of both access and quality. Early childhood education has been a much lower government priority. For example, the 1994 Education Training Policy, introduced by the EPRDF government soon after taking power in 1991, undertook to develop a curriculum and quality assurance standards for ECCE. However, it cited insufficient resources for setting up ECCE programmes itself and called on the private sector, NGOs, and communities to play a major role in setting up ECCE programmes (Tefera et al. 2009). According to the second ESDP:

\footnotetext{
"Even though the importance of pre-school education is believed to be tremendous... it may not be an absolute necessity for children to pass through it... as children can get the required skill and knowledge informally from their families...in a condition where families can play such role, and in a situa-
}

tion where the country wouldn't be able to accommodate all children who are ready for school, pre-primary education is not a priority of the Government under the current economic status of the country. As a result, this programme can be covered by private, public, religious and other organisations for those children whose parents can afford to send them" (Ministry of Education 2002).

\section{Low levels of access}

In the absence of government provision of ECCE, growth in pre-school services has been limited and patchy, with an increase in coverage of only 2 percent between 1999 and 2006 (UNESCO 2009). More recently, the government reported higher rates of growth in ECCE, approximately 17.5 percent per year in the period between 2004/5 and 2008/9, largely concentrated in Addis Ababa, Dire Dawa, and Harari, the major urban centres (Ministry of Education 2010a: 21).

Between 2004/5 and 2008/9, there was also growth in both the number of teachers working at pre-schools (31.6 percent per year) and pre-school construction (26.8 percent per year) (Engel 2010: 18). However, as shown in Table 1 , the absolute number of schools and trained teachers remains small. The table shows only the five regions covered in the Young Lives study (which excludes pastoralist areas and less-populated emerging regions).

\section{Types of ECCE providers}

There are a number of different types of providers of ECCE. Box 2.1 summarises the catego- 
Table 1: National statistics on ECCE in the five regions covered by Young Lives

\begin{tabular}{|l|r|r|r|r|}
\hline & $\begin{array}{r}\text { Gross enrolment } \\
\text { ratio (percentage) }\end{array}$ & $\begin{array}{r}\text { Number of } \\
\text { pre-schools }\end{array}$ & $\begin{array}{r}\text { Number of trained } \\
\text { teachers }\end{array}$ & $\begin{array}{r}\text { Number of } \\
\text { untrained teachers }\end{array}$ \\
\hline Tigray & 1.0 & 36 & 1 & 117 \\
\hline Amhara & 2.2 & 372 & 351 & 626 \\
\hline Oromia & 3.4 & 967 & 1369 & 3325 \\
\hline SNNPR & 3.5 & 457 & 801 & 1133 \\
\hline Addis Ababa & 73.5 & 968 & 4002 & 1666 \\
\hline
\end{tabular}

Source: Ministry of Education (2010a: 21).

ries of providers included in the Young Lives survey; these are described in more detail in the next chapter.

As in other African countries where the government does not directly provide ECCE, access to education is limited to children from more advantaged backgrounds. This is because most private sector providers of ECCE charge fees and are located in urban areas. Such providers are described in Box 2.2 below.

In rural areas, there are very few private ECCE providers, either because parents cannot afford to pay school fees or because they are not informed about the benefits of ECCE and do not demand services. Ethiopia is another example of UNESCO's (2010a: 39) argument about the difficulties of relying on private and community providers of ECCE in very poor countries where there is limited awareness about its benefits.

Although service delivery in Ethiopia is highly decentralised, relatively few community-based programmes have developed in rural areas. This is different from other countries with extensive decentralisation (Okengo 2010: 17). Thus, in rural areas, most children either have no access to ECCE or are only able to attend informal priest schools.

The government's stance, namely that private, public, religious and other organisations should be tasked with providing ECCE, was questioned by academics, NGOs and even branches of the government in Ethiopia. Habtamu (1996: 104), for example, argued that the lack of detailed policy support and training of teachers by the federal government and the fact that regional governments played no role in the establishment and supervision of preschools meant that the participation rates in such schools were inevitably low. The Ministry of Labour and Social Affairs argued that ECCE suffered from both a lack of resources from the government and a lack of awareness by parents about the benefits of education (Government of Ethiopia 2006). 


\section{Box. 2.1: Types of ECCE providers in Ethiopia}

- $\quad$ Private schools are fee paying and are mostly located in urban areas.

- Public schools are funded partly by the government and partly by student fees. They are largely located in urban areas. Many public primary schools include pre-school classes. Public school facilities and the quality of service they provide are more similar to private schools than to government schools. In this paper, public and private schools are grouped together for this reason.

- Government pre-schools include pre-schools set up and managed by kebele offices, largely in urban areas. They also include a limited number of Grade 0 classes attached to government primary schools in both rural and urban areas. In both cases, teachers tend not to be paid from the school's government-allocated budget and are paid by fees from parents or from community contributions.

- Community schools are run by non-governmental providers.

- NGO schools tend to be relatively high quality, but charge low or no fees because they target poor communities. They exist predominantly in urban areas. Most community-based programmes are provided by international NGOs, such as Save the Children, the Christian Children's Fund, and SOS Children's Villages. Local NGOs, such as Addis Development Vision, Abebech Gobena Children's Care and Development Organisation, Selam Children's Village, and CODE Ethiopia also provide school facilities (Ministry of Education 2010d: 3).

o Formal church schools are provided by, among others, the Ethiopian Orthodox Church, the Catholic Church and the Seventh Day Adventist Church (Ministry of Education 2010d: 3).

These are usually attached to formal religious primary schools and high schools in urban areas. These schools combine the teaching of a secular curriculum with some religious instruction. There are many madrassas attached to mosques. These differ from church schools in that they only offer a religious curriculum, although children may acquire basic literacy from chanting and reading the Koran. Both charge fees, but these are much lower than those of private schools.

- Informal religious schools, colloquially known as priest schools, should be differentiated from formal schools. Children are typically taught by a single teacher, who hosts them in his own home or in the open air (see also Woodhead et al. 2009: Chapter 2). The instructors who run priest schools have no formal training except for a religious education and the schools do not have a set curriculum. Particularly in urban areas, the instructors may only be loosely affiliated with the local church. These schools also charge fees, but they are lower than those charged by almost all other providers. 


\section{Box. 2.2: Urban pre-schools in Ethiopia}

In 2008, UNICEF funded a survey of 65 ECCE facilities in urban areas in all regions (Tefera et al. 2009). The sample was not representative of the parents at these pre-schools because only respondents were chosen who could read and write. Nonetheless, the survey gives a picture of urban pre-schools and the types of families who can afford them:

- There were on average 110 children and three teachers per school.

- 65.63 percent of the parents surveyed had a post-secondary education (the national average is 1.2 percent) and the average number of children per family was two (the average woman in Ethiopia has 5.4 children). National statistics are taken from the 2005 Demographic and Health Survey (DHS) (Central Statistical Agency 2006).

- Children in the sample started school at age four. Pre-schools allow entrance from between two and five years.

- Pre-schools require birth certificates and vaccination certificates. Children were required to be healthy, not to have a disability and to be able to speak fluently. Even if schools were available in rural areas, which they largely are not, these conditions for entry would put pre-schools out of the reach of most children. For example, according to the situation analysis in the ECCE Policy Frame work, only 7 percent of Ethiopian children below the age of five have had their births registered and 95 percent do not have birth certificates (Ministry of Education 2010b: 10)

\section{The 2010 ECCE Policy Framework}

In light of these concerns, UNICEF offered support to the federal government for strategic planning and piloting of ECCE initiatives. In 2007, a situation analysis was conducted. This identified a number of weaknesses in the system: high fees, lack of teacher training, lack of a standard curriculum, lack of culturally relevant storybooks, low teacher salaries and thus high turnover, the use of English as a medium of instruction, and, most importantly, a lack of awareness of the importance of ECCE (Ministry of Education 2010b: 13). It also identified a number of existing opportunities:

- A curriculum for three-to six-year-olds exists but is not widely used.
- Quality assurance and licensing mechanisms and administrative offices are in place in some regions.

- There are many experienced teachers in Ethiopia, although very few have ECCE training.

- Private investors, NGOs and religious institutions have already shown an interest in ECCE.

- There are cultural and social institutions like iddirs (funeral associations) and local rural institutions such as woman's associations and farmers' associations.

- Great progress has been made in providing village-level basic health services. 
A technical committee, including the Ministries of Women, Youth and Children's Affairs, Education and Health, UNICEF, Save the Children, the Basic Education Network, and two universities worked on a number of policy documents. In 2010, the Federal Education Ministry released a National Policy Framework (Ministry of Education 2010b), Strategic Operational Plan (Ministry of Education 2010d) and Guidelines (Ministry of Education 2010c) for ECCE. The ECCE Policy Framework gives federal and regional governments a much greater role in the provision of ECCE. The Framework has four pillars, which are summarised in Figure 5. It aims to address children's needs for education, health and nutrition in an integrated fashion through collaboration between the Ministries of Women, Youth and Children's Affairs, Education, and Health.
The first two pillars prioritise parental education and health and early stimulation. Through the Family Health Package, a network of health posts and health centres is currently being set up around the country. These posts and centres are staffed by health extension workers, who in some cases supervise voluntary community health workers (Ministry of Education 2010c: 17). Health extension workers are supposed to have completed a one year training course. They currently provide antenatal care, delivery, immunisation, growth monitoring, nutritional advice, family planning and referral services. Under the ECCE Framework, they will be responsible for training parents at home and at health centres to improve knowledge about hygiene, nutrition and early stimulation (Ministry of Education 2010c: 19).

Figure 5: Pillars of the 2010 ECCE Framework

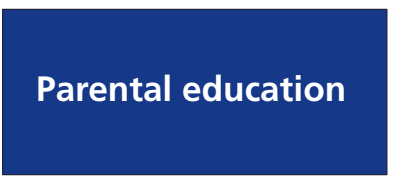

- Hygiene, nutrition and early stimulation

- All age groups

- Delivered by the Health Extension Programme, Model Families programme and Adult Literacy Programme.

\section{Health and early stimulation}

- Monitoring growth and nutrition, immunisation, and preventative health care

- Prenatal period to age three

- Part of the Family Health Package

\section{Non-formal school readiness}

- Child-to-Child programme

- Six-year-old children taught for one year by a Grade Six child

- Organised by local primary school directors and Grade Six teachers with parental support

\section{Establishment of pre-schools}

- Basic skills, social and emotional competence

- Initially six-year-old children taught for one year, extended to children aged four to six

- Ministry of Education responsible for supervision, training, curriculum development; District Education Offices responsible for community-based schools

Source: Ministry of Education (2010b) 
The second two pillars prioritise non-formal school readiness and the establishment of preschools. These policies target children between four and six years old and are the main focus for this working paper.

Improving school readiness: The Child-toChild initiative

A Child-to-Child initiative is proposed as the major strategy for improving school readiness. Grade 6 and Grade 1 teachers train Grade 5 or 6 students to be facilitators, using a teachers' guide and a facilitators' manual. The young facilitators then work with groups of sixyear-old children. Training focuses on school readiness skills related to reading, writing, and mathematics, mainly to give younger children self-confidence, develop their self-esteem and teach them to ask questions and to learn alongside other children (UNICEF 2010). The programme is to be organised by the directors of local primary schools and members of the Parent-Teacher Association are expected to provide supervision (Ministry of Education 2010b: 21).

UNICEF gave funding for a pilot of the Childto-Child initiative. Materials developed by the Child-to-Child Trust and UNICEF were adapted and translated. By June 2009, the approach had been piloted at 20 schools in Harar (with 1050 participants and 210 young facilitators), Tigray (with 1080 participants and 210 facilitators) and Oromia (with 972 participants and 182 facilitators). According to UNICEF, feedback was extremely positive. The parents of facilitators approved of the initiative because the facilitators learned about teaching. The parents of participants thought the activity was stimulating and positive. The facilitators said they learned a lot and liked teaching younger children, who grew very fond of them. A second phase of the pilot is currently underway in the Southern Nations, Nationalities and People's Region (SNNPR), Benishangul-Gumuz and Addis Ababa (UNICEF 2010). Eventually, the Guidelines anticipate that 30 Grade 5 or 6 student facilitators will be trained per school and that each will interact with 3 to 5 six-yearold children (Ministry of Education 2010c: 33).

\section{Establishment of pre-schools}

The fourth pillar of the 2010 ECCE Framework envisages a programme to establish pre-schools (Ministry of Education 2010c: 21). These will be community-based, privately run, or faith-based and it is suggested that community organisations, such as iddirs and farmers' cooperatives may also take the initiative to establish and manage pre-schools (Ministry of Education 2010c: 24). The Ministry of Education is responsible for providing an enabling environment for the establishment of pre-schools. This includes training teachers, developing a curriculum, providing play and teaching materials, providing supervision and quality assurance, and registering pre-schools at the regional level. District education offices are responsible for providing facilities, but the ECCE Framework encourages the use of existing community centres, churches, mosques, alternative basic education centres and primary school compounds, rather than building new facilities. 
According to the ECCE Framework, pre-schools will encourage the acquisition of basic skills (pre-reading, pre-writing, counting, and arithmetic) in preparation for formal schooling. There is also an emphasis on "social emotional competence, including self-regulation, intrinsic learning motivation, and the ability to cooperate with other students" and "basic life skills such as hand-washing and good eating habits" (Ministry of Education 2010c: 21). The programme aims to be "child-centred" and "will include culturally relevant, developmentally appropriate, and inclusive indoor and outdoor materials and activities" (Ministry of Education 2010c: 21). Pre-schools are also expected to be an entry point for providing immunisation programmes, growth monitoring and preventative health care.

The Guidelines envision that teachers will hold a ten month pre-school teacher training certificate from the Kotebe Teacher Education Institute or have attended a two month course to upgrade their skills, particularly in "active learning of young children.” The upgrading course will be offered through the same summer courses at Teacher Training Institutes that have been used to upgrade the qualifications of primary school teachers (Ministry of Education 2010c: 27). Teachers will be assisted by assistant teachers, who should have attended school to between Grades 8 and 10 and hold Health Volunteer or Health Assistant Certificates. The Strategic Operational Plan states that an ECCE centre will be established at Addis Ababa University between 2010 and 2011, with regional ECCE units in universities and health colleges established between 2010 and 2014.

\section{Management and budgeting}

The 2010 ECCE Framework proposes that at the national and regional levels there will be a steering group including representatives from the Ministries of Education, Health and Women's Affairs, with the Ministry of Health taking lead responsibility for children from the prenatal period to age three and the Ministry of Education taking lead responsibility for children from ages four to six and having overall responsibility for ECCE (Ministry of Education 2010b: 19). At the local level, an ECCE Implementation Committee is suggested, which will include members of the kebele Education and Training Board, the kebele Health Committee, and the kebele Women's Association.

The Framework states that bilateral and multilateral development partners will "mobilise resources and provide funding for ECCE" (Ministry of Education 2010b), but it is not clear which donors will provide assistance and how much will be provided. At the time of writing, none of the national planning documents have any budgets attached to them.

The challenge of matching policy aspirations with financial investment is highlighted by the fourth ESDP, which covers the period 2010 to 2014. It aims for an increase in the GER in pre-school to 20 percent by 2014 and for a preschool class to exist in at least 40 percent of all rural primary school compounds (Ministry of Education 2010e: 29). However, ECCE has a share of only 0.06 percent of the total budget for ESDP IV, which is around 115 billion birr. This share is entirely allocated to federal and 
Table 2: Share of programmes in the total cost of ESDP IV

\begin{tabular}{|l|c|}
\hline & Percentage of total cost \\
\hline ECCE & 0.06 \\
\hline Primary level & 42.20 \\
\hline Special education & 0.22 \\
\hline Adult education & 2.59 \\
\hline Secondary level & 13.74 \\
\hline Colleges of teacher education & 1.22 \\
\hline Technical and vocational education and training (TVET) & 5.02 \\
\hline Higher education & 24.75 \\
\hline Other programmes & 1.47 \\
\hline Advisory and support services & 8.71 \\
\hline
\end{tabular}

Source: Ministry of Education (2010e: 85)

regional government support, with no individual line items for teacher training, provision of materials, operating costs or teacher salaries.

It is not clear to what extent the government of Ethiopia will provide extra finances for the construction of facilities, operating costs or the payment of teachers. There are likely to be expectations that communities will cover all or part of these costs through user fees or community contributions. There is also some possibility that donors will provide funding once community-run or community-funded centres have been established.

\section{Summary}

- There is a long history of early childhood education in Ethiopia, with churches and mosques playing a prominent role before the secular education system developed.
Until recently, the government has left the provision of ECCE programmes up to NGOs, the private sector and communities.

- Enrolment rates have remained lower than in many other African countries. The GER for pre-school in 2008/9 was 4.2 percent. Recently, there has been rapid growth in enrolment in urban centres, especially in fee-paying private pre-schools.

- Low investment in ECCE needs to be understood in the context of the remarkable expansion in primary enrolment in Ethiopia. Although dropout rates remain high, throughput rates are declining and achievement remains low. The government is increasingly focused on improving the quality of education through GEQIP, a multi-donor education improvement programme focusing on curriculum development and textbook provision, teacher 
training, leadership training, and school improvement.

- In 2010, the government distributed a national ECCE Policy Framework. Two of the four pillars of the Framework are the focus of this paper. The third pillar (nonformal school readiness) proposes a Childto-Child programme, partly in order to bridge gaps in ECCE provision in the short term. UNICEF has already supported a pilot of the Child-to-Child programme and a second phase of the pilot is underway.

- The fourth and final pillar of the ECCE Framework is the establishment of preschools. These may be run by communities, private providers or faith-based providers, or they can be attached to government primary schools if adequate facilities are available. Communities will be encouraged to contribute resources to building ECCE facilities and paying teachers and operating costs. In rural areas, the latest ESDP aims for 40 percent of rural primary schools to have a pre-school class by 2014.

- The Framework envisages a two year pilot period for all of the pillars, beginning in 2010. It anticipates that donors will provide the funding for ECCE. However, only 0.06 percent of the funding for the latest ESDP, the main vehicle for channelling donor funding, will go to ECCE.

- The ECCE Framework will be able to build on a number of strengths in the primary system, including a government that has been able to train large numbers of teachers in a short period of time and an established ethos of communities contributing to the construction of educational facilities and the payment of teachers. Greater accessibility and quality of ECCE also has the potential to support learning achievement when children reach primary school. 


\section{Chapter 3: Studying early childhood transitions in Ethiopia}

In this chapter, we begin by briefly introducing Young Lives, the research project that has provided the data for this paper. Next, we summarise survey-based evidence about the trajectories through pre-school and the early years of primary school among Young Lives' younger and older cohorts in Ethiopia. We describe which children are able to access pre-schools and how patterns of access to early education have changed over time. We also describe trends in children's enrolment and progression in the first few years of primary school, using the longitudinal Young Lives dataset to provide greater depth to some of the trends discussed in Chapter 2. Finally, we outline the methods used to collect the qualitative data on which Chapters 4 and 5 are based.

\section{Young Lives quantitative research in Ethiopia}

Young Lives is an innovative longitudinal study investigating the changing nature of childhood poverty. Young Lives is tracking 12,000 children in Ethiopia, India (in the state of Andhra Pradesh), Peru, and Vietnam over 15 years through quantitative surveys and participatory qualitative research linked to policy analysis. Young Lives seeks to improve the understanding of the causes and consequences of childhood poverty, to examine how policies affect children's well-being, and to inform the development and implementation of future policies and practices to reduce childhood poverty. Young Lives is collecting longitudinal survey data on two cohorts of children: approximately 2000 children in each country born in 2000/1 (called the younger cohort) and 1000 children in each country born in 1994/5 (called the older cohort).

This chapter summarises data on access to ECCE and primary school from the first three survey rounds, in 2002, 2006/7 and 2009/10. In 2002, the younger cohort children were babies. By 2006/7, they were five or six and had started to attend pre-school; by 2009/10 they were eight or nine and were either still in pre-school or enrolled in the first few grades of formal school. The older cohort children were between seven and eight years old when they were first interviewed in 2002 and would have either been enrolled in pre-school or beginning formal school. In $2006 / 7$, they were 12 or 13 . If they had enrolled - and were still enrolled - they were between Grades 1 and 4 in primary school.

Young Lives covers five of the nine regions in Ethiopia, although these five regions (Addis Ababa, Amhara, Oromia, SNNPR, and Tigray) account for 96 percent of the national population. The sampling methodology adopted for Ethiopia is a sentinel site surveillance system (Outes-Leon and Sanchez 2008). Twenty sentinel sites were chosen to capture (i) the cultural and geographic diversity of the country and (ii) urban and rural differences, while ensuring that the study has a pro-poor bias. Within each sentinel site, households were selected ran- 
domly from the population of households with children of the required ages. ${ }^{7}$

\section{Increased pre-school participation in urban areas and by better-off children}

The unique design of the Young Lives sample, with two cohorts of children born seven years apart, enables us to explore how opportunities for children have changed over time. In the three figures below, we compare pre-school participation among the older and younger cohorts of children. Older cohort children were enrolled in pre-school between 1997 and 2002, while children in the younger cohort enrolled between 2004 and 2009.

Figure 6 captures information on pre-school participation of the older cohort children, 1000 of which were interviewed in 2002. Nine hundred and eighty children were re-interviewed in 2006 and 973 were re-interviewed in 2009. In 2009, Young Lives recorded an annual history of children's schooling trajectories. For each year, starting from when the child was three years of age, parents were asked whether the child attended any school, pre-school, early learn- ing programme or kindergarten for more than six months. The children were coded as having attended pre-school if they attended kindergarten or religious school for at least six months between the ages of three and five, which would have been roughly between 1997 and 1999. This does not represent children's completed pre-school trajectories, as children could still have enrolled in pre-school after age five and before the compulsory age of primary school enrolment at age seven. It underestimates the number of older cohort children who will have exposure to pre-school at some stage in their schooling trajectories.

Figure 6 divides the Young Lives sample into five quintiles (groups of equal size) according to their per capita household consumption, where the lowest quintile (20th) of families is considered as the 'poorest' and those in the highest quintile (100th) as 'least-poor.'

Children's access to pre-school is heavily influenced by the socio-economic status of their households. According to this data, among children in the poorest quintile, 2.6 percent

\footnotetext{
7 The survey is thus not nationally representative. Households in the Young Lives sample were compared to nationally representative surveys, such as the Demographic and Health Survey (DHS) in 2006. Young Lives households were slightly better-off and had better access to basic services than the average household in the same regions in Ethiopia (Outes-Leon and Sanchez 2008). However, Young Lives households owned less land and livestock and were less likely to own their own house. Young Lives also over-samples urban areas. About 86 percent of the Ethiopian population live in rural areas (Central Statistical Agency 2007: 4) but 76 percent of the Young Lives sample live in rural areas. The sample is not suited for simple monitoring of child outcome indicators. However, it is an appropriate and valuable instrument for analysing child and household behaviour and its longitudinal dynamics.

8 Household consumption per capita is considered the most appropriate poverty indicator. It is the estimated monetary value of all food and non-food expenditure in the household in the past 30 days divided by the number of household members. It includes not just commodities bought in the market but also gifts and consumption from own production. Non-food expenditure does not include expenditure on durables, such as furniture or tools.
} 
Figure 6: Pre-school attendance among the older cohort between ages three and five (between 1997 and 1999) by poverty levels

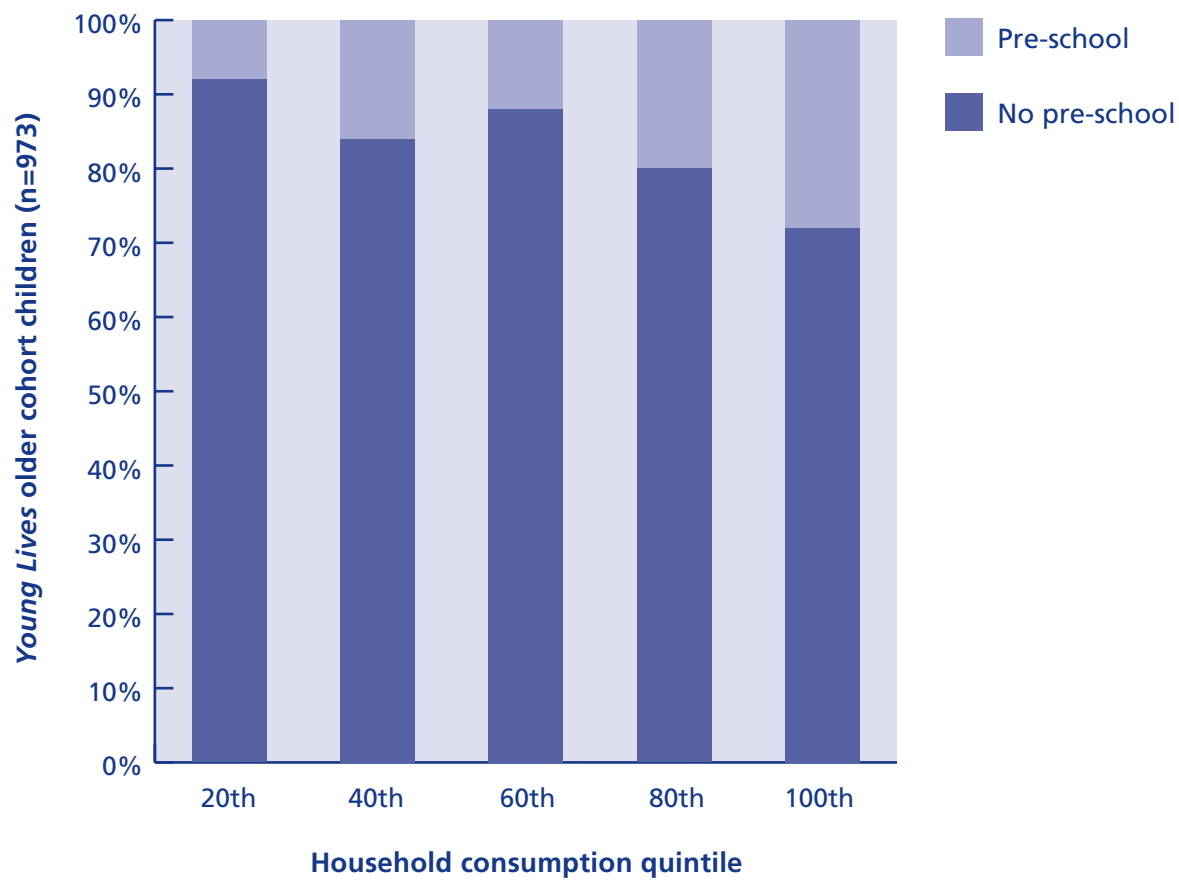

attended pre-school at some point between the ages of three and five. Among children in the highest quintile, 20 percent attended pre-school.

Figure 7 captures pre-school attendance among the younger cohort of Young Lives children between the ages of three and five, between 2004 and 2006. ${ }^{9}$ It does not represent children's completed pre-school trajectories, as children could still have enrolled in pre-school after the age of five. It underestimates the number of younger cohort children that will have expo- sure to pre-school at some stage. As in the older cohort, pre-school attendance was associated with poverty levels, strongly disadvantaging the poorest groups.

Figures 6 and 7 can be compared, as both show pre-school attendance between the ages of three and five. There have been dramatic increases in the proportion of children attending some form of pre-school in the seven years between when the older and younger cohorts attended pre-school. On average across the five quintiles, 8.5 percent of the older cohort attended some

\footnotetext{
9 Unfortunately, the survey did not collect data on the pre-school attendance of the younger cohort between 2007 and 2009. This information will be collected in the next survey round.
} 
Figure 7: Pre-school attendance among the younger cohort between ages three and five (between 2004 and 2006) by poverty levels

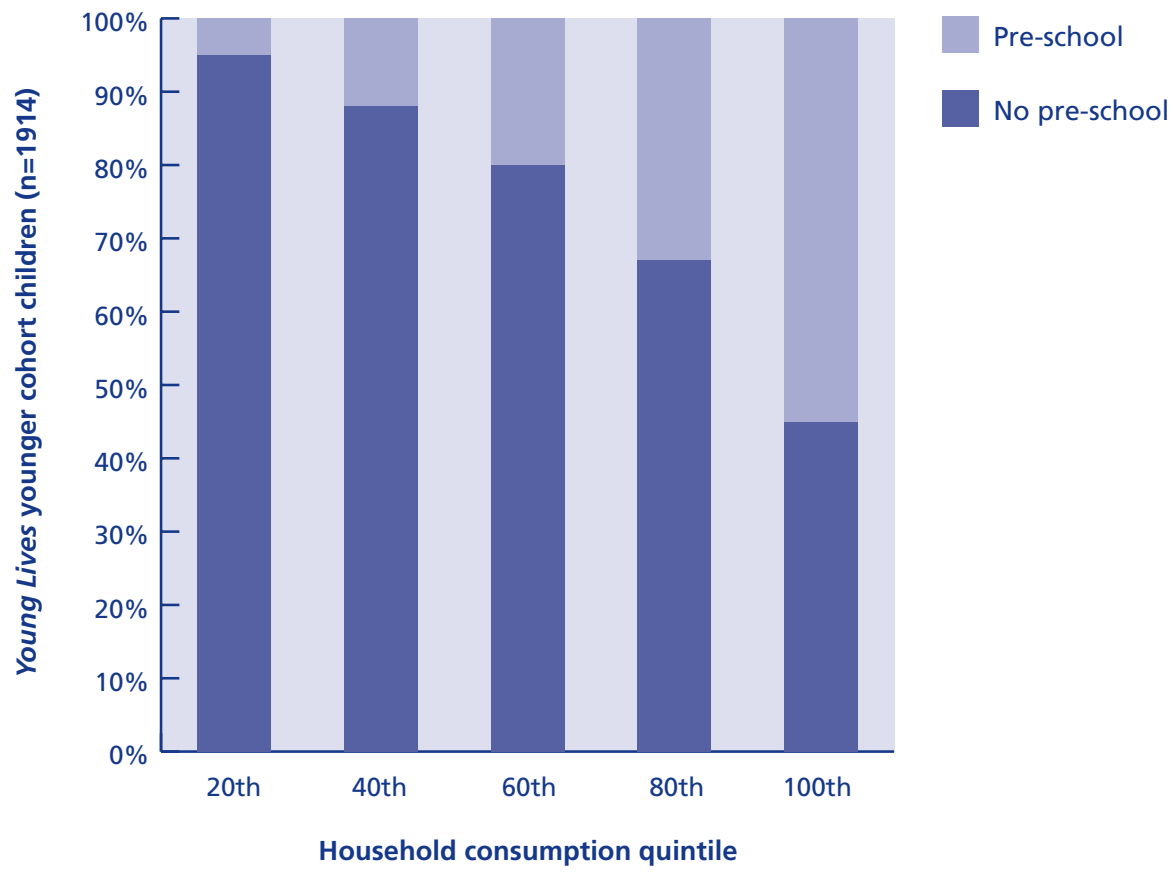

form of pre-school between 1997 and 1999, compared to 24.9 percent of the younger cohort between 2004 and 2006. This is similar to the increases found in national government data, described in Chapter 2.

National data does not enable an analysis of the family backgrounds of children attending pre-school. This is possible with Young Lives data, which contains detailed information on the socio-economic status of the children's families. Access to pre-school has improved most dramatically among children whose families have higher incomes. In the highest consumption quintile, 55.2 percent of younger cohort children attended pre-school (between 2004 and 2006), compared to 19.6 percent of older cohort children in the earlier period (between 1997 and 1999).

However, access to pre-school has stayed extremely low among children whose families have lower incomes. In the lowest quintile, 5.5 percent of younger cohort children attended pre-school, which is only slightly higher than the 2.6 percent of older cohort children in the earlier period. Private providers tend to set up pre-schools that cater to better-off families who are able to afford fees, and the community sector battles to provide enough subsidised or low-cost places for poorer children. This has also been the case in many African countries that have allocated responsibility for providing pre-school to non-state providers. 
Figure 8 breaks down pre-school attendance by region and by whether children live in rural or urban areas. ${ }^{10}$ It shows the proportion of children in each type of site who had attended pre-school for some period of time. For example, 46.6 percent of older cohort children in Addis Ababa attended pre-school, whereas seven years later, 94.2 percent of younger cohort children in Addis Ababa attended pre-school.

Figure 8 shows that there has been rapid growth in the proportion of children attending preschool in urban areas. In total, among the older cohort, 19.9 percent of urban children attended pre-school, compared to 1 percent of rural children. Among the younger cohort, 57.5 percent of urban children attended some form of preschool, compared to 3.3 percent of rural children. As found in the national data discussed in Chapter 2, there have been increases in urban centres outside of Addis Ababa: attendance has increased from 0 percent of the older cohort aged five, to 40 percent of the younger cohort aged five in urban Amhara; from 9.8 to 36.2 percent of children in urban Oromia; and from 6.5 to 47.6 percent of children in urban SNNPR.

Figure 8: Pre-school attendance among the younger cohort between ages three and five (between 2004 and 2006) and the older cohort between age three and five (between 1997 and 1999) by region and urban/rural
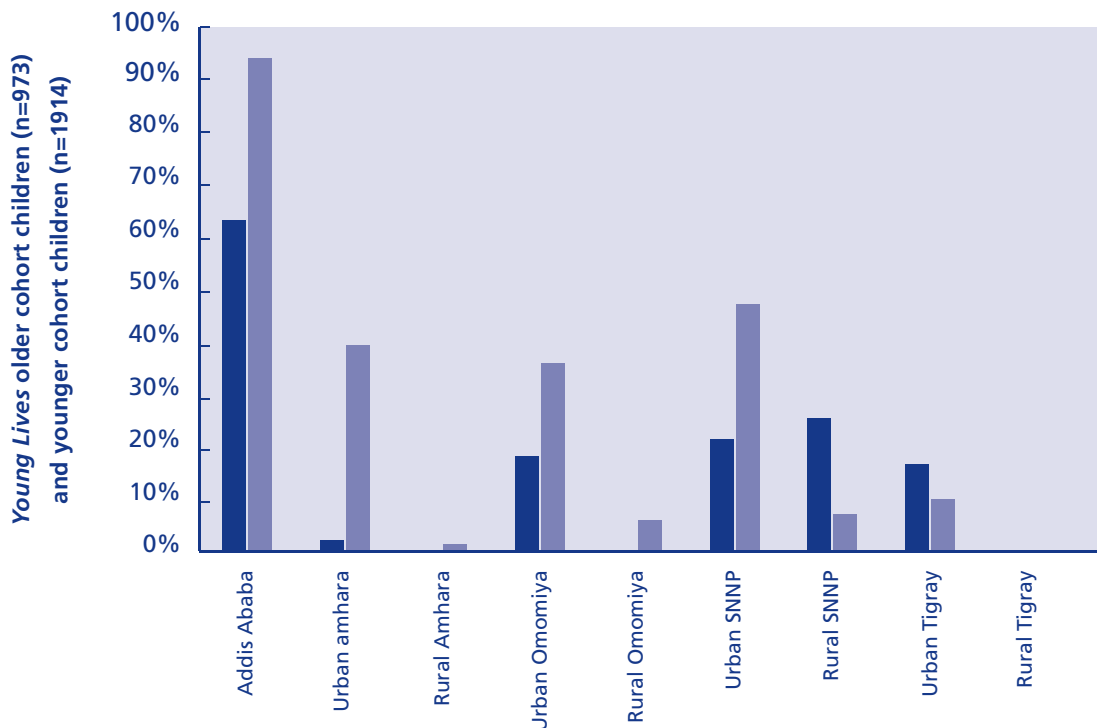

Older cohort (attendance between 1997 and 2002)

Younger cohort (attendance between 2004 and 2007)

\footnotetext{
${ }^{10}$ The numbers of children represented by each bar are different as there are more children in rural sites than in urban sites. If one considers the younger cohort, for example, there are four sites and 400 children in urban Addis Ababa. There is one site and 100 children in urban Amhara and three sites and 300 children in rural Amhara; the same is true of Oromiya, SNNPR and Tigray.
} 
The large increase in the proportion of urban children attending pre-school possibly reflects increased access to pre-schools in urban areas, as well as greater understanding among urban parents of the benefits of pre-school for children's later education.

For both the younger and older cohorts of children, there were no statistically significant differences in the proportions of girls and boys attending pre-school. This agrees with findings from an earlier monograph in this series (Woodhead et al. 2009).

\section{Pre-school providers}

Here, we analyse the types of pre-school that children attended when they were five years old. For the older cohort of children, this would have been in 1999. We analyse only the children who live in urban areas $(n=403)$, because the sample of children with pre-school experience in rural areas was too small to disaggregate into different types of providers $(n=12)$. All 12 children in rural areas who were enrolled in pre-school at some stage attended government schools. This reflects that the private sector is providing very few pre-schools in rural areas.

In 1999, socio-economic status was strongly predictive of whether children in urban areas could access private or public pre-schools, which are of the highest quality. ${ }^{11}$ Among the least-poor quintile, 18.5 percent of children attended public or private pre-schools. In

Figure 9: Type of pre-school provider among older cohort children age five (in 1999) in urban areas by poverty levels

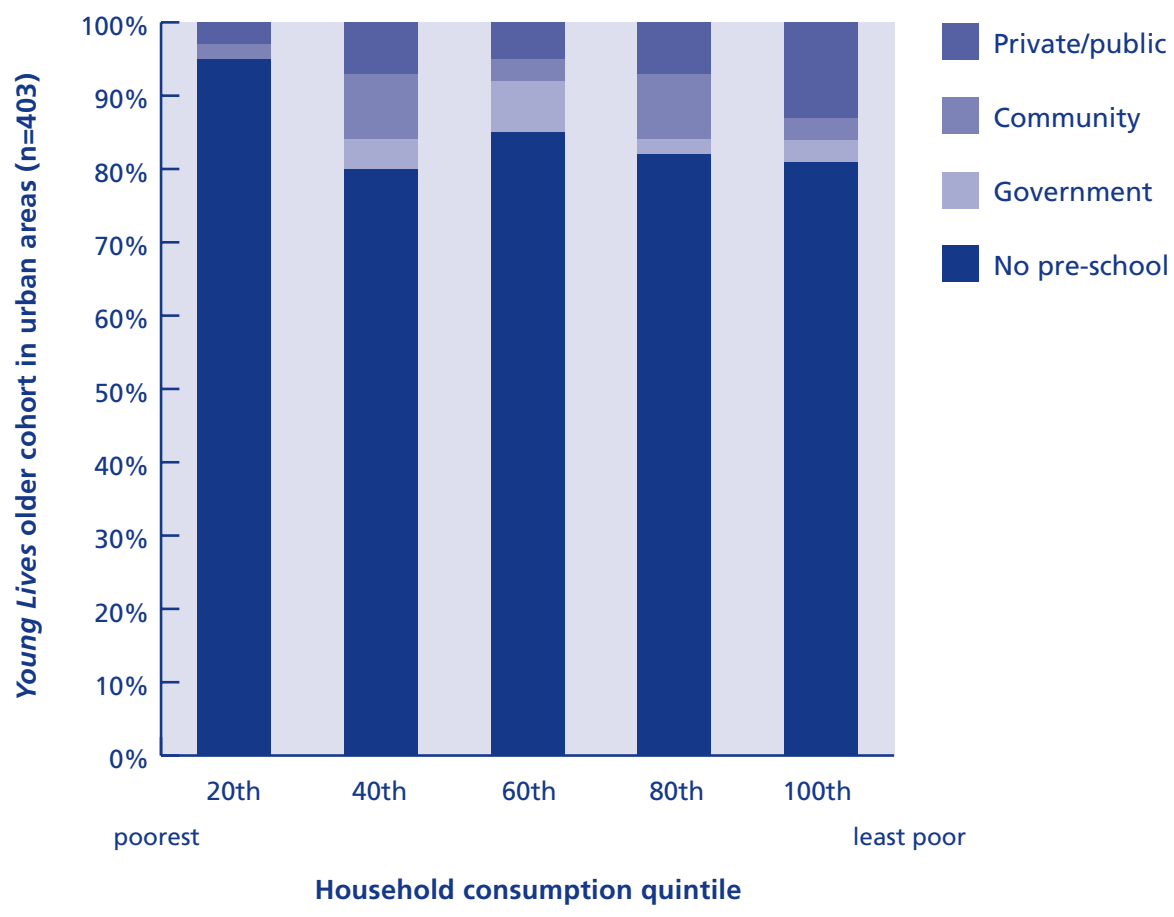

${ }^{11}$ Box 2.1 in Chapter 2 describes the different types of pre-schools. 
contrast, only 4.7 percent of children in the poorest quintile attended public or private preschools (in absolute numbers, only two out of 64 children).

Community pre-schools are largely used by those in the middle quintiles. The community category of pre-schools includes religious and NGO schools. Better-off families may choose not to send their children to religious schools, or they may not be able to send them to NGO schools, which may target less-well off families. Results for the poorest quintile should be interpreted with caution because the number of children attending pre-school - three - is too small to disaggregate. But the small number of children in this quintile attending pre-school may reflect that all pre-schools charge some form of fees, making them difficult for poor parents to afford.

In Figure 10, we analyse the 762 younger cohort children who lived in urban areas and were five years old in 2006. As shown in Figure 8, the proportion of children in urban areas who attend some form of pre-school increased dramatically in the seven years since the older cohort were five. Figure 10 shows that the increase was largely in the proportion of children in the higher income quintiles that attend public or private pre-schools (the purple bars). In 1999, 18.5 of the least-poor quintile attended private or public pre-schools. In 2006, 67.6 of this quintile attended private or public pre-schools.

Figure 10: Type of pre-school provider among younger cohort age five (in 2006) in urban areas by poverty levels

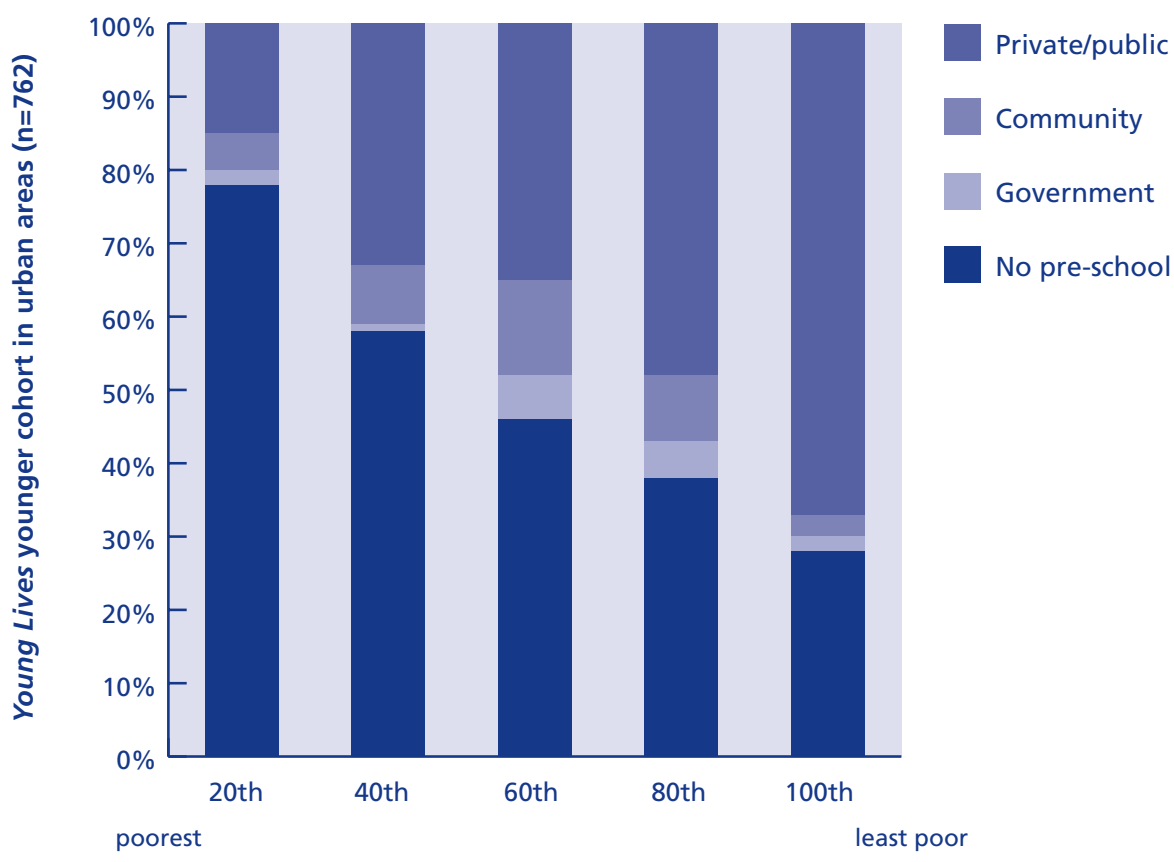

Household consumption quintile 
In 1999, 7.8 percent of children in the second least-poor quintile were in private or public pre-schools; by 2006, this had increased to 48.9 percent. The proportions of urban parents choosing private or public pre-schools were smaller but not negligible in the poorer quintiles: 35.3 percent of the middle quintile, 32.2 of the second poorest quintile, and 15.5 percent of the poorest quintile of parents sent their children to public or private pre-schools.

In urban areas, the number of children sent to community and government pre-schools was largely unchanged: 7.3 percent of the older cohort of children went to community or government pre-schools in 1999, compared to 9.4 percent of the younger cohort of children in 2006.

\section{Primary school trajectories: Late enrolment and high dropout rates}

The next two sections of this paper describe the pre-school and primary school trajectories of the older cohort of children, who were 15 to 16 years old in $2009 / 10$. They should have completed the eighth grade of primary school by this time, although the data shows that in practice very few children had completed their primary education. Considering slightly older children enables us to more closely examine some of the trends in the primary education system described in Chapter 2 - near universal enrolment, high dropout rates and low survival rates in later grades - using longitudinal data. It gives us a more complete picture of the children's trajectories as they progressed through pre-school and the early grades of primary school in the period from 1997 to 2009.
Unlike cross-sectional data, longitudinal data enables us to suggest links between the different types of experiences that children have (for example, children who enrol late may also be more likely to drop out early). Data on children's families also enables us to understand the influence of household socio-economic characteristics on children's schooling trajectories.

Figure 11 summarises detailed data about the educational trajectories of older cohort children. Data on children's schooling were collected in each year since they started preschool. As would be expected from the national statistics, very few children have never enrolled in school: the majority of older cohort children (99.0 percent) enrolled in primary school at some stage. Figure 11 shows that only 74 children (7.61 percent of the total sample) never enrolled or dropped out of school at some point. There are no statistically significant differences in the percentage of rural (1.4 percent) and urban ( 0.3 percent) children and of boys (1.4 percent) and girls (0.4 percent) who never enrolled, indicating that there is relatively equal access to enrolment.

As Lewin (2007: 28) highlights, in most African countries the majority of children who are not currently enrolled in school have been enrolled at some stage and have dropped out. In the regions of Ethiopia studied by Young Lives (which does not cover regions with substantial pastoralist populations), as in many African countries, the challenge to achieving Education for All is not getting children into school in the first place, but keeping them there and ensuring that they progress through grades. 
Figure 11 supports Lewin's point. It shows that the proportion of children who have dropped out at some point (the three rightmost bars in each category) is significantly higher (6.68 percent) than that of those who have never enrolled (0.9 percent). More boys (8.4 percent) have dropped out than girls (4.9 percent). More rural children (9.0 percent) have dropped out than urban children (3.5 percent). Qualitative research will show that, although education is nominally free, children and families still have to pay for materials, uniforms and books. They must also bear the opportunity cost of the children's time, which could otherwise be spent on paid work or working for the family. Rural children often face financial pressures, which require them to 'pause' schooling for a year or two and work to save money to cover their schooling costs. When finances are extremely tight and families face a difficulty, such as ill- ness or an economic shock, children may stop school for some time to help look after sick family members or to earn money (Orkin 2011).

A significant proportion of children that drop out of school re-enrol at a later date. Such children are represented by the green and purple bars in Figure 11. This trend is not captured in the cross-sectional data collected by the Education Ministry, but it is significant nonetheless. It indicates that it is important not to consider children who have dropped out as lost to the education system, but instead to spend time and resources on making it as easy as possible for them to re-enrol in school when they are able to do so. Schools can, for example, keep lists of children who have dropped out and contact them at the beginning of the next school year to encourage them to return.

Figure 11: Children who have not enrolled or have not been continuously enrolled by gender and rural/urban location between the ages of 3 and 15 (1997 and 2009)

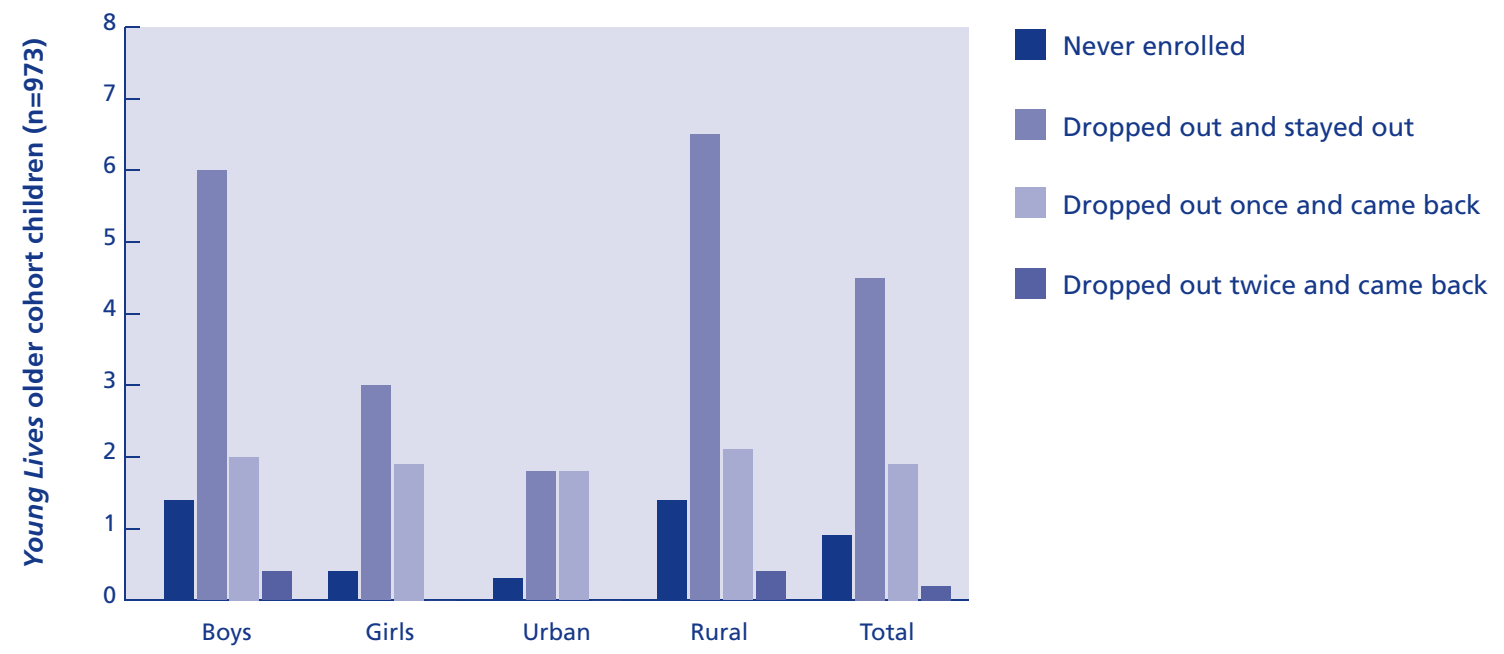


Returning dropouts are older than the children in their class and may face difficulties as a result. The same problem applies to children who have enrolled in school when they are older than seven, the compulsory age of enrolment. Lewin (2007: 24) highlights the prevalence of wide age gaps in African classrooms, where as many as 25 percent of children may be overage, with the proportion of overage children rising in higher grades. He highlights the challenges inherent in teaching children at very different stages of physical and emotional maturity. Children who are overage may become frustrated with curricula that are not relevant to their needs and interests. Lewin also argues that overage children face pressures that may compete with school, such as social expectations that they will begin to earn a livelihood, start farming or get married. They are thus more likely to drop out than children who start school at the correct age.

The Young Lives data supports this hypothesis. Figure 12 examines the dropout rates among groups of children that enrolled in school at different ages. For example, the first point on the blue bar denotes the percentage of children that enrolled when they were younger than seven and that had dropped out by the time they were 15. Four percent of children who enrolled when they were younger than seven had dropped out by the time they were 15. Figure 12 demonstrates that a much higher proportion - 17.8 percent - of children who first enrolled when they were older than ten years is likely to have dropped out by age 15 compared to children who enrol when they are younger, across genders and locations. However, it also shows that as long as children have enrolled by the time they are ten, they are not much more likely to drop out than children who enrol at the correct age. This indicates that while it is not vital to be very rigid about the compulsory age of enrolment, it is important to make every effort to ensure that children are enrolled in school by age ten. Lewin's argument explains this: if children enrol after the age of ten, they may have to deal with the pressures of marriage and work while they are still in the first few years of primary school and may see little point in continuing.

In rural areas, 14 percent of the children who enrolled when they were younger than seven had dropped out by the time they were fifteen, a higher proportion than in other groups. This may reflect the fact that in rural areas, children are often enrolled early because parents are unable to care for them. The Ethiopian first cycle of primary education uses continuous assessment, so children will often be promoted from Grade 1 to Grade 4 if they attend regularly. They may, however, learn very little, fail in the higher grades because they have not picked up the necessary skills and eventually drop out of school. In urban areas, in contrast, children are more likely to undergo some school readiness assessment. The children who enrol early may have been assessed as ready to start school and are thus less likely to drop out.

We also have information on the transition into primary school by the younger cohort of children, who were eight to nine years old 
Figure 12: Dropout rates among children who began school at different ages among the older cohort children, aged 15 (in 2009/10)

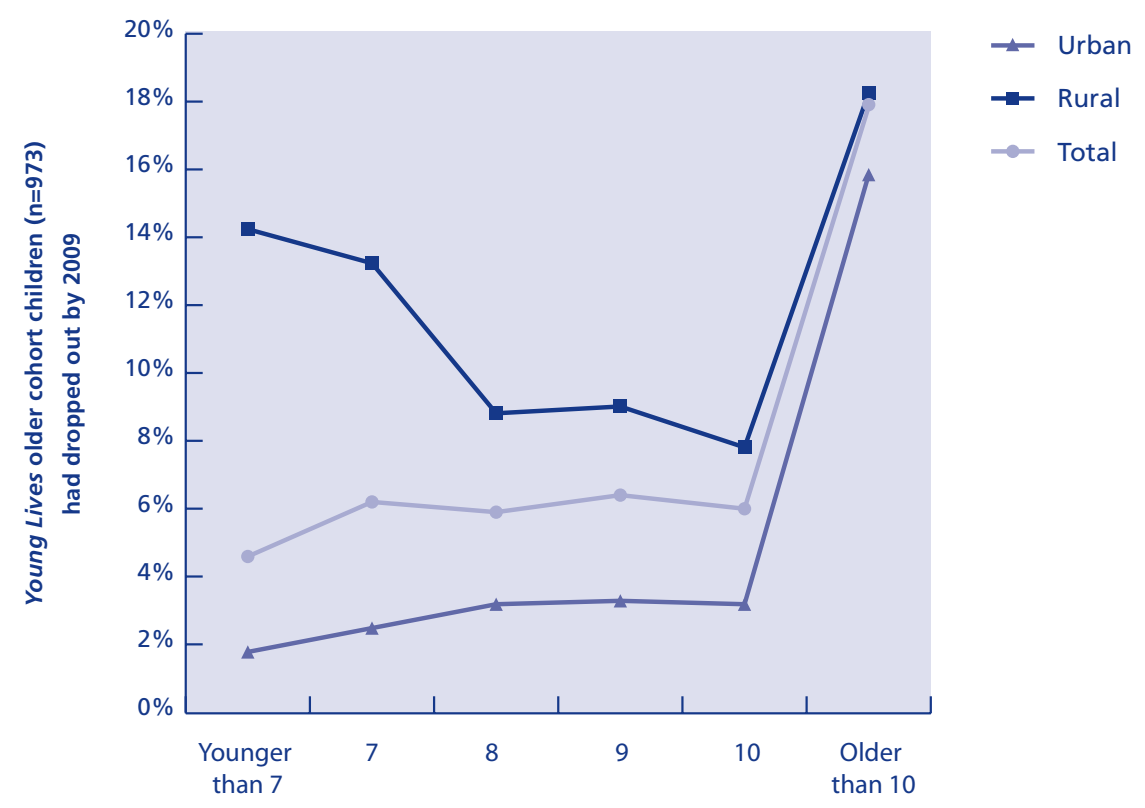

Age at which child first enrolled in school

in 2009/10. Children in Ethiopia are officially required to enter school at seven, so younger cohort children should have already enrolled in school by then. However, Figure 13 shows that Ethiopian schools still battle with late enrolment. A substantial proportion of the younger cohort children (15.7 percent) had never been enrolled in any educational institution. A small fraction (1.4 percent) had already dropped out, although the evidence from the older cohort, as shown in Figure 10, suggests that some of these students may return to school.

A further 6.9 percent of children were still enrolled in pre-school, even though they were overage and eligible to enrol in formal school. This may be because parents increasingly see pre-school as a valuable and necessary prepa- ration for formal schooling. As qualitative accounts will show, it may also be because children have been prevented from joining school at the correct age since they do not have birth certificates nor are they the correct height and physical build for teachers to consider them ready for primary school. They thus have to enrol in pre-school.

If children are progressing normally through school, we would expect most eight-year-olds to be in Grade 2. The proportion of children who are at least two grades behind where they would be if they had enrolled on time (either not enrolled, in pre-school, or having dropped out) is much higher in the poorest quintile of households (38.7 percent) than in the richest (11.7 percent). As will be seen from the qualita- 
Figure 13: School participation by poverty levels among the younger cohort age 8 (in 2009/10)

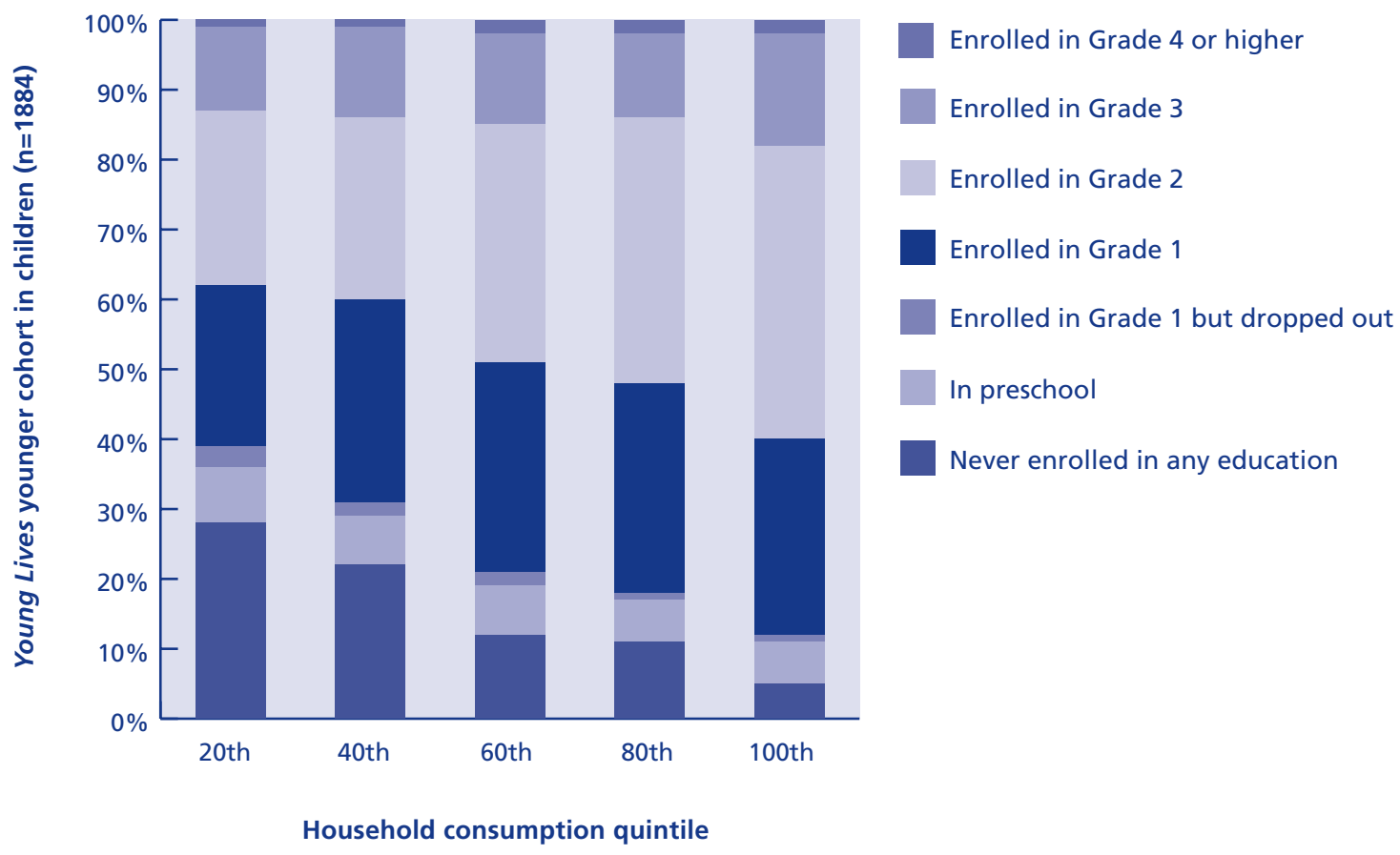

tive research reported in later chapters, this is largely because many poor families are rural and rural children often enrol late because they are needed to herd cattle or to care for their younger siblings.

\section{Summary}

- The Young Lives data allows comparisons between children in the same communities at different points in time. There were large increases in the number of children attending pre-school between 2006 and 2009. The proportion of children using government or community pre-schools barely changed between 1999 and 2006, indicating that, for poorer families, there are few alternatives to fee-charging private or public schools.
- Increases in pre-school enrolment have largely occurred in urban areas. This finding agrees with the national-level data on ECCE presented in Chapter 2. The increases have largely occurred among better-off families. The rates of enrolment in preschool among the poorest quintile of Young Lives children have stayed constant and the rates of enrolment in pre-school in rural areas have stayed close to zero.

- There is a strong equity argument for a shift to arrangements that improve the level of pre-school services for children from less well-off families and in rural areas. Existing arrangements, where pre-schools are largely provided by the private sector or by NGOs, provide very little access to preschool for the poorest children. 
- The type of pre-school that children attend is heavily influenced by the socio-economic status of their households. Children from better-off families are much more likely to attend a private or public pre-school, although some poorer families in urban areas are making considerable sacrifices to send their children to private pre-schools.

- The overwhelming majority of children enrol in primary school at some stage but a substantial number of children enrol after the compulsory age of seven and are thus behind their age peers by one or two grades. The percentage of children aged eight who have not enrolled at all or who have enrolled late is much higher among the poorest families.
- Longitudinal data shows that children who enrol when they are over the age of ten or below the age of seven are more likely to drop out. Children who enrol between the ages of seven and ten are not much more likely to drop out than other children, indicating the importance of getting children enrolled at the correct age.

- The availability of pre-school means that children are more likely to enrol in primary school at the correct age, so a strong argument for broader access to pre-school is that it may reduce the number of overage and underage children and hence reduce dropout rates. Access to pre-school may ensure that children are more school-ready and thus reduce the rates of dropout. 


\section{Chapter 4: Unequal pathways into education: Case studies from an urban community}

Educational opportunities for young children are strikingly different in urban and in rural contexts, as was made clear in Chapter 3. In Chapters 4 and 5, we draw on qualitative research and case studies to explore these differences and the issues they raise for implementing policies on early childhood and transition to school.

The first round of qualitative research on Young Lives sites was carried out in late 2007 and the second round in late 2008. The research was based on a sub-sample of 40 children (20 children from the younger cohort and 20 children from the older cohort) living in five communities. Two communities were urban, one is rural (but close to a town), and two are rural and more isolated. ${ }^{12}$

The children in the sample were between the ages of 6 and 7 in 2007 and between 7 and 8 years in 2008. The five communities in the qualitative study included one site in each of five regions. Under Ethiopia's system of ethnic federalism, regions have significant responsibility for the development and implementation of policy and there is considerable diversity across regions in terms of their education policies. The selection of communities also sought a diversity of rural and urban sites to capture rural and urban liveli- hoods and different levels of connectedness and remoteness. Finally, the communities included a diversity of religions and ethnic groups. The children in the case studies were chosen to capture diversity across a number of categories: whether they were orphans or living with one or both parents, or other caregivers; whether they were attending school or not (in the case of the older cohort since the younger cohort was largely not enrolled when the first round of qualitative research took place); whether they had attended pre-school or not; and the type of schools they attended (government or private).

The methods used in all of the sites included individual interviews and participatory group exercises with children (from both the older and younger cohorts); individual interviews and focus groups with caregivers and other key stakeholders, such as teachers of pre-schools and primary schools, health extension workers, kebele chairpersons, and education and health representatives; and semi-structured observations in home, school, and community settings. The next two chapters draw on data collected from children, caregivers, and teachers, and on observations made at pre-schools and primary schools in two of the sub-sample communities in Ethiopia: an urban site we will call 'Leku' and a rural site called 'Leki' (Chapter 5).

\footnotetext{
${ }^{12}$ All names of villages, children and caregivers have been changed to ensure the anonymity of research participants.
} 


\section{Early childhood opportunities in urban Leku}

In Leku, children potentially have access to a wider range of pre-schools and primary schools than in rural areas, but access is strongly constrained by the level of fees involved. There were very few government pre-schools at the time fieldwork was carried out in 2007/8, with the result that parents had to rely on private, NGO and church-based pre-schools, all of which expected some financial contribution. In particular, the fees for better-quality private pre-schools are prohibitively expensive for most poor families. Consequently, children make the transition to school via different pathways and at very different stages of readiness. As a rule, early inequalities are reinforced as children progress, or fail to progress, through the early grades.

Leku is a district of a fast-growing business and tourist town in the SNNPR, 273 kilometres from Addis Ababa. The town has an estimated population of 156,000. Around 23,000 people live in the Leku district. Leku is one of the oldest areas in the town and there are relatively poor sanitation, water and health facilities. Many of the residents are rural migrants and are very poor. There is a widespread shortage of housing and a large number of people may live together in the same house. Many residents are older people, who depend on remittances from their children living abroad or else they depend on pensions. Others run small-scale businesses. Some residents are civil servants and factory workers.

In Leku, many children are involved in income-generating activities from the age of eight onwards, including small-scale trading, or street vending of sugar cane, bananas, potatoes or roasted beans. Children work in a family business or on their own. Children from poor households work to bring in additional income. The majority of the people in the community are jobless and do not have sufficient income to feed their children properly. Many of the Young Lives children reported that they do not get sufficient food at home, which greatly affects their school attendance and performance. Observations of the community and homes of Young Lives children indicated that they were also involved in domestic chores, such as fetching water, cleaning homes, cooking and caring for younger siblings. Girls were observed to be more involved in these activities than were boys.

When fieldwork was carried out in 2008, the following pre-schools and primary schools were available to young children in Leku:

- A formal school run by an NGO offering one year of kindergarten, Grades 1 and 2 and costing parents about 40 birr per month. The NGO also funds a number of public toilets, communal water pipes and showers, a youth recreational centre, education about HIV/AIDS, health services, and financial assistance for the poor.

- A combined pre-school and primary school run by a faith-based organisation (FBO) and located on the grounds of the local Ethiopian Orthodox Church. The school covers three years of kindergarten and eight grades of primary school and costs parents 45 birr per month. 
- Two private combined pre-schools and primary schools. These cost parents 90 to 100 birr per month for pre-school.

- Three government primary schools. One government primary school opened many years ago and included both the first cycle (Grade 1 to 4 ) and the second cycle (Grade 5 to 8). The other schools opened in 2005 and only offered Grades 1 to 4; the kebele education and health representatives said there were plans to extend one of the schools to Grade 8.

- A number of informal 'priest' schools, where a religious instructor charged about ten birr a month to teach the alphabet and various religious songs to children of preschool age. Such schools usually serve only 10 to 20 children, are held in the priest's home or outdoors and have very poor facilities.

- In addition, a public pre-school had recently opened downtown, which orphans could attend without paying; other students pay a minimal price.

The cost of fees is a major factor shaping access to schools. Better-off families are able to send their children to private pre-schools starting from the age of three. NGO- or FBO-run preschools are usually partly subsidised, but families still have to pay fees. Poorer families send their children to an NGO- or church-run preschool if one is available and they can afford the fees. Otherwise, they send their children to an informal priest school. Alternatively, they simply do not send their children to pre-school at all and wait until they are seven years old and can be admitted to Grade 1 in the government primary school.

In the rest of this chapter, we will highlight three contrasting pathways through early childhood in urban Leku, based on case studies of individual Young Lives children:

- Private pre-school to private school - illustrated by the case study of Hagos

- Priest school to church-run school - illustrated by the case study of Kelile

- Home to government school - illustrated by the case study of Aamina

These diverse, partly poverty-linked pathways echo those identified through Young Lives research in India and reported in Working Paper 58, Chapter 3 (Streuli et al. 2011).

\section{Private pre-school to private school}

Private pre-school is an option for children from economically well-off families and most often provides the foundation of a relatively privileged private education for urban children. Typically, children enter private pre-kindergarten (pre-KG) at three, then progress to lower kindergarten (LKG), and upper kindergarten (UKG) by the age of six before making the transition to first grade at seven.

As a private school teacher explained to Young Lives researchers, children acquire different types of knowledge and skills when they pass through the different levels of KGs. In pre-KG, they learn to use visual pictures and sounds, which eventually help them to start writing 
and learning their alphabets. In LKG, children start to form words and to make some short sentences by joining together two or three words. Because they learn in both English and Amharic, children improve their reading skills in both languages. In UKG, they start writing paragraphs and learn simple addition and subtraction. At the end of UKG, children are evaluated through examinations before being promoted to Grade 1. These children would normally be very far ahead of children that join primary school without any ECCE.

\section{Hagos - a private education for those who can afford it}

The case of Hagos illustrates the relative privilege of children that follow a private school pathway. When we first met Hagos in 2007, he was six years old and already in his third year of pre-school, in UKG. His mother expected that he would join Grade 1 at the age of seven. Hagos was asked to explain the difference between learning and staying at home. He said he liked to be at school because he could play on the swings and sit on chairs in the classroom. He added that he learned the English alphabet and practised how to write letters. His mother reported that Hagos showed good progress:

When he was at nursery, he was shy and his teachers told me that he did not play with other children. They had a sleeping time and they went out of school at midday. He learned the numbers and some songs. When he joined LKG, he showed improvement. He started playing. He has just started UKG, and he is very active and clever.
Overall, Hagos's mother was very happy with his pre-school and valued the facilities it offered: tap water, toilets for boys and girls, a big compound for children to play in and good teachers and babysitters. Even so, she felt the school lacked some facilities as compared to others in Leku. It did not have any computers and there was a severe shortage of learning materials. She complained that the monthly payment of 100 birr seemed expensive, especially because the family was also paying fees for Hagos's older brother, who was in Grade 1 at another private primary school. The boys' schools were both a long way from home, so it was necessary to hire a horse cart, which added an additional 55 birr a month to the costs for each child. At that time, Hagos's mother was clearly unhappy about her boys being in different schools, not least because of the extra travel costs.

We were thus not surprised on our second visit in 2008 to find that Hagos had moved to Grade 1 at the private school attended by his brother. But Hagos faced some challenges in moving to his new school, according to his mother:

I am not happy with the situation in his [new] school. I would be happy if he continued in the former school. He knew the teachers very well in his previous school. Now, he is afraid of the new teachers. His friends are also new and none of his former friends joined this school. He complained that other students beat him in the current school and the follow up from teachers is very poor. There are many students in the current school. 
Hagos's mother also explained that one of the reasons for moving him to the same school as his brother was that the fees were lower in the new school and they could also save on transport costs. She had some concerns about the quality of the new school. She said that the teachers did not properly monitor the education and discipline of individual students. However, her son had shown good progress in his educational performance. She said that he previously learned words by relating them with pictures but was now able to read and write.

Hagos also reported major differences between pre-school and first grade. He said that there were more subjects and that what he learned was different. Unlike in pre-school, there were no pictures, alphabets and other visual aids in first grade. Rather, students copied from the blackboard. In pre-school, students sat on small chairs, but in primary school two or three children sat at the same desk. Nevertheless, unlike his mother, Hagos preferred his new school, although he found some of the games rough. In this and other excerpts, YL refers to the Young Lives fieldworker.

YL - Which school do you like most?

HAGOS - I like the current school.

YL - Why?

HAGOS - This is because they [teachers]

teach us very well. I like the education and the playing.

YL - What do you play?

HAGOS - We play football and then we learn in the classroom. I also like to play on rotating [jungle gym]. However, I do not like the swing, as students fall down. I do not like the playing where children slide. I do not like to play balance either because it hurts my legs.

Despite her worries about the costs and quality of her boys' private school, Hagos's mother said she wouldn't want a different kind of education for them. She had attended a government school as a child, where she was in Grade 4 before she learned the skills her boys had mastered by Grade 1. In addition, her sons had the chance to learn computer skills, which she had not. She was also very aware that Hagos had a relatively privileged education compared with others in their community, because the family had enough money to pay private school fees.

Fieldworker visits to Hagos's pre-school confirmed that it was well-decorated with pictures of numbers, words and animals; well equipped with different teaching aids; and had well-constructed, clean toilets. Children were expected to begin their formal learning at an early age. Teachers expected them to be able to write sentences and do addition and subtraction by the time they left pre-school at age seven.

\section{Priest school to church-run pre-school}

Education has been associated with the church in Ethiopia from its earliest days and priests are seen as playing an important role in the community, including providing basic education to very young children. As described in Box 2.1 in Chapter 2, this takes various forms, the simplest of which is provided through priest schools, where children are typically taught by a single 
teacher, who hosts them in his home or outside in the open air (see also Woodhead et al. 2009, Chapter 2). The instructors at the priest schools are men that have undergone religious instruction in a monastery of the Ethiopian Orthodox Church. They are usually closely affiliated with the local Ethiopian Orthodox Church. In some cases, the church may provide facilities for priest schools, but in most cases the schools are organised informally by the priests themselves. The cost to parents is very low, so that even poor parents can afford the fees.

A group of parents from Leku, interviewed in 2008, agreed that priest schools could prepare their children for primary education because they could learn the Amharic alphabet and numbers there. They also learned how to be in a group with other children and how to behave in class. But the parents also commented that priest schools often lack proper educational facilities. Such schools do not have dedicated buildings. There are no chairs and tables: children either sit on the ground or bring chairs from their homes. A single teacher has to teach all lessons and ages. Since the students are at different levels of learning, the teacher often requires them to teach each other. Because of concerns about the quality of education in some of the priest schools, the parents said that a number of poor families choose to send their children directly to first grade at the age of seven without prior learning experience.

The case study of Kelile illustrates the benefits that informal priest schools and formal church schools can offer to families with sufficient income to pay the modest fees. Kelile moved from an informal priest school to the formal church pre-school. He went on to attend the formal church primary school.

\section{Kelile - low-cost priest school as a transition to formal NGO-run pre-school and primary school}

Kelile never knew his father, who left the area during the boy's infancy. His mother earned a living as a casual labourer. Kelile was mainly looked after by his grandmother, who suffered from a serious illness. Kelile's mother had to leave school when she became pregnant and gave birth without being married to his father. She said that other family members considered Kelile to be an illegitimate child. The family struggled with poverty.

When interviewed in 2007, Kelile's grandmother described how he joined a priest school to learn alphabets and numbers. She reported on what he had learned at the school.

YL - How did Kelile's life change after he started to attend priest school? KELILE'S GRANDM OTHER - He spends the whole day there and this is change. YL - Can he write and read? KELILE'S GRANDM OTHER - He can read but cannot write.

YL - What do you think is the advantage of learning in priest school? KELLE'S GRANDM OTHER - He identifies alphabets.... YL - What does he need now? KELILE'S GRANDM OTHER - He needs to get 
care and education. It is a good thing for a child to get everything, including food, clothing and care.

YL - So, what is [the] obstacle to sending Kelile to [formal] school now? KELLE'S GRANDM OTHER - It is a financial problem. There is no one to help him [financially].

YL - What changes has he shown because of his enrolment in priest school last year? KELLE'S GRANDM OTHER - He is now able to identify alphabets. They teach not to steal, to attend learning properly.

When we next visited the family in 2008, Kelile had moved to the combined pre-school and primary school funded by the local Ethiopian Orthodox Church. As he was already seven years old and had spent several years in priest school, his new school allowed him to be promoted to Grade 1 after he had attended pre-school for some months. His grandmother said that the quality of education in the church school was not perfect, but it was better for him to learn there than to stay at home. She also considered it better than the priest school. Kelile thought his teachers taught well but he was aware that other schools had better facilities than his school.

My school had no playing materials. It was a new school. I like play materials like zewazewye (swings). I also like the schools that have a shertate (slide). However, my school does not have such things, though they [teachers] teach well and do not ask students to leave the class.
Young Lives researchers interviewed Kelile's teacher and went to visit his new school and classroom. The school had a kindergarten class and covered Grades 1 to 8. The classrooms were well constructed and clean and had cement floors, the furniture was sturdy and there was a school library, clean toilets, and a number of playing fields. However, students had to buy their own textbooks, which was an additional financial burden on their relatively poor parents.

Kelile's teacher said that the school emphasised the use of a student-centred approach to learning. She highlighted that good Grade 1 teachers should be creative and entertaining and make students feel comfortable in class. When asked about Kelile, his teacher said:

He writes well, he attends school regularly, and his test results are also good... He doesn't miss school days...He is better than other students. He doesn't miss classes and he doesn't disturb in the class; so, I think he is a good boy.

One of the consequences of rapid primary school expansion in Ethiopia is that children begin school at very different stages of readiness. There are often children of different ages in the same school grade, because some children start late, have disrupted schooling, or aren't promoted to higher grades. Kelile's Grade 1 class was typical, with children between seven and eleven years old in the same class. Recognising this problem, Kelile's teacher felt that priest schools had a role to play in preparing children for formal school. 
While some children have graduated from $K G$, some of them join the school without having any of the foundations they need for successful learning. That is why they need special care and entertainment. I think it is better if they join after they become somewhat mature. In this society a basic start to education is offered in churches [priest schools], thus it is good if children go through such education before they come to this school.

Interestingly, this teacher had high expectations for children starting Grade 1.

At this time, in our country, to join Grade 1 a child should have the capacity to read and write. You cannot teach them how to hold a pen; we are sending children who have such problems back to their parents.

She said that parents should help their children to learn the alphabet through songs, to learn numbers, and to develop their language skills. Clearly, if teachers have such expectations of children, they will struggle in Grade 1 if they do not attend some form of pre-school.

\section{Home to government school}

The examples provided so far in this chapter illustrate early education transition experiences for children whose families find sufficient resources to pay fees and other costs associated with private schools or less expensive, partially subsidised church schools. In the Young Lives survey of 2000 households, conducted in 2006, 57.5 percent of urban parents reported that their children had attended some kind of pre- school by the age of six. Forty eight percent of children had attended a private or public preschool and 9.4 percent had attended a government or community pre-school.

The rest of the urban sample reported having no access to pre-school before their children were due to start Grade 1 at the age of seven. This final section focuses on the disadvantages of starting school straight from home, especially at a time when so many other children have already benefited from attending preschool. Aamina's experience of starting school is common in urban Ethiopia, but it is the norm in rural communities (see Chapter 5).

\section{Aamina - a delayed and difficult start to primary school}

Aamina was considerably older than Hagos and Kelile when we first met her for the study of educational transitions. As part of the Young Lives older cohort, she was already twelve years old in 2007, but only in Grade 3. We learned she had first enrolled in Grade 1 at the age of nine. She explained that she joined Grade 1 without attending either a priest school or a pre-school.

During her stay in school, Aamina's rank in class ranged between ninth and eleventh, which she considered a good performance. However, her mother was not happy with her daughter's progress as she said that Aamina had been absent from school at different times and had not paid attention to her studies. Aamina had suffered from different kinds of diseases (malaria, common cold and stomach ache) since early childhood. Her own illness and the 
illnesses of family members often prevented her from going to school.

The interview with Aamina's mother provided a fuller understanding of the many hurdles faced by her daughter. Aamina's father died when she was three. Her father's relatives confiscated their land and other possessions and the family migrated from their original home in a rural area to live in Leku. Her mother found it increasingly difficult to make a living and gave some of her children up to foster care. For a time, Aamina worked for another family as a live-in domestic servant.

The family's declining income forced them to seek support from the government and aid organisations. When Aamina was nine, the family started to get food support from an NGO, which may have helped Aamina to start her schooling. In 2007, both Aamina and her mother reported that the family suffered greatly from chronic poverty and that this had an adverse impact on her educational performance. By 2008, the situation had become worse due to high inflation. Aamina said that most of the time she ate only once a day. Since Aamina went to school without eating breakfast, she could not concentrate properly. Her mother confirmed that she could not provide her nine family members with enough food and that Aamina was sometimes absent from school due to hunger.

Aamina should have reached Grade 5 or 6 by the age of 12 but instead she was in Grade 3. Her case study vividly illustrates that poorer children and children who enrol late will tend to progress more slowly through school. Of course, both late enrolment and slow progress may be caused by the same socio-economic circumstances.

Aamina believed that she would complete secondary education and help her family, particularly her mother. Her mother also hoped she would achieve this goal. However, Aamina was concerned about the quality of education in her government school. She said that she joined the school because it was close to her house and because the family could not afford to pay for a private school. However, she was not satisfied with her current school.

The school has no director. The ex-director left and was replaced by one teacher. He is not capable to manage the school activities. It seems that there is no director in the school, and the school is hideous. I do not want to learn in that school. Sometimes, I do not even want to go to school. I am also afraid because children who learn in other schools insult me when I walk on the road in my [school] uniform. This is because students in other school consider my school as if it is least in quality. Of course, they are right, because there is no director in the school and the teachers are not teaching properly. Therefore, it is an inferior one as compared with other schools. Moreover, as the grade level increases, some of the courses become tougher and tougher. For example, I am facing difficulty in mathematics, and my result in this subject is becoming poorer and poorer. 
Hagos and Aamina's experiences of the transition into primary school and their subsequent primary school experiences were very different. Aamina's lack of pre-school experience interacted with her own and family illnesses, poverty and resulting poor nutrition, and the fact that she was overage when she enrolled for the first time, to make her schooling trajectory a slow and difficult one. In many ways, she battled intersecting disadvantages: illness and poverty at home, poor school management in the classroom and shame in her community because she did not go to a good school. By contrast, Hagos was able to move relatively easily from his private pre-school to a private primary school. He still faced challenges. His family could not afford to enrol him in the school they would have liked because it was too expensive to travel there. There were many children at his new school and he complained of bullying and lack of individual attention from teachers. Nonetheless, he was likely to have a smoother educational trajectory than would Aamina. Our third case study of Kelile offers a more optimistic picture of how a child from relatively poor circumstances has been helped by being able to attend a school of relatively good quality because it is partly subsidised by the church.

\section{Teachers' perspectives on readiness for school}

In preparing these case studies, we were also able to draw on interviews with teachers and the kebele education and health representatives. Teachers emphasised that children's readiness for school had a major impact on their subsequent school trajectories. An NGO teacher spoke about a better-off child attending a private school.

The child of the rich is being helped in three ways, one from the school, second from a good family, thirdly by being provided with the necessary reference books.

The teachers placed a lot of responsibility on parents for their children's development, possibly ignoring the influence of other structural factors, such as poverty and poor nutrition. But they did recognise the relative advantage of children who grew up in the town and received a more formal pre-school education, as compared to children who migrated from rural areas. Kelile's teacher explained.

I am comparing the students in the rural areas with the urban students. Students in the rural areas are expected to know the alphabets.... However, students in the urban areas are far ahead. They can even form sentences and read them. But rural children join Grade 1 without any knowledge. The parents just push them to come to school without any preparation.

A teacher from the NGO school, which was not attended by any of the children discussed in this chapter, agreed that children who came "from the villages" to schools in the town were less likely to be well-prepared for school, even though they were often older than the urban children starting school. Another teacher, who taught Grades 5 to 8 at a government primary school in the community, thought this was 
partly because parents didn't monitor their children.

...parents of children in this school most regularly go to market. They don't follow up with their children. Children should be followed up. They have to be asked where and how they spend the day.

But the teachers also emphasised that schools had to be ready for the children. Kelile's teacher said:

The school is expected to make the school environment more conducive so that the child may be attracted with the environment and adjust to the school environment.

The NGO teacher emphasised that private schools did take children who had not received pre-school education and were not ready for school. The schools had their own pre-schools, so they had the resources to provide a shorter course of pre-school so that the children would be ready to start Grade 1.

Private schools accept them. They won't accept them in Grade 1. They may put them in nursery... So whether it is for 1 or 2 months or even for half a semester, they should be shaped in the nursery class. Private schools make serious follow-up as there are two teachers... The two teachers in the class could shape them in the first semester and send them to lower pre-school. You see, as they are older than the other students, they may have been given the chance to be promoted before a full year. But they won't be given the chance to go to Grade 1 automatically.

Another issue affecting Leku children is that they struggle to learn in languages other than their mother tongue. As one teacher working with older students explained, English is the medium of instruction from Grade 5 on in SNNPR, where Leku is located. Children who move from rural to urban areas also struggle. Rural areas are more ethnically homogenous, so children are taught in their mother tongue in the first four grades of primary school. But when they move to urban areas, the language of instruction is usually Amharic, the national language, because of ethnic diversity in the classroom. Children thus struggle if they do not have adequate Amharic language ability. As the government school teacher explained:

Some have been learning in their local language (for instance students from the Wolayita ethnic group) and when they come here they go back to Grade 5 (from Grade 7 or 8). The reason is the language... Even if they are in Grade 8, they face difficulty in understanding some concepts since the teachers translate them [from English] into Amharic. So, some don't understand Amharic well and prefer to go back to lower grades.

\section{Opportunities and challenges in urban Ethiopia}

As was explained in Chapter 2, the 2010 ECCE Framework anticipates that the non-governmental and private sectors will continue to provide early education in urban areas. How- 
ever, insofar as the ECCE Framework aims to improve the equity of access to pre-school, this chapter highlights three areas where difficulties are likely to arise in doing so.

\section{Costs and quality of provision}

The status of NGO, private and faith-based pre-school providers in urban areas means that there are major differences between children's ECCE experiences, based on what their parents can afford. Cost considerations also influence the length of time that children are able to attend pre-school, with some families only able to afford one or two years and many that are not able to afford pre-school at all and must send their children directly to Grade 1. As a result of the widely differing pre-school experiences, primary school teachers argue that children arrive at school with dramatically different levels of preparation. Children who attend pre-school are reported to fare much better in the transition to primary school and teachers complain that children who haven't attended pre-school aren't school-ready. Leaving early education to the non-governmental sector, as government policy promoted before the 2010 ECCE Framework, has had profoundly inequitable consequences.

Government-level intervention would be required to reduce the costs of pre-school attendance for poorer parents: school fees are currently a barrier to pre-school attendance for many children. Many NGO facilities, for example, charge parents small fees and have succeeded in providing access to poorer families, but these facilities are heavily subsidised. Without some form of subsidy, it may not be profit- able for private providers to establish school facilities: if parents are unable to afford school fees, the schools are certain not to be viable. It may be possible to provide inexpensive government incentives to educational providers, such as tax breaks or easy access to land, although these have not always been effective in other African countries.

It might also be possible to provide scholarships or grants to poor families or to subsidise the delivery of services in poorer communities. Penn's (2008) experience with ECCE in Namibia, discussed in Chapter 1, suggests that providing targeted grants to households can be extremely difficult (and expensive) because of difficulties in getting documented proof of family earnings. Kebele authorities have developed ways to assess the socio-economic status of families in order to allocate food aid in public works schemes and these could be used to target ECCE. An alternative strategy of area-based targeting (subsidising ECCE for all households in areas with a particular need) may also be pragmatic in communities where most households are poor and could avoid the need for targeting individual households.

In smaller urban centres, where private providers may not provide facilities and NGOs are less common, the government may need to adapt public services designed for rural areas so that the poorest children are able to access ECCE.

\section{Regulation and quality assurance for radi- cally different providers}

Regulation and quality assurance in urban areas will pose a number of challenges, depending 
on the type of provider. Some private and NGO providers are registered but very few religious schools are, and there is limited inspection of schools or quality assurance.

Although a play-centred, mother tongue ECCE curriculum has been developed by the government, it is rarely applied. Private, NGO and religious schools all tend to emphasise formal learning of numbers and alphabets and sometimes, in the case of private schools, instruction in English. It may be difficult for the government to persuade schools and parents to use a play-centred, mother tongue approach. There are disjunctions between the ECCE Framework, which argues that ECCE should be child-centred and aim at children's holistic development, and the requirements of the primary school curriculum, where pre-school teachers perceive that children need to have basic literacy when they start Grade 1.

At religious schools, where teachers are not trained in any form of early childhood education, they largely use recitation methods to teach letters and numbers. Such schools might provide a structure through which ECCE could be quickly expanded, but relying on these facilities to provide ECCE will require the availability of basic short courses for the people running them and a curriculum and materials. This assumes, of course, that churches and mosques are prepared to be part of the government's national plan for ECCE, which is by no means certain.

\section{Continued challenges in the primary sector}

This chapter also highlights continuing challenges in providing basic education. Although not attending pre-school is one reason that some urban children do less well than others, other factors, such as late enrolment, sickness, and poverty can result in difficult transitions into primary school and slow progression through grades. This has two implications. Firstly, older children selected to participate in Child-to-Child programmes need to be carefully selected so as not to overburden children that are already struggling to stay in school. Secondly, improving the delivery of ECCE in Ethiopia should not be seen as a solution to all of the factors that can have negative impacts on school careers. Better ECCE does not mean that school feeding schemes, improved delivery of child health programmes and scholarships for poorer students are no longer necessary to keep older children in school.

Finally, although not the main focus of this paper, teachers raised concerns about children not understanding the medium of instruction. From Grade 5 onwards, children often have to learn in English and struggle to understand the teacher, who then often translates into Amharic. Children from rural areas who have moved to urban areas also struggle to understand the language of instruction in the earlier grades. In Grades 1 to 4, children in rural areas in SNNPR are usually taught in their mother tongue, which may be one of 18 languages common in the region. Each language is relatively concentrated in a particular area. However, in urban areas there is more linguistic diversity and it is more difficult to provide mother tongue instruction. In such cases, instruction is provided in Amharic. But children who move from rural to urban areas often do not understand 
Amharic, speaking only the language of their area. There is a more challenging situation in SNNPR than in other regions, because the region is linguistically diverse.

\section{Summary}

- Qualitative research in urban Leku highlights the challenges for parents seeking ECCE where the main providers are private, NGO and church-based pre-schools. Case studies illustrate three different pathways through early childhood education.

- Hagos's family was able to pay fees in order to give him the best educational start, although attending the private pre-school involved quite a long journey. Hagos made the transition from private pre-school to the private school attended by his brother. Expectations are high for children to begin formal learning at an early age, starting in pre-school.

- Kelile's family couldn't afford the fees for private school, but he was able to attend a small priest school and then transfer to a primary school run by the Ethiopian Orthodox Church, which partially subsidises the fees charged by the school.
- Aamina is like most children in the Young Lives sample, who have no access to preschool and make a start at a government school according to the availability of a place, their parents' circumstances, and the judgement of the teachers as to their readiness. In Aamina's case, this was not until she was 9 years old, amplifying her educational disadvantage.

- Interviews with teachers reinforced the evidence of disadvantage for poor urban children with little or no ECCE experience, who very often are also overage once they begin school and who progress slowly through the grades. Even so, they have better opportunities than do rural children.

- From these case studies, three specific issues were identified, relating to the very variable costs and quality of early education: the need for quality assurance across all providers; and the continuing challenges for children once they begin primary school, notably slow progression: and the need to adjust to instruction in Amharic. 


\section{Chapter 5: Accessing 'Education for All': Multiple challenges in a rural community}

This chapter continues the accounts of early childhood begun in Chapter 4. It analyses factors shaping early educational transitions in a semi-rural community in the South-East Oromia region, (called 'Leki' for the purposes of this paper), providing in-depth accounts of the challenges faced by children in accessing early childhood and primary education. These contrast in significant ways with the experiences of urban children, described in the previous chapter.

Leki is 164 kilometres from Addis Ababa in the Oromia region. It is on the shores of Lake Ziway, so there is plentiful water and the soil is fertile. Most of the population is involved in fishing, animal husbandry and crop production. Roughly one third of households have land close to the lake and participate in an irrigation scheme that enables them to produce crops two or three times a year and to grow cash crops, such as tomatoes and onions. Vegetable farming is labour-intensive and, from a young age, most children spend several hours a day working to help support their families. Children from the poorest households also begin wage labour from as early as ten years old, working for private commercial farms and, in the case of girls, doing domestic work for other families.

Leki is about a 90 minute walk from the nearest town and thus is not as remote as other rural sites in the Young Lives study. However, between the first and second rounds of quali- tative fieldwork, the road that connected the community to the local town was washed out by the lake and people had to begin paying to cross by boat. The community attempted to build a bridge but this was also washed away and the price of boat transport was increased. The construction of a solid bridge in 2009 made access to town much easier. The village has services that are not available in many more remote rural sites: the local government has constructed four water points and some households have electricity. The village is part of the Productive Safety Net Programme (PSNP), under which families sign up a number of members, based on the poverty of the household, each of which is employed on public works projects in exchange for food.

There is very little ECCE in Leki, with the exception of a summer programme that was run by secondary school students, which will be described in the first section of this chapter. Later sections look at the many challenges faced by rural children in their transitions into - and out of - primary school. These include schoollevel barriers to access, the cost of school materials, the difficulties children face in balancing work and school, and poor quality schools.

\section{A summer school programme for children}

There were no formal pre-schools available in Leki at the time research was conducted for this report. When fieldworkers first visited the com- 
munity in 2007, the only preparation available for primary school was an innovative summer school programme, which was facilitated by college and university students during their summer vacations. The programme began in the summer of 2002 when district officials introduced a literacy campaign for young children. By the summer of 2007, a group of 22 young people was working with 210 children from the locality. Sixty six percent of local children had not yet started school, so the programme served as preparation for primary school. The remaining 33 percent of the children had completed Grade 1 in 2007, but their families were worried about their performance and encouraged them to attend the summer school for revision. One of the facilitators reported that more boys participated than girls because "girls were required for household responsibilities."

The ten week programme lasted 80 minutes per day, five days a week. It focused on teaching children to count, identify numbers, and read the Latin alphabet (the script for Oromiffa, the local language) and some words. The participating children were enthusiastic. One group of girls interviewed in 2007 said that the summer school enabled "bigger and cleverer" pupils to skip Grade 1 and go straight to Grade 2. However, the summer school was not strictly an ECCE initiative. One of the facilitators said:

We teach those children who are seven years or above. We do not accept below this age because parents are not willing to send their smaller children to the summer programme due to the rain. Even a large number of the bigger children did not join, as their parents badly needed them for family work, both at home and in the field.

The main focus of the summer school was on school readiness, in terms of skills for literacy and numeracy. It is unlikely at any rate that college students would be qualified to give children access to play-based learning opportunities.

Despite its evident popularity with both children and their parents, the summer programme was discontinued in the summer of 2008. Since it was an informal project, not part of a national or regional structure, no one had responsibility for coordinating and continuing the initiative. There was also little incentive for the university students to give their time to running the programme since they received no salary or benefits despite making a major time commitment. Since the end of the programme, the local school and kebele administration have discussed with an NGO whether it could build pre-school facilities in the village. However, nothing had been agreed when the community was next visited by Young Lives in 2009.

In summary, local education officials, local administration and the local school had clearly identified the need for some sort of school readiness programme long before the ECCE Framework was developed in 2010 and had taken the initiative to develop a cost-effective method of providing early education. This suggests that community-based ECCE interventions might be possible, but it also draws attention to the pitfalls of coordinating ECCE 
through a kebele-level committee (as suggested in the ECCE Framework) without higher-level coordination, as well as the difficulties faced by poor communities in finding enough basic funding to ensure sustainability. As Penn (2008) found in Namibia, it is important to properly budget for community-based ECCE programmes: if a community-based pre-school cannot survive on the amount that parents are able to pay, the programme will have to be subsidised, otherwise long term sustainability will not be possible.

At the same time, school readiness issues are far from straightforward in Leki. They do not just relate to a specific age group, because children in Leki don't all start school at the same age nor do they necessarily stay in school. And readiness is often as much about the schools' readiness for children as about the children's readiness for school (Arnold et al. 2007).

\section{Barriers to primary school access}

There is one primary school in Leki, which was established in 1973 for Grades 1 to 4. In 2007, the primary school was extended to Grade 6 and in 2008 it was extended to Grade 7. The primary school is located in the village. Leki was built during a 'villagisation' programme under the Derg regime, so residents live relatively close together and walk to their fields, which are outside the village. As a result, most of the children travel less than half an hour to reach the school, which is particularly important to parents, who are less likely to enrol their young children if they are required to make a long and potentially hazardous journey.
National policies encourage parents to enrol their children in primary school. There are no fees and no school uniforms, because this could prevent children from attending school. Textbooks are also provided by the school.

The language of instruction is another important factor impacting school access. In Leki, the vast majority of children speak Oromiffa - the working language in the Oromia region - as their mother tongue. Oromiffa is the language of instruction from Grades 1 to 8 . In focus groups, parents said that they are happy to send their children to schools where they get instruction in their mother tongue. This contrasts with the experiences of children in the previous chapter, who struggled because they did not properly understand the language of instruction.

Despite the many respects in which primary school is accessible to children in Leki, a major barrier is the difficulty of proving that children are seven years old, the legal age of enrolment. Of 12 Young Lives case study children who were between seven and eight years old in 2008, only one had started school more or less at the correct time. Parents complained that the school prevented their children from enrolling in Grade 1, although the parents believed that they were the correct age. It was difficult for parents to make their case to the school because birth registration is still not universal, so parents were not to prove their child's eligibility for first grade. In the absence of birth records, teachers use simple developmental tests of children's maturity. For example, they ask the children to stretch their hands over their heads and touch 
their opposite ear or they check whether milk teeth have been replaced by adult teeth, which are taken as indicators that the children are at least seven years old and old enough to join first grade (see also Woodhead et al. 2009).

\section{Aida-barriers to starting school and staying in school}

Aida had started school at around the correct age, but her education was soon disrupted by family pressures. Aida's mother reported that when she first tried to enrol her in school in 2006, the teachers refused to accept her into Grade 1, saying she didn't show enough maturity. She waited another year. At our next interview, although Aida was preparing to start school in a few weeks, her mother and the school were still discussing whether she would be allowed to join Grade 1. Aida's mother was concerned that her daughter would face difficulties learning in the first grade, saying, "My daughter has never attended school previously except going to church to learn church songs and hymns." Aida had attended the summer school in 2007, where she learned the alphabet in Oromiffa and English. She expected that this would help her to understand her lessons.

In September 2007, Aida joined Grade 1, but was only enrolled for two months. In November, her mother sent her to another community to look after her sick grandmother, so she dropped out of primary school. In 2008, she re-enrolled in Grade 1 in her grandmother's village.

AIDA'S M OTHER - My mother became sick, and had no one to help her. I sent [Aida] to my mother so that she could take care of her. YL - Was she used doing work before she went to her grandmother's? AIDA'S M OTHER - She used to fetch water, collect firewood, and care for her younger sibling.

$\mathrm{YL}$ - What additional things did she perform for her grandmother then?

AIDA'S M OTHER - She boiled coffee, cleans house and baked injera (Ethiopian traditional flat bread).

When we interviewed Aida, she offered her own account:

AIDA - My mother sent me to school last year [2007] to learn in Grade 1. I attended Grade 1 for some time, and my mother [then] took me to the home of my grandmother. YL - Why are you still attending Grade 1? Did not you pass to Grade 2? AIDA - I was neither promoted nor repeated the grade. I dropped out to help my grandmother. That is why I am still attending Grade 1 at my current school. $\mathrm{YL}$ - Which one is better - Leki or your current school?

AIDA - That of Leki is much better. Because teachers at my current school beat students when they talk, they beat all the students without identifying who disturbs the class. They beat me many times. My male teacher beat me on my hand with a stick. YL - Do teachers at Leki beat students? AIDA - No, they do not beat students. I prefer Leki School to my current school for this reason. 
YL - Which school provides better education to the students? AIDA - In my current school, teachers do not enter class on time; the education given at Leki is quality.

YL - You have performed some works; do you properly attend your education? AID A - I feel tired in class because of the workload at home.

Interestingly, Aida's mother had a different view of her daughter's schooling:

YL- You told me that she has changed school. Does not that affect her education? AIDA'S MOTHER - It does not affect her. I think it is better there. I sent her there because education is not good here. The teachers do not control students who escape from school. They do not report to parents. There is [good] control and follow up in her current school. Her cousins also help her in studying.

By the age of eight, Aida had already taken on domestic chores, coped with a change of schools and moved to her grandmother's home where her responsibilities were much greater. This undoubtedly had negative effects on her schooling and the chances of her progressing. As so often becomes clear in Young Lives research, parents and children have different perspectives on their circumstances, including what counts as a good school.

\section{Costs of school materials}

School access is only one of many challenges that families face. Even if they do not have to pay for children's fees, uniforms or textbooks, they are still responsible for providing children with school materials, such as pens and exercise books and appropriate clothes and shoes to wear to school. Many children and families explained that it is difficult for them to pay for such materials and this is sometimes given as a reason for children failing to enrol on time or for dropping out of school. As Degife's story (below) shows, it is difficult to tell the extent to which this is a major barrier and the extent to which parents and children report the high cost of school materials as being a barrier because it is more socially acceptable than saying that children are not sent to school so that they can do paid work.

\section{Degife - the cost of schooling or parental pressure to work?}

Degife was twelve when he was first interviewed in 2007. This was the first year he was enrolled in formal school. Degife's father said that poverty was the major reason that his child did not enrol in school earlier. He said that every year the family wanted to enrol Degife in school, but could not provide him with educational materials and clothing because of a shortage of money. Degife offered a different version of the story:

My parents prevented me from joining school; they forced me to herd cattle; they give more priority to their cattle than to my education. Sometimes, I have to move to the field with cattle before dusk. I am not happy about not joining school. This is my bad experience. 
When the family was interviewed the following year, Degife had already dropped out of school. Degife's mother explained that the school administration dismissed him from school because he quarrelled with the other children.

Again, Degife had a different version of the story. He said that his parents' refusal to buy him educational materials and their pressure on him to work for pay were the major reasons that he dropped out.

YL - Did you join school last year? DEGIFE - Yes, but I dropped out because my parents refused to buy me educational materials. They forced me to drop out and to keep cattle; then I had to be involved in daily work.

YL - What did you feel when you were forced to drop out?

DEGIFE - I was crying the whole day. I even refused to herd cattle that day; I only brought them home. I used to cry so many days. YL - Why do you like education? DEGIFE - If I learn, I can be a doctor. YL - What did you do after discontinuing education last year? DEGIFE - I worked in one investor's irrigation farm. I earned 110 birr per month. I had worked for two months.

YL - Did you participate in planting and harvesting onions last year? DEGIFE - Yes, I worked and earned a lot of money.

Degife's story highlights one of the major obstacles to reaching the poorest rural fami- lies. Children attending school incur costs and while they are in school they are not contributing to the family economically. Many children who work for pay report using their wages to pay for their school materials, to cover other personal costs, like soap, clothing and food, and to subsidise their households during times of economic hardship. Paid work may enable children to attend school if their parents are otherwise unable or unwilling to pay their schooling expenses. Degife's story also illustrates the trend, reported in Chapter 3, that a growing proportion of children that join school when they are significantly overage, like Degife, do not remain enrolled.

\section{Balancing work and school}

Working for pay undoubtedly competes with going to school. When interviewed in 2008, teachers reported that many boys dropped out of school to work in fishing, especially around the ages of 13 to 15. Girls tended to be involved in piece rate work on irrigated vegetable farms, which also caused them to be absent from school (Orkin 2010). A group of fourteen-yearold girls described the effect of paid work on their education. They described headaches, back pain, and problems with their joints if they did work for which they were not strong enough. Even if they went to class after work, they were not able to concentrate, because they often felt dizzy and sleepy during class. One girl explained that a friend was often absent from school to work on vegetable farms. As a result, she had dropped out of Grade 1 five times, never progressed to a higher grade, and in 2008 finally dropped out of school altogether. 
Girls frequently talked about children who were often absent being required to repeat grades.

Children also have to assist their families at home and on the family farm, which can interfere with school attendance. Girls begin to have responsibilities in the home from the time they are five or six years old and they are solely responsible for many household chores from the age of nine. These responsibilities can include caring for younger siblings and old family members. Girls are also involved in farming activities, such as weeding and harvesting. Boys are responsible for a range of farming activities. These include herding cattle, harvesting, threshing and farming. Boys start herding at the age of five or six and begin farming once they turn nine (Box 5.1).

Differences of opinion were expressed about the degree to which work interfered with schooling. Many children argued that they are largely involved in piece rate work and fishing after school or on weekends and remain enrolled in school, with their wages helping pay school fees.

But teachers did not agree that the children successfully combine work with study. They stated that working children were regularly absent from school, which often eventually led to them dropping out. One teacher, interviewed in 2007, explained that children of both sexes were attracted by the expansion of private irrigation investment in the area. Many were absent from school every day. Others disappeared from school during breaks and went to the irrigation farms to work. If working children did come to school, they often did not concentrate in class. The teacher complained that working children often did not listen when teachers and parents urged them to pay greater attention to their studies.

\section{Box. 5.1: The growing responsibilities of children in Leki}

Community representatives participating in group interviews summarised children's responsibilities as follows:

Ages 4-6: Children play with other children in the neighbourhood, they start to go to church and mosque to learn religious songs and to pray.

Ages 5-7: Girls start cleaning their houses, fetching water and firewood, making coffee, and caring for their siblings. Boys start herding cattle.

Age 7: Children can start their formal education.

Ages 8-10: Boys start helping on the family farm.

Ages 12: Girls start baking injera and managing all household chores. Boys start taking full responsibility for aspects of farming. Boys and girls begin to work for pay. 
Parents and children often had different opinions as to whether children should work either in or outside of the home. Naomi's case (below) shows how both working for pay and working in the home can compete with education and how parents and children may have different preferences about the relative importance of these activities.

\section{Naomi - work for pay, work in the home, and attend school?}

The case of Naomi illustrates competing pressures on children and families and the repeated disruptions these pressures have on school attendance. Naomi was 12 years old when we first visited the family in 2007. Three years earlier, her mother had been very ill and Naomi, only nine years old, was responsible for doing all the household chores, including preparing food for family members. As a result, she stopped her education in Grade 2 and remained out of school for three years.

By 2007, she had re-enrolled in Grade 2 in the Leki primary school. She was also trying to combine school with working outside of her home. She worked planting, hoeing, weeding and collecting vegetables at private irrigation farms, as she explained:

NAOM I - I plant avocados and onions. YL - When do you work?

NAOM I - Sometimes, I work on Sundays. On school days, I work in the afternoon.

YL - Have you ever missed school due to daily work?

NAOM I - I ask permission from my teacher when I have to go on school days.

YL - What do you say to get permission? NAOM I - (Laughter) I do not mention that I will go for planting. I tell her that my parents are not at home.

YL - Why don't you tell her the truth? NAOM I - She wouldn't allow me to go. YL - Hasn't your health been affected by daily work?

NAOM I - I work a maximum of 50 rows.

YL - How much do you earn by working 50 rows?

NAOM I - If the rate is 10 cents, it is 5 birr; if the rate is 20 cents, it is 10 birr.

Naomi recognised the huge impact of workload on her education. At the same time, she highlighted that her work financed education materials and personal items like clothing.

My parents had little money to buy me education materials. They used to buy me exercise books by borrowing money from neighbours. That is why I got involved in daily labour even on school days. I started school at eight, at exactly the age I started to take on responsibilities at home. I was baking unleavened bread and injera and cooking coffee. I also started to fetch water and firewood, and went wherever mother sent me. I also started getting involved in daily labour and gave the money for my parents. I give it [to my parents] most of the time but during the time of school, I use the money to buy clothes and education materials. I am involved in paid labour for two or three days a week when the daily work is available. I am happy in my working and my education. 
I am very happy with the daily work because I get the money. When I get money, even my parents are happy. At the beginning, my parents prevented me from doing daily work but now they are happy with what I am doing. My elder sister and I are also fully involved in domestic chores. I am very busy and mostly I study during the night.

Teachers took a number of different actions to reduce poor attendance and dropout rates in the Leki primary school. One of the teachers interviewed in the first round of data collection reported that the school wrote to the investors in the local irrigation farm asking them only to hire children in the afternoon so that they could combine work and school. However, the investors did not take the necessary action. Another teacher involved in the second round reported that many students dropped out because of paid work. In order to reduce these problems, the school administration and teachers tried to convince parents to urge their children to stay in school rather than dropping out for the sake of earning small amounts of money. He said, "We advise them (the students) that earning a little money today may not help in future life..."

In summary, responsibilities at home and on family farms, combined with the need to cover educational and personal costs, may mean that rural children struggle to enrol on time, attend school regularly, do their homework and progress through grades. Twelve children were interviewed in 2007, when they were between twelve and thirteen years old. One of the chil- dren had never joined formal school and four had enrolled late or had dropped out and reenrolled and were far below the expected grade level. These individual histories from Young Lives research elaborate on the trends reported in Chapter 3 (Figure 11), which showed that a higher percentage of rural than urban children has never enrolled (1.4 percent compared to 0.9 percent) or has dropped out and stayed out of school (6.5 percent compared to 4.5 percent; differences statistically significant $\mathrm{p}>0.05$ ).

\section{Poor school quality}

Finally, even when children do enrol in school, quality issues often impact their ability to learn. The primary school in rural Leki illustrates the challenges. First, there was a severe shortage of classrooms, which meant that the teacherstudent ratio was high. The school director reported that he had raised funds from the Royal Netherlands Embassy in Addis Ababa to build an additional classroom for the 2008 school year in order to expand the school to Grade 7, but this had not solved the problem of large classes in other grades. A significant number of students (up to 224) were registered for one grade held in a single classroom during our first visit in 2007. The school director reported that an average 120 students had enrolled in Grade 1 over the last few years. In classroom observations, fieldworkers reported that high temperatures in the classrooms made it difficult for the children to concentrate. The Netherlands Embassy funding paid for new desks and chairs, but in 2008 there were still shortages due to very large classes. 
Nevertheless, the actual number of students in a particular class was often lower than the number of children that were registered. This was mainly due to widespread absenteeism and dropouts. In 2008, fieldworkers observed 106 and 78 students in Grade 1 and 2 classrooms respectively. They also observed that children were sharing Amharic, English and civics books in groups of three. Moreover, most of the books were very old and difficult to use. Children in focus groups complained that there was no place at the school for them to study. Only the teachers were allowed to read in the library and the books in the library were not accessible by the children. Old blackboards were still used, which were difficult to read, and there were no play materials available. There was no laboratory for the Grade 5 to 7 students, even though the curriculum required a laboratory for basic science experiments. The Netherlands Embassy provided funds to build six toilets (three for boys and three for girls) between 2007 and 2008 . However, the school did not have water on site.

Students were also concerned about the amount of time they spent in class. Classes were only held in the morning because the teachers lived in town and had to travel home in the afternoon. They travelled half of the distance one hour - on foot and the remainder by horse cart. Children reported that the teachers were often either absent or arrived very late. When the teachers were absent, the children either spent their time playing or went to work.

\section{Opportunities and challenges in rural Ethiopia}

Children face many difficulties in making the transition to primary school, which presents an argument for increased access to ECCE. However, as this chapter has made clear, any ECCE initiatives in rural areas must recognise the major challenges to children's education, which affect all age groups. At the same time, improving ECCE in rural areas has huge potential to benefit poorer children. Primary school teachers and directors already have extensive responsibilities trying to keep children enrolled in primary school and ensure they attend classes, and they often work in poor conditions and with limited resources. Families living in rural poverty have to balance their desire to send their children to school against the demands of domestic responsibilities and income generation, partly to pay school costs. Difficulties in balancing work and school have been described in other research in Ethiopia (Camfield 2009; Orkin 2012) as well as in research done other parts of the world (Boyden et al. 1998; Woodhead 1998). For example, based on his fourcountry study, Woodhead concluded that it is crucial to balance any hazardous effects of children's work with recognition of the "value children place on their work, their personal investment in their occupation as a long-term future, as well as childhood necessity" (Woodhead 2001:106).

The evidence presented in this chapter supports four conclusions. Firstly, in many rural areas there is no provision for ECCE, despite some communities and education departments taking initiatives to provide it through local, low-cost structures. As evidence from other countries (presented in Chapter 1) suggests, private providers may not supply services in 
very poor or rural areas, partly because there is limited demand from parents, who are not aware of the benefits of ECCE facilities and who may not be able to pay school fees.

In this context, the primary school curriculum cannot expect children to enter Grade 1 able to identify letters and numbers or read, or even to adjust to being in a classroom. Either ECCE needs to be much more widely available or else the curriculum in the first years of primary school needs to take on some of the functions of ECCE, such as getting children used to a learning environment and teaching them how to relate to adults and peers. Rural children automatically begin school at a disadvantage because of the design of the curriculum.

Some rural communities do recognise the importance of early education and, through district education offices, may be able to take initiatives to organise some type of ECCE, as envisaged in the 2010 Framework. However, resources will be required if such initiatives are to be successful and sustainable. For example, the Leki summer programme failed partly because the facilitators were not paid. The initiative would also probably have been more successful if it had run throughout the whole year, but there were no dedicated ECCE classrooms and the primary school premises could only be used during the summer holidays. The funds to pay staff and build facilities could partly be raised from communities, which have traditionally supported basic education in Ethiopia. However, some communities are better able to provide resources than others. In addition, local funding has usually been complemented by additional government resources, which is currently not envisioned in the ECCE Framework. Community-based ECCE also requires contributions from experts in curriculum and materials design, as well as the training of facilitators.

Rural children face a number of challenges in enrolling in primary school on time and progressing through grades. Parents and children emphasise different factors as being responsible for these challenges: parents blame school costs and their children's behaviour and attitudes; children blame their parents for requiring them to work too much and for not prioritising their schooling. But both parents and children highlight the competing pressures that are placed on children: the need to work to cover their schooling costs, the need to work in the home, including caring for relatives and the need to attend school. This highlights the importance of interventions to address external factors that can affect the education of children. Such interventions include pro-poor economic growth, better health care, social protection schemes like the PSNP, and community-based organisations that support families facing illness, as do some iddir (funeral associations). School-based interventions could include providing grants for school materials for the poorest children and increased teacher follow-up with children who are regularly absent.

These competing pressures add to the difficulties that the Child-to-Child programme may encounter. Although Naomi and Degife are behind where they should be in school, children their age (in Grade 6) are expected by the Child-to-Child programme to act as facilita- 
tors of small groups of pre-school children. It is hard to imagine these children taking on more responsibility than they already have. This might be alleviated by paying participating children a small stipend for contributing their time to the programme.

The problems faced by Leki are typical of most rural Ethiopian schools and show that primary schools often do not have the physical or human resources to provide pre-schools, or at least they did not at the time of fieldwork in $2007 / 8$. Other countries have found that there are considerable advantages to housing one year of pre-school in primary schools, as there is often some fixed infrastructure and management system available. However, even if communities are able to raise the funds to provide ECCE facilities in primary schools, the major issue in many countries is how to pay the teachers. Just as in Ethiopia, government-run programmes in many other countries do not fund teacher salaries. Motivation is therefore often a problem and the temptation is great for teachers to leave government schools for the private sector. If ECCE teachers are volunteers or are poorly paid, there will tend to be high turnover, leading to a loss of any investment in teacher training.

The ECCE Framework in Ethiopia hands primary schools an unfunded mandate in the context of already scarce resources. Requiring schools to provide any kind of ECCE facilities without additional resources is likely to have a negative impact on the quality of the education offered to primary school children.
Implementing the Framework requires careful consideration of how to staff ECCE centres and administer the Child-to-Child programme without relying on schoolteachers.

\section{Summary}

- Qualitative research in rural Leki highlights numerous obstacles to ECCE. This is a farming community and children are expected to take on responsibilities from an early age, with some of the poorest children engaged in wage labour by the age of ten.

- No ECCE was available in Leki, although, for a time, a summer programme was administered by university students to help prepare children for school. Most of the participating children were already seven years old or older and the main focus was on providing them with very narrow school readiness skills. The programme only ran for a few years.

- Only one primary school is available to the children of Leki and, in the absence of universal birth registration, it isn't always easy for parents to assure their child a place, even when they have reached seven years old. Many children's school attendance is disrupted because they are needed to help on the farm, to earn money, or to care for sick relatives.

- While government schooling is free, there are hidden costs that put additional pressures on very poor families. The need to pay for school clothes and materials is one of the reasons children have to work outside the home. School quality in Leki was also reported to be very variable, with 
insufficient materials available, and teachers absent or late because of their long journeys to school.

- Local realities need to be the starting point for implementing the national EECE policy, recognising that: (i) children currently start school with very little preparation; (ii) innovative finance and programmes are needed in order to make learning opportunities more widely available; (iii) even when children do begin school they face multiple challenges in making progress; and (iv) the difficulties inherent in ensuring adequate quality in primary classes suggest it may not be straightforward to add quality pre-school classes to existing schools. 


\section{Chapter 6: Discussion and conclusions}

Ethiopia offers a strong example of many of the trends in ECCE policy development and access being witnessed across sub-Saharan Africa. This report makes three major arguments:

- The case for investing in early childhood is increasingly well understood in African countries, as is the argument for improving equitable access to high quality ECCE as a foundation for child development. Our research shows that, in Ethiopia, ECCE is recognised to be a priority by national policy makers, parents and teachers.

- Experience from other African countries demonstrates that leaving investment in the education sector to private, $\mathrm{NGO}$ and faith-based providers results in a low level of access to ECCE and in access being restricted to more privileged children.

- The introduction of the ECCE Policy Framework for Ethiopia in 2010 represents significant progress. However, at the time of writing, comprehensive budgets have not yet been released for its implementation. The Framework thus attempts to deliver major and ambitious increases in ECCE access without a substantial extra injection of resources, partly by relying heavily on the primary school system. Rolling out an ambitious plan for ECCE without extra resources could have repercussions for other sectors. There is a risk of placing a new burden on an already overstretched primary education system, which could compromise promising initiatives to improve education quality for school age children.

In this chapter we summarise Young Lives research on these issues and suggest four areas for the further development of the ECCE Framework:

- a more detailed strategy for training and adequate funding for ECCE staff;

- a national curriculum, with technical support and structures to ensure compliance;

- in rural areas, alternative structures for ECCE that rely less on primary schools;

- in urban areas, if the government continues to rely on non-government providers to provide ECCE, some mechanisms to ensure that poor children can access these schools.

\section{Clear benefits from equitable access to high quality ECCE}

There are undoubtedly major benefits to be gained from more equitable access to ECCE. Evidence shows that ECCE or pre-schools improve a range of cognitive and non-cognitive outcomes for children. Provided the initiatives are well targeted, ECCE can mitigate the disadvantages faced by children from a range of vulnerable groups. ECCE improves their readiness for school, reducing the likelihood of dropout and repetition, which are currently widespread in many African education systems, including in Ethiopia. Economic analyses also suggest 
that high quality, early childhood programmes should not be considered a financial burden on constrained budgets, but should rather be seen as a long-term investment in human capital, which will bring returns for individuals, communities, and society as a whole (Heckman 2006).

The benefits of ECCE are beginning to be recognised in Ethiopia, where many teachers and parents articulate the benefits for children of accessing high quality ECCE. In urban areas, comparing the schooling trajectories of children who have access to ECCE and those who do not indicates that the former have substantial advantages. Children who attend private pre-school are often basically literate and numerate and learn some English, putting them at a substantial advantage for the rest of their school careers.

In rural areas, ECCE is rarely available. Research shows that a lack of early education may contribute to two behavioural patterns. Firstly, many children struggle to make a smooth transition into primary school. The overwhelming majority of children enrol in primary school at some stage, but a substantial number of children, particularly poorer children, enrol late. Teachers struggle to assess whether students are ready for school, so children also sometimes enrol too early. Secondly, without ECCE, children make slow and difficult progress through primary school. The curriculum assumes children have learned certain skills through ECCE before starting Grade 1, so children without ECCE begin their schooling careers at a disadvantage. A significant minority of children drop out; those who enrol when they are overage or too young are more likely to do so. A strong argument for broader access to pre-school education is that it may ensure that children are more school-ready. This might reduce the number of overage and underage children and thus reduce dropout rates.

There is thus a pressing and immediate need for universal ECCE in Ethiopia. But our key message is that for early childhood education to provide the greatest benefits, it may be worthwhile investing in longer-term strategies rather than attempting to score quick wins. Much of the evidence on the benefits of ECCE comes from small-scale, relatively well-funded community-based programmes. The limited evidence from large-scale government programmes in developing countries indicates that such programmes may be inadequately resourced and of poorer quality, and thus have more limited impact. In other words, if scalingup is not adequately planned and resourced, there is the risk that ECCE will not achieve its maximum potential for children (Bernard van Leer Foundation 2011).

\section{Inequitable access when ECCE is provided by the private and non- governmental sectors}

Many sub-Saharan African countries have included ECCE policies in sectoral and multisectoral strategic plans. However, in many countries, central and local governments have concentrated their efforts on delivering EFA goals for primary schooling. Ethiopia adopted its own ECCE Framework and Guidelines in 
2010. But the government has mainly focused on increasing enrolment in primary schools over a very short period of time, through rapidly training new teachers and building school facilities, rather than on improving the quality of primary schooling.

Inevitably, in this context, early childhood education is at risk of being seen as 'one step too many' and as adding to the financial and governance burdens on an already stretched education and social care system. This is particularly true in Ethiopia, given the size of the country, the remoteness of many rural populations, and the limited resources available. Therefore, as in many African countries that share these challenges, Ethiopia initially relied on donors, NGOs, faith-based organisations and the private sector to provide ECCE. This led to increased access to education, but often only for more privileged children in the urban areas. In Ethiopia, for example, the GER for pre-school in 2010/11 was 5.2 percent, which is low even for African countries. While national statistics show a rapid growth in enrolment in urban centres, this growth has been from a very low base. Young Lives data supports this conclusion: among the least-poor quintile of Young Lives children, the percentage being sent to pre-school has increased over time, indicating that families who can afford pre-school and have access increasingly see the need to send their children there. However, the private sector largely supports only fee-paying schools in urban areas, which are only accessible to better-off children.

For urban children whose families are unable to afford private pre-schools or rural children who do not have private pre-schools in their communities, churches and mosques provide religious pre-schools. There are very few community-based schools and these are largely run by local or international NGOs in urban areas. Young Lives is able to provide some information on these other forms of ECCE, which have largely not been studied in Ethiopia. We find that where government and community services exist, they mainly serve less well-off children. But access to this type of education is low. Over the period of the study, the rates of pre-school enrolment in rural areas have stayed close to zero. Across rural and urban areas, the rates of enrolment in community and government pre-schools have stayed low and constant. Even where such facilities are available, they are of highly variable quality. NGO schools in urban areas often have relatively good facilities and use similar educational methods to private schools. At religious schools, the quality of the facilities tends to be poor, instructors have no ECCE training, and children learn the alphabet and numbers through recitation.

Experience from the non-governmental sector can inform the implementation of ECCE in low-resource contexts. As in the rest of Africa, without some form of subsidy it is unlikely to be profitable (and therefore sustainable) for private providers to establish facilities in rural or poorer urban areas. New frameworks for ECCE should therefore attempt to encourage growth and improvement in the quality of pre-school services provided by the NGO sector to children from less well-off families and in rural areas. Government intervention could take a variety of forms, described in the final section of this report. 


\section{Limited capacity and insufficient funding for rapidly scaling up ECCE}

Increasingly, sub-Saharan African countries have attempted to design and scale up low-cost government ECCE interventions to address gaps in educational access. These have included Rapid School Readiness Programmes, community-based centres and the attachment of one year of pre-school to government schools. However, many of these interventions remain at the pilot phase and governments have not costed or planned how to apply these interventions nationally. Governments have often struggled to develop concrete ECCE plans, so early education is often not included in education sector plans or FTI plans. As a result, only a handful of countries have been able to find a large amount of donor funding for ECCE.

Ethiopia provides an example of this trend. In 2010, the government distributed the ambitious national ECCE Framework, described in detail in Chapter 2. Two of the four pillars of the Framework have been thoroughly addressed in this paper. The Child-to-Child programme is the main strategy proposed in the third 'nonformal school readiness' pillar, where Grade 5 or 6 students facilitate a play-based programme of school readiness with groups of six-year-old children for a year, with the aim to bridge gaps in ECCE availability in the short term. In the longer term, the fourth pillar of the Framework also envisions the establishment of pre-schools run by communities, private providers or faith-based providers. If government-run, the pre-schools will be attached to primary schools. Communities will be encouraged to contribute resources for building ECCE facilities. In rural areas, the latest ESDP aims for 40 percent of rural primary schools to include a pre-school class by 2014.

The ECCE Framework had only just been published when the latest ESDP was developed and it appears that budgets have not yet been developed for its implementation. At the time of writing, only 0.06 percent of the budget for the ESDP, the main vehicle for channelling donor funding, has been allocated to ECCE and all of this was allocated to federal and regional government support for ECCE. The ECCE Framework does not expect the government to provide funds for ECCE, but contends that donor funding and community contributions will be sufficient. However, separate donor funding has not yet been identified.

In the short term, the ECCE Framework thus attempts to deliver major and ambitious increases in ECCE without substantial extra resources. The two pillars examined in this paper draw heavily on the primary school system: the Child-to-Child programme relies on Grade 1 and 6 teachers to train young facilitators and the establishment of pre-schools depends on principals, teachers and communities to fundraise, coordinate and staff Grade 0 classes at primary schools.

There remain major resource constraints in the primary education sector, which are particularly acute in rural areas and at the Grade 1 level. Basic education is under stress, with overcrowded classrooms, split shifts, 
lack of textbooks and insufficient numbers of teachers, particularly in rural areas. High salary costs mean there is little money left for infrastructure, textbooks and other nonrecurrent expenditures (World Bank 2005b). Non-salary recurrent expenditure per pupil is around $\$ 2$ each year (Dom 2009). Teachers are often highly motivated but overstretched, particularly because they have a heavy burden of pastoral responsibility for poor children in difficult circumstances. In other cases, teachers are unmotivated and do not perform their responsibilities adequately. The government is attempting to tackle these deficits in general education as a priority.

It is obviously important that long-term delivery of ECCE is integrated into the primary education system. Experience in other African countries indicates that there are considerable advantages to hosting one year of pre-school in primary schools, since there is usually some fixed infrastructure and management system available. The delivery of ECCE is likely to benefit from the strength of the primary system, as outlined in Chapter 2.

Nevertheless, if the primary education system is tasked with most of the operational responsibility for delivering ECCE in rural areas, without additional resources, this could have negative impacts on the quality of primary education and the resulting ECCE is also likely to be of poor quality. Current plans for ECCE raise questions about the relative merits of investing in additional activities and attempting to integrate efforts rather than focusing on existing programmes in basic educa- tion, which are having some success in improving access and the quality of services.

\section{Conclusions}

In the UNESCO report cited in Chapter 2 (2010a: 52), Alain Mingat argues that scaling up ECCE nationally in a developing country requires three key ingredients:

- a national institutional structure, even if there is some autonomy at local levels (Ethiopia has made important advances here);

- national financing, even if community ECCE workers are not government employees, because "we know the limits of voluntary work";

- appropriate technical support, such as training of community leaders, close monitoring, and the development of curricula and kits.

The ECCE Framework for Ethiopia sets out national institutional arrangements across three ministries. To help inform the development and implementation of the Framework, we conclude that there is need for adequate funding for staff and a national curriculum and suggest two further issues that are a priority for rural and urban settings.

\section{A strategy and adequate funding to develop a cadre of ECCE teachers}

It is important that human resource capacity is developed before schools start providing ECCE, otherwise an already strained primary schooling system will be further burdened, with major impact on the quality of primary education provision. 
The ECCE Framework envisions three types of ECCE staff. New teachers could qualify with a ten month pre-school teacher training certificate. Already-trained primary school teachers could attend a two month course to upgrade their skills at existing Teacher Training Institutes, particularly in the "active learning of young children." Finally, assistant teachers could be required to attend school to at least the Grade 8 level and to hold health volunteer or health assistant certificates. UNESCO (2010:14) highlights that many African countries have not developed specific ECCE qualifications. It is a positive development that the planned system of teacher training in Ethiopia allows for such qualifications, allows ECCE staff to be recruited from outside the existing group of teachers and provides for in-service workshops.

There are a number of areas where difficulties may arise:

- It is not clear whether the government has included the costs of training ECCE teachers in existing budgets or has established how these costs will be met. In Chapter 2, we described problems arising in other African countries, where governments have not budgeted for ECCE teacher training. Training is then provided on an ad hoc basis by NGOs or other partners in one or two week workshops, which are much shorter than the qualifications require. There is also often no coordinated curriculum, so the quality of training is poor.

- It is not clear if the government plans to pay ECCE teachers who work in schools attached to government primary schools or if they have to be paid by the community. In other African countries, where ECCE facilities have been attached to primary schools, the government has not paid teachers' salaries. As a result, motivation is often a problem and ECCE teachers may leave their schools for the private sector. If teachers are volunteers or are poorly paid, there will tend to be high turnover, which results in a loss of investment in training. This suggests that ECCE teacher salaries may need to be partly funded by the government, even if communities and fees provide some of the funding.

- If all ECCE training is done through existing Teacher Training Institutions, it may not be appropriate or accessible for faithbased ECCE providers or for caregivers without teaching experience, as they may only have a primary education.

- There is a need to target current and prospective teachers in rural areas to be trained as ECCE teachers. The need for qualified personnel is highest in rural areas and people originating from such areas may be more likely to work there for long periods.

The Grade 6 children, usually about 12 years old, on whom the Child-to-Child programme depends, are often already overcommitted and struggle to balance a variety of responsibilities both in and out of school, including working for pay, caring for sick family members, and carrying out substantial chores and responsibilities on the family farm. In this context, it is difficult to know how they will have time to 
contribute to an ECCE programme. One possible option would be to provide cash incentives to children who act as Child-to-Child facilitators, to compensate the children and their families for loss of cash or in-kind income.

\section{A national curriculum, with technical sup-} port and structures to ensure compliance

Where ECCE providers already exist, the government may face significant regulatory challenges. Some private and NGO providers are registered, but very few religious schools are and there is limited inspection of schools. The system of registration and inspection needs to be improved to ensure that new non-government facilities meet very basic quality requirements.

The government is also likely to face challenges when attempting to move teaching methods towards the child-centred, play-based model envisioned in the ECCE Framework. Firstly, many private and NGO facilities currently emphasise more formal learning as a preparation for the first few grades of primary school. It may be difficult for the government to persuade schools and parents to use government curricula, which exist but are ignored. Secondly, experience in other African countries suggests that if training for ECCE teachers is provided through the same structures used to train early primary school teachers, the emphasis on formal learning may continue. Similarly, formal learning tends to be more prominent in ECCE curricula when ECCE is provided through school-based reception years.

The government should urgently address disjunctions between the model of teaching proposed in the ECCE Framework and the requirements of the primary school curriculum, to reduce pressure on pre-school teachers to teach formal skills. This would improve the implementation of the child-centred, playbased model of ECCE.

As UNESCO (2010: 52) notes, ensuring that a new curriculum is implemented in practice requires adequate resources, such as kits and materials. It also requires close monitoring, possibly by including adherence to the national curriculum as part of registration and inspection processes.

\section{In rural areas, alternative structures for ECCE that rely less on primary schools}

The ECCE Framework only considers three possible options for ECCE in rural areas: pre-schools supported by private or nongovernmental sources, government pre-schools attached to primary schools, or Child-to-Child programmes. The government is not setting up or facilitating an alternative to formal pre-schools, except for the Child-to-Child programme. Evidence from other countries suggests that there are other low-cost programme alternatives available that do not draw as extensively on the resources of the primary school sector as do government pre-schools and the Child-to-Child programme. These include government or NGO-run Rapid School Readiness Programmes (as in Namibia and Kenya) and community-based programmes (as in the DRC, Malawi, Mozambique, Swaziland, Zambia, Zimbabwe, and Tanzania). Potentially, the ECCE Framework should include government structures to support additional 
initiatives, such as training and curriculum development and alternative forms of preschool, such as Rapid School Readiness Programmes.

\section{In urban areas, structures to ensure poorer children can access non-government providers} The ECCE Framework suggests that the government will continue to rely on private and NGO providers to deliver pre-school in urban areas. Our evidence strongly suggests that poorer urban children will only be able to access informal religious schools. It is vital that these schools be drawn into government regulatory and quality assurance structures so that teachers are appropriately trained, the national curriculum is introduced and facilities are of adequate quality.
Alternatively, if the intention is for ECCE to largely occur through an expansion of private and NGO schools, it may be necessary to provide some form of subsidy for poorer urban children, either directly to providers or in the form of vouchers issued to parents. In other countries, school meal programmes or subsidies provided to schools have been effective in improving enrolment from the most disadvantaged groups. Subsidies based on family need, such as in Namibia, can be difficult to implement. Community-based subsidies to pre-schools in poor areas, as in South Africa, may be easier to administer. If, despite subsidy arrangements, private and NGO providers still do not set up facilities in smaller urban centres, the government may need to play a more active role in providing services in these areas. 


\section{Appendix 1: The Young Lives communities}

Young Lives sites followed the boundaries of kebeles in 2002, when the first round of research was conducted. Leki is a kebele situated in the Eastern part of Oromia regional state. Predominately Oromiffa-speaking Orthodox Christians live there. The population is estimated to be 2835, with 422 households that earn their living through agriculture. Irrigable fields and fishing are also important sources of livelihoods. There is one primary school in the community and a health post. For secondary school and better health care, community members must travel to the nearest town, about 15 kilometres away. At the time of the research, community members had to cross a river to get to the town, requiring them to pay a small fee for a boat.

Subsequently, a bridge has been built, making it easier to get to the nearby town.

There are no pre-schools, but parents send their younger children to religious schools attached to the local church or mosque. Many respondents complained about the lack of a secondary school and the quality of the health services. Sick people could not cross the lake as there are no boats at night and, even when they are available, it is too expensive. Consequently, many reportedly use traditional practices when they fall ill.
Leku, composed of three former kebeles, is one administrative unit of Mehal Ketema. It is the oldest neighbourhood of Awassa City, the capital of the SNNPR. It is difficult to give a figure for the population, but the local administration estimates it to be about 23,000. The Wolayita and Sidama ethnic groups, who are Protestant or Orthodox Christians, dominate the area.

The area is densely populated and households are highly overcrowded, with some accommodating 15 to 20 people. The size is due to high levels of fertility and continuous migration from the surrounding rural areas. As the area was originally inhabited by soldiers of the imperial times, many of the inhabitants are very old or are pensioners. Others settled there as tenants on very small plots of land rented from ex-soldiers. Most people in the community are engaged in petty trading, street vending, or are self-employed. Children are also involved in such activities. There are three government primary schools and one secondary school operating in the neighbourhood. Two private primary schools and two NGO-based primary schools have also operated in the site in recent years. In relation to child-focused educational institutions, there are two NGO-based pre-schools and two other private pre-schools. 


\section{References}

Ames, P., Rojas, V. and Portugal, T. (2010) Continuity and respect for diversity: Strengthening early transitions in Peru. Working Paper 56: Studies in Early Childhood Transitions. The Hague: Bernard van Leer Foundation).

Anis, K. (2007) Ethiopia: Non-formal education. Country Profile for UNESCO Global Monitoring Report. Paris: UNESCO.

Bernard van Leer Foundation (2011) Early learning: lessons from scaling up. Early Childhood Matters 117. The Hague: Bernard van Leer Foundation.

Biersteker, L. et al. (2008) Introducing preprimary classes in Africa: Opportunities and challenges. In: Garcia, M., Pence, A. and Evans, J.L (Eds.) Africa's Future, Africa's Challenge: Early Childhood Care and Development in Sub-Saharan Africa. Directions in Development: Human Development 42700 Washington, D.C.: World Bank 227-48.

Boyden, J., Ling, B. and Myers, W. (1998) What Works for Working Children. Stockholm: Radda Barnen.

Boyden, J. and Dercon, S. (2012) Child development and economic development: Lessons and future challenges. Young Lives Working Paper 1-58.

Camfield, L. (2009) A girl never finishes her journey: Mixing methods to understand female experiences of education in contemporary Ethiopia. Research Papers in Education 26 (4), 1-11.

Central Statistical Agency (2006) Ethiopia Demographic and Health Survey 2005. Addis Ababa: Central Statistical Agency 1-448.

Central Statistical Agency (2007) The 2007 National Statistics Population. Addis Ababa: Central Statistical Agency of Ethiopia.

Dom, C. (2010) Ethiopia country desk study: Mid-term evaluation of the Education For All Fast Track Initiative. Cambridge: Cambridge Education, Mokoro Consultants and Oxford Policy Management 1-141.

Dom, C. (2009) Ethiopia Country Desk Study: Mid-Term Evaluation of the Education for All Fast Track Initiative. London: Mokoro Consultants.

Engel, J. (2010) Ethiopia's progress in education: A rapid and equitable expansion of access. Development Progress Stories. London: Overseas Development Institute 1-29.

Engle, P. et al. (2007) Strategies to avoid the loss of developmental potential in more than 200 million children in the developing world. The Lancet 369 (9557), 229-42.

Engle, P. et al. (2011) Strategies for reducing inequalities and improving developmental outcomes for young children in low-income and middle-income countries. The Lancet 378 (9799), 1339-53.

Garcia, M. and Rajkumar, A.S (2008) Achieving better service delivery through decentralization in Ethiopia. World Bank Working Paper: African Human Development Series 131, 1-134.

Government of Ethiopia (2006) Child Labor in Ethiopia: Analysis of a Survey Conducted in 2001. Addis Ababa: Ministry of Labor and Social Affairs. 
Habtamu, W. (1996) Research papers on the situation of children and adolescents in Ethiopia. Proceedings of the Conference on the Situation of Children and Adolescents in Ethiopia. Addis Ababa: Addis Ababa University.

Heckman, J. (2006) Skill formation and the economics of investing in disadvantaged children. Science 312 1900-2. Jennings, M. et al. (2011) Social Assessment for the Education Sector, Ethiopia. Addis Ababa: Department for International Development.

Lewin, K. (2007) Improving access, equity and transitions in education: Creating a research agenda. CREATE Pathways to Access Monographs 1. Brighton: Consortium for Research on Educational Access Transitions and Equity, University of Sussex 1-50.

Martinez, S., Naudeau, S. and Pereira, V. (2012) The Promise of Preschool in Africa: A Randomized Impact Evaluation of Early Childhood Development in Rural Mozambique. Washington, D.C.: The World Bank and Save the Children.

Ministry of Education (1994) Education and Training Policy. Addis Ababa: St. George Printing Press, Government of Ethiopia.

Ministry of Education (2002) Education Sector Development Programme II 2002/3 - 2005/6 Programme Action Plan. Addis Ababa: Government of Ethiopia.

Ministry of Education (2006) Teacher Development Programme Mid-Term Review. Addis Ababa: Government of Ethiopia.

Ministry of Education (2007) General Education Quality Improvement Programme Document 2008/9 - 2012/13. Addis Ababa: Government of Ethiopia.

Ministry of Education (2010a) Education Statistics Annual Abstract 2008/9. Addis Ababa: Government of Ethiopia.

Ministry of Education (2010b) Guidelines for Early Childhood Care and Education for Ethiopia. Addis Ababa: Government of Ethiopia 1-34.

Ministry of Education (2010c) National Policy Framework for Early Childhood Care and Education. (Addis Ababa: Government of Ethiopia) 1-31.

Ministry of Education (2010d) Strategic Operation Plan for Early Childhood Care and Education for Ethiopia. (Addis Abba: Government of Ethiopia) 1-28.

Ministry of Education (2010e) Education Sector Development Plan IV 2010/11 - 2014/15. Addis Ababa: Government of Ethiopia 1-95. (2012) Education Statistics Annual Abstract 2010/11. Addis Ababa: Government of Ethiopia.

Ministry of Education/USAID (2008) Ethiopian Third National Learning Assessment of Grade 4 Students. Addis Ababa: National Organization for Examination.

Okengo, L. (2011) The scaling up of early childhood development provision in Kenya since independence. Early Childhood Matters 117 33-37.

Okengo, L. (2010) Overview of early childhood development in Southern Africa. Nairobi: Open Society Institute Southern Africa. 
Orkin, K. (2010) In the best interests of the child? Legislation on children's work in rural Ethiopia. Journal of International Development 22 (8) 1102-14.

Orkin, K. (2011) If God wills...next year I will send her back to school: The effects of child and parental illness on school participation in rural Ethiopia. CREATE Pathways to Access Monographs, 60, 1-50.

Orkin, K. (2012) Are work and schooling complementary or competitive for children in rural Ethiopia? A mixed-methods study. In: Bourdillon, M. and Boyden, J. (Eds.) Childhood Poverty: Multidisciplinary Approaches. Houndmills, Basingstoke: Palgrave Macmillan 298-315.

Outes-Leon, I. and Sanchez, A. (2008) An assessment of the Young Lives sampling approach in Ethiopia. Young Lives Technical Note 1 1-37.

Penn, H. (2008) Working on the impossible: Early childhood policies in Namibia. Childhood 15, 379-95.

Poluha, E. (2004) The power of continuity: Ethiopia through the eyes of its children. Uppsala: Nordic Africa Institute.

Shibeshi, A. and Arsano, Y. (2007) The case of Ethiopia. In: Yamada, S. (Ed.), The Local Meanings of Educating All, and the Process of Adopting EFA Development Goals in Kenya, Tanzania, and Ethiopia. Tokyo: National Graduate Institute for Policy Studies (GRIPS)-Japan).

Streuli, N., Vennam, U. and Woodhead, M. (2011) Increasing choice or inequality? Pathways through early education in Andhra Pradesh, India. Working Paper 58: Studies in Early Childhood Transitions. The Hague: Bernard van Leer Foundation.

Tefera, T, et al. (2009) Status of early childhood care and education in Ethiopia. First International Development Conference on Educational Research for Development. Addis Ababa 188-203.

Teshome, A. (2008) A review of education policy, strategies and programs. In: Taye Assefa (ed.) Digest of Ethiopia's National Policies, Strategies and Programs (Addis Ababa: Forum for Social Studies), 47-93.

UNDP. Ethiopia: Human Development Report 2009. <http://hdrstats.undp.org/en/countries/country_fact_ sheets/cty_fs_ETH.html.>, accessed 28 December 2009.

UNESCO (2000) The Dakar Framework for Action: Education for all: Meeting our collective commitments. Paper given at World Education Forum, Dakar, Senegal, 26-28 April 2000.

UNESCO (2004) Enrolment gaps in pre-primary education: The impact of a compulsory attendance policy. UNESCO Policy Brief on Early Childhood 21. Paris: UNESCO.

UNESCO (2007) Strong foundations: early childhood care and education. Education for All Global Monitoring Report 2008 (Paris: UNESCO).

UNESCO (2008) Education for all by 2015 - Will we make it? Education for All Global Monitoring Report 2008. Paris: UNESCO.

UNESCO (2009) Overcoming inequality: Why governance matters. Education For All Global Monitoring Report 2009. Oxford: Oxford University Press.

UNESCO (2010a) Early Childhood Care and Education Regional Report: Africa. Dakar: Regional Bureau for Education in Africa.

UNESCO (2010b) Reaching and teaching the marginalised. Education for All Global Monitoring Report 2010. Paris: UNESCO. 
UNICEF/World Bank (2009) Abolishing School Fees in Africa: Lessons from Ethiopia, Ghana, Kenya, Malawi, and Mozambique. Washington, D.C.: World Bank.

UNICEF (2010) Getting Ready for School: A Child-to-Child Approach. Programme Evaluation: Year One. New York: UNICEF.

Vogler, P., Crivello, G. and Woodhead, M. (2008) Early childhood transitions research: A review of concepts, theory and practice. Working Paper 48: Studies in Early Childhood Transitions. The Hague: Bernard van Leer Foundation.

Walker, S. et al. (2011) Inequality in early childhood: risk and protective factors for early child development. The Lancet, 378 (9799), 1325-38.

Woodhead, M. (1998) Children's Perspectives on their Working lives: a Participatory Study in Bangladesh, Ethiopia, the Philippines, Guatemala, El Salvador, and Nicaragua. Stockholm: Raedda Barnen.

Woodhead, M. et al. (2009) Equity and quality? Challenges for early childhood and primary education in Ethiopia, India and Peru. Working Paper 55: Studies in Early Childhood Transitions. The Hague: Bernard van Leer Foundation.

World Bank (2005a) Education in Ethiopia: strengthening the foundations for sustainable progress. Africa Region Human Development Working Paper Series. Washington, D.C.: World Bank 1-64.

World Bank (2005b) Education in Ethiopia: Strengthening the Foundation for Sustainable Progress. Washington, D.C.: World Bank.

World Bank (2008) Project Appraisal Document on a Proposed Credit: Report 45140-ET. Washington, D.C.: World Bank.

World Bank (2011) Learning for All: Investing in People's Knowledge and Skills to Promote Development Washington, D.C.: World Bank.

Yamada, S. (2007) Overview and synthesis. In: S. Yamada (Ed.) The Local Meanings of Educating All, and the Process of Adopting EFA Development Goals in Kenya, Tanzania, and Ethiopia. Tokyo: GRIPS. 
( 


\section{Bernard van Leer Foundation}

\section{P.O. Box 82334}

\section{EH The Hague}

The Netherlands

Bernard

van Leer

FOUNDATION
Tel: $+31(0) 703312200$

www.bernardvanleer.org

\section{About the Bernard van Leer Foundation}

The Bernard van Leer Foundation funds and shares knowledge about work in early childhood development. The Foundation was established in 1949 and is based in the Netherlands. Our income is derived from the sale of Royal Packaging Industries Van Leer N.V., bequeathed to the Foundation by Dutch industrialist and philanthropist Bernard van Leer (1883 to 1958).

Our mission is to improve opportunities for children up to age 8 who are growing up in socially and economically difficult circumstances. We see this both as a valuable end in itself and as a long-term means to promoting more cohesive, considerate and creative societies with equal opportunities and rights for all.

We work primarily by supporting programmes implemented by local partners. These include public, private and community-based organisations. Working through partnerships is intended to build local capacity, promote innovation and flexibility, and help to ensure that the work we fund is culturally and contextually appropriate.

We also aim to leverage our impact by working with influential allies to advocate for young children. Our free publications share lessons we have learned from our own grantmaking activities and feature agendasetting contributions from outside experts. Through our publications and advocacy, we aim to inform and influence policy and practice not only in the countries where we operate, but globally.
In our current strategic plan, we are pursuing three programme goals: reducing violence in young children's lives, taking quality early education to scale, and improving young children's physical environments. We are pursuing these goals in eight countries - Brazil, India, Israel, Tanzania, the Netherlands, Turkey, Peru and Uganda - as well as undertaking a regional approach within the European Union.

In addition, until 2012 we will continue to work in Mexico, the Caribbean and South Africa on strengthening the care environment, transitions from home to school and respect for diversity.

\section{Information on the series}

Working Papers in Early Childhood Development is a 'work in progress' series that presents relevant findings and reflection on issues relating to early childhood care and development. This working paper is part of a series of 'Studies in Early Childhood Transitions' from Young Lives, a 15-year longitudinal study of childhood poverty in Ethiopia, India, Peru and Vietnam. Further information about Young Lives is available on the website: www.younglives.org.uk

The findings, interpretations, conclusions and opinions expressed in this series are those of the authors and do not necessarily reflect the views or policies of the Bernard van Leer Foundation. 